
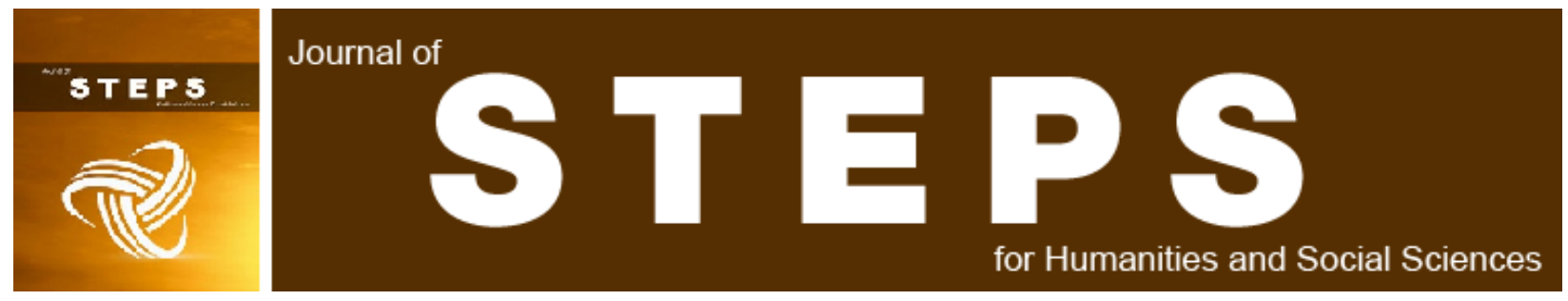

Volume 1 | Issue 1

Article 7

\title{
Architectural product between necessity and perfection - a reading of the moral architectural act
}

Rabab Jassim

University of Technology, Iraq, ae.20.46@grad.uotechnology.edu.iq

Sabeeh Farhan

Wasit University, Iraq

Abdullah Salman

University of Technology, Iraq

Zahraa Shamam

University of Technology, Iraq

Follow this and additional works at: https://www.steps-journal.com/jshss

Part of the Arts and Humanities Commons

\section{Recommended Citation}

Jassim, Rabab; Farhan, Sabeeh; Salman, Abdullah; and Shamam, Zahraa (2022) "Architectural product between necessity and perfection - a reading of the moral architectural act," Journal of STEPS for Humanities and Social Sciences: Vol. 1 : Iss. 1 , Article 7.

Available at: https://doi.org/10.55384/2790-4237.1003

This Original Study is brought to you for free and open access by Journal of STEPS for Humanities and Social Sciences (STEPS). It has been accepted for inclusion in Journal of STEPS for Humanities and Social Sciences by an authorized editor of Journal of STEPS for Humanities and Social Sciences (STEPS). 


\section{النتاج المعماري بين الضروة والكمال ـ قراعة في الفعل المعماري الاخلاقي}

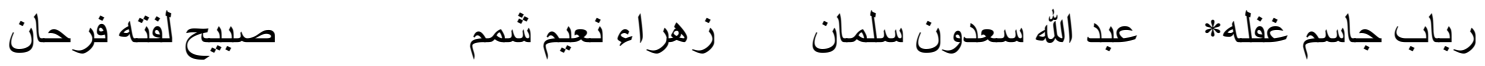

الكمال هو اعلى درجة في سُلَّم القِيَم و كمال الثيء هو لإتيان بأركانه التي لا بصح إلا بها ويتمثل مفهوم

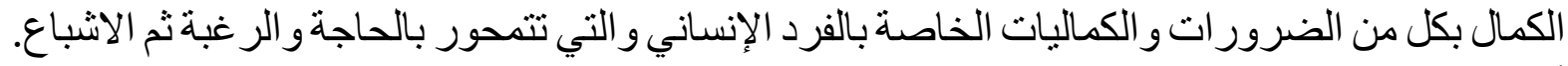

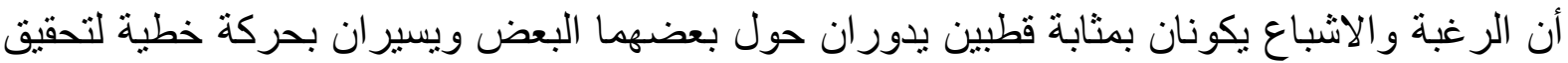

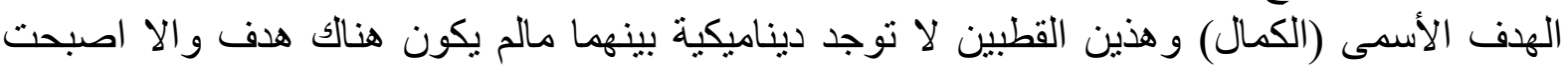

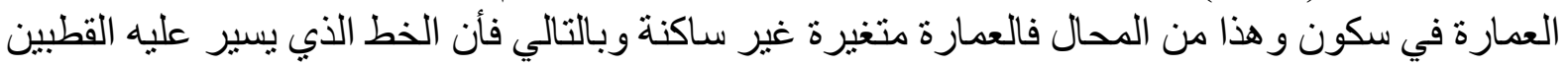

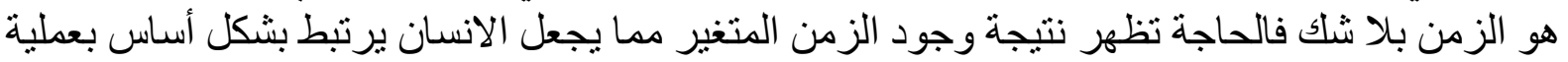

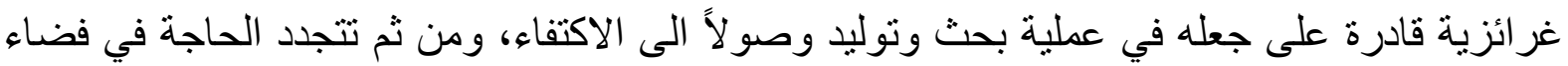

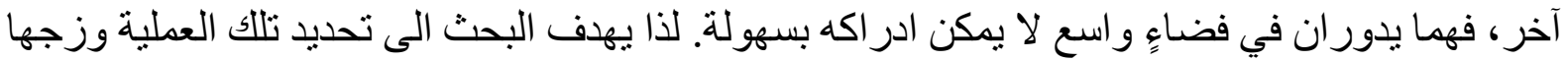

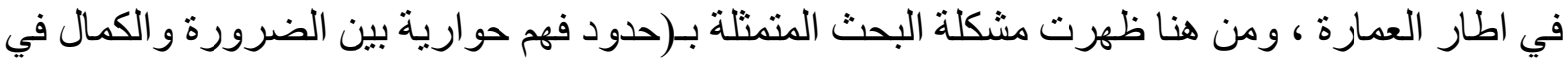

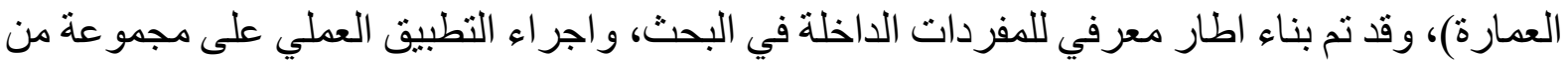

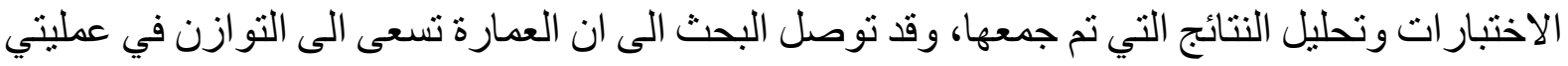

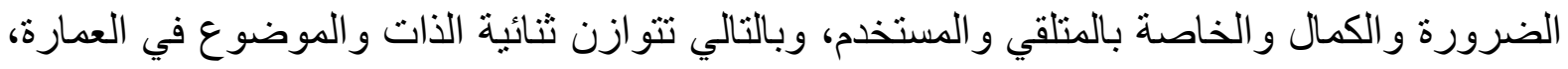
التي فيها يمكن الوصول الى حالة الاستقر ار في الفكر والفعل.

كلمات مفتاحية: الكمال ،الضرورة ،الحاجة ، الر غبة ، الفعل الاخلاقي ،الكمال الاخلاقي ،التكامل المعماري الاخلاقي. 


\section{Architectural product between necessity and perfection - A reading of the moral architectural act}

Rabab Jassim Ghaflah, Architecture Department, University of Technology, Iraq.

Abdullah Saadoon Salman, Architecture Department, University of Technology, Iraq.

Zahraa Naeem Shamam, Architecture Department, University of Technology, Iraq.

Sabeeh Lafta Farhan, Architecture Department, University of Wasit, Iraq.

\section{Abstract (bold, times new romans 14)}

Perfection is the highest level in the ladder of values, and the perfection of a thing is to come up with its pillars that are only valid. The concept of perfection is represented by all the necessities and luxuries of the human individual, which center on need and desire and then gratification. Desire and gratification are like two poles that revolve around each other and move in a linear motion to achieve the goal. supreme (perfect) and these two poles do not have a dynamic between them unless there is a goal, otherwise architecture will become in silence and this is impossible. Architecture is changing and not static. Therefore, the line on which the two poles walk is undoubtedly time. In the process of research and generation, reaching sufficiency, and then the need is renewed in another space, as they revolve in a wide space that cannot be easily perceived. Therefore, the research aims to identify that process and integrate it into the framework of architecture, and from here the research problem emerged, represented by (the limits of a dialogue understanding between necessity and perfection in architecture), and a cognitive framework was built for the vocabulary included in the research, and practical application was carried out on a set of tests and analysis of the results that It was collected, and the research concluded that architecture seeks balance in the processes of necessity and perfection of the recipient and the user, and thus the duality of subject and object is balanced in architecture, in which a state of stability in thought and action can be reached.

Keywords: Perfection, Necessity, Need, Desire, Moral Action, Moral Perfection, Moral Architectural Integration. 


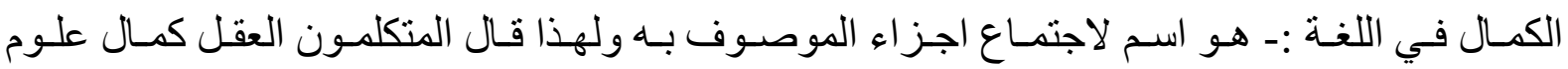

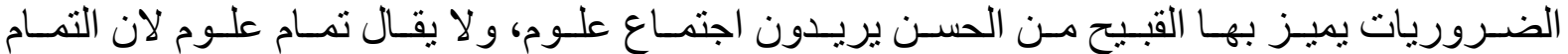

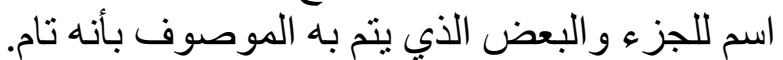

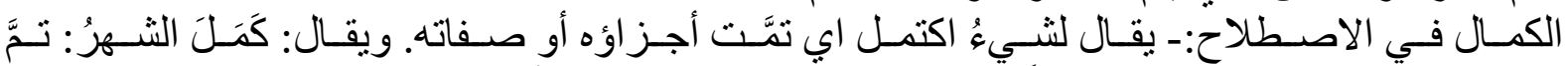

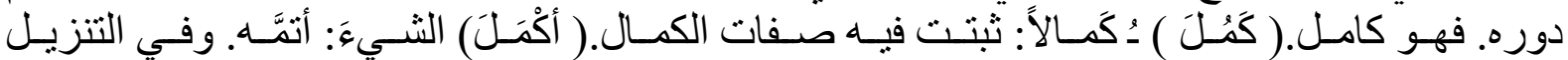

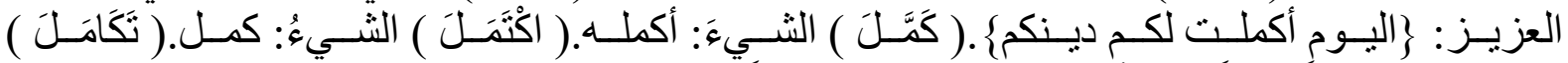

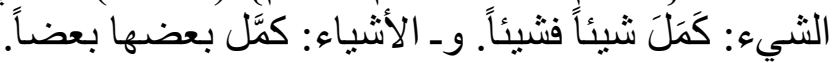

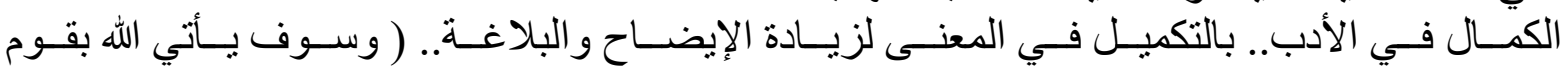

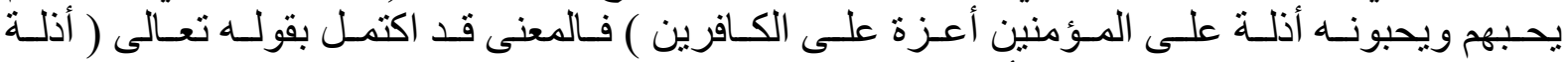

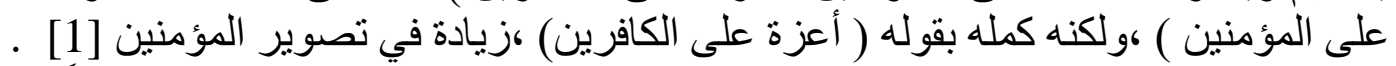

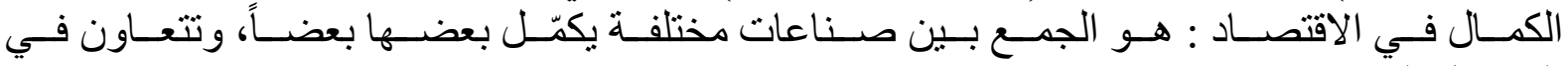

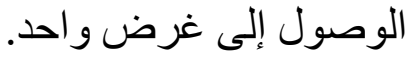

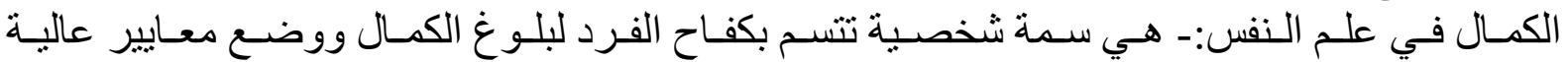

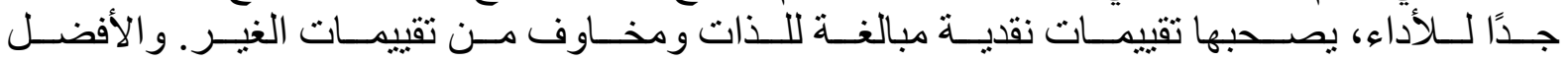

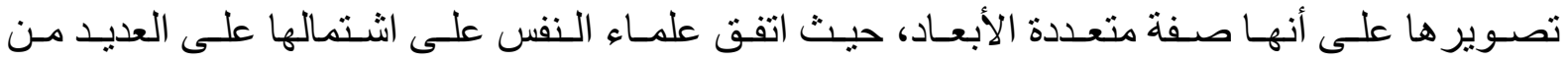

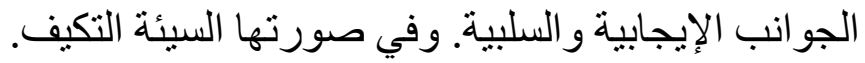

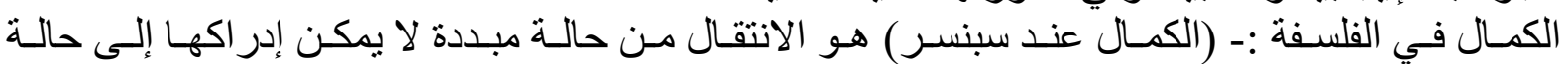

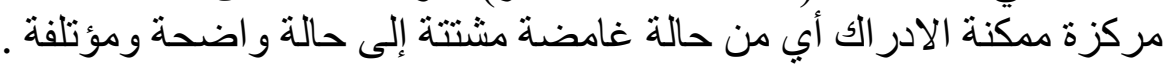

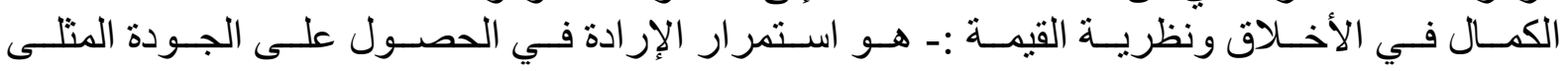

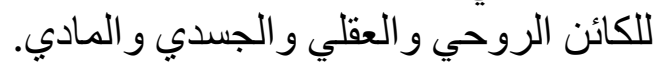

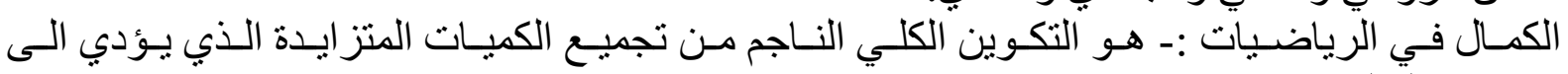

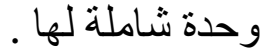

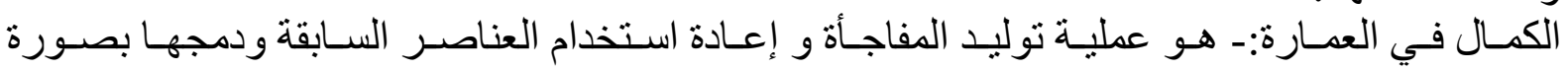

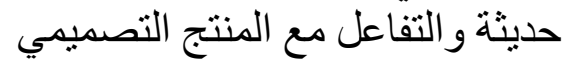

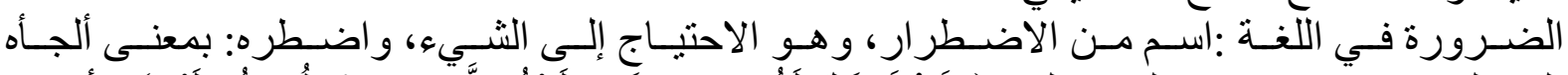

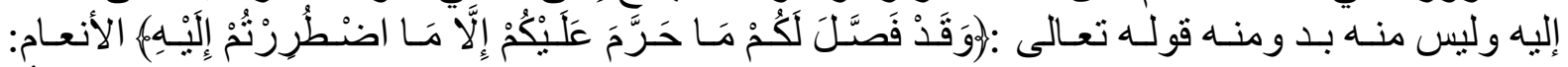

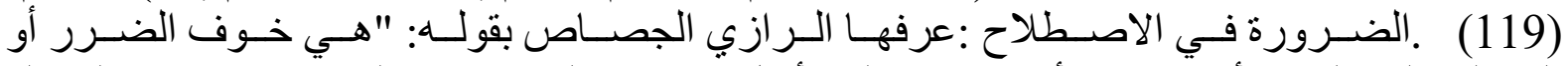

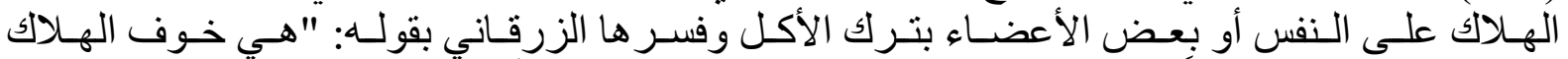

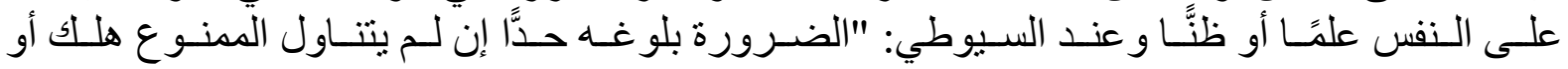

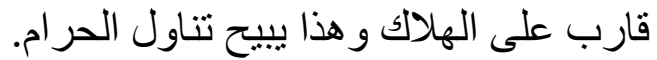

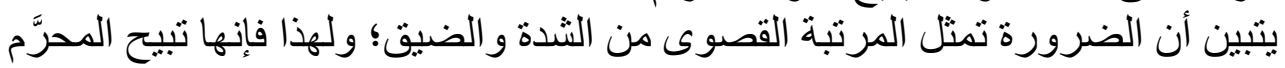

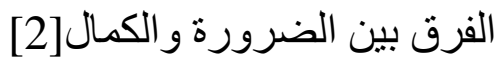

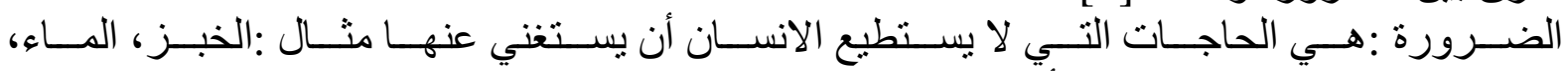

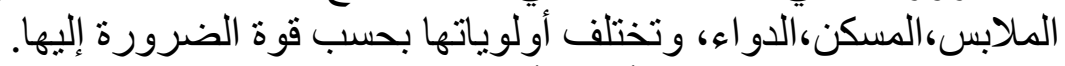

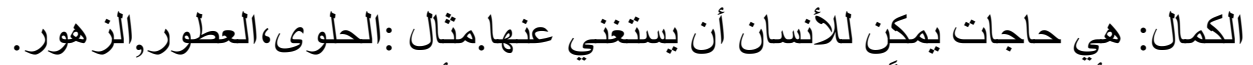

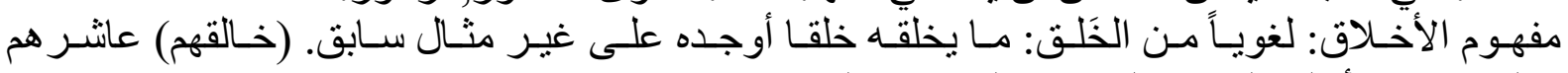

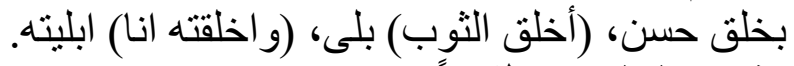
مفهوم الخلق اصطلاحاً

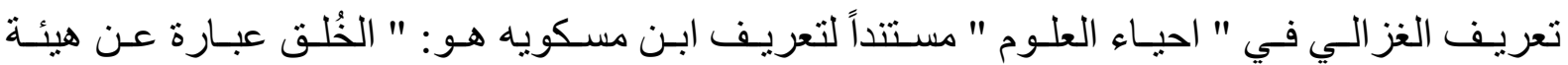

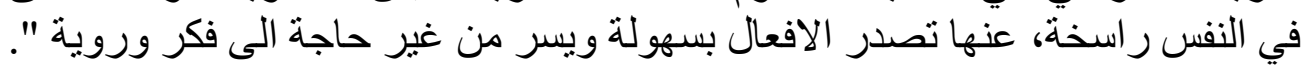

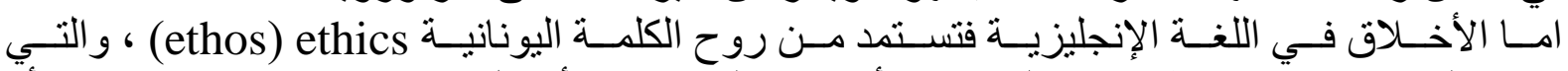

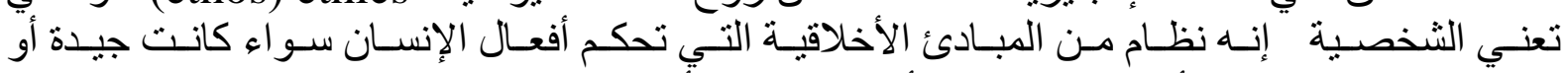

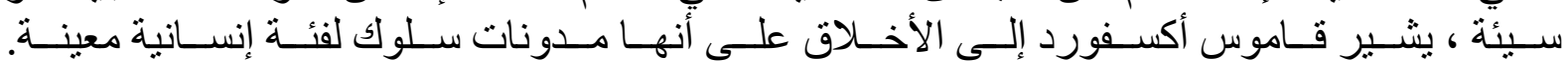




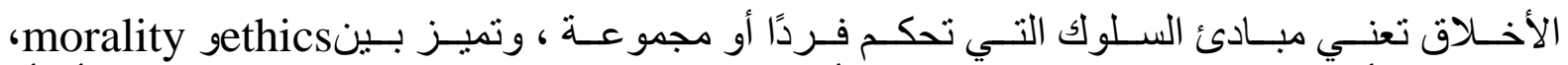

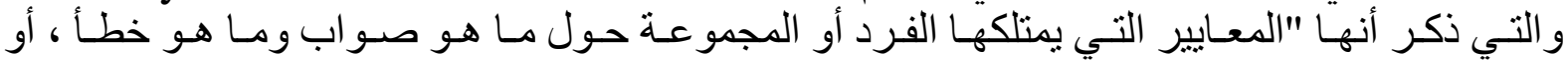

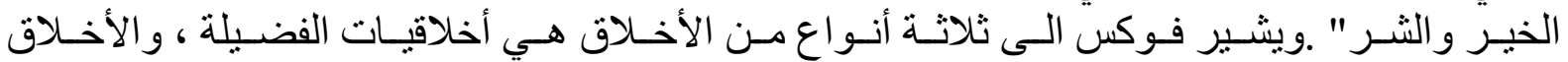

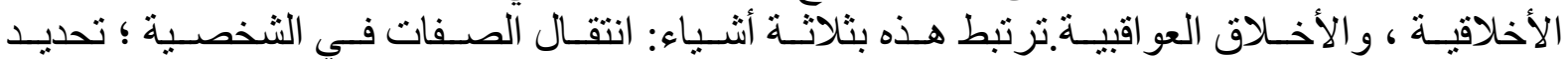

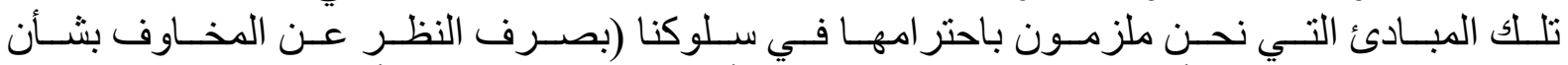

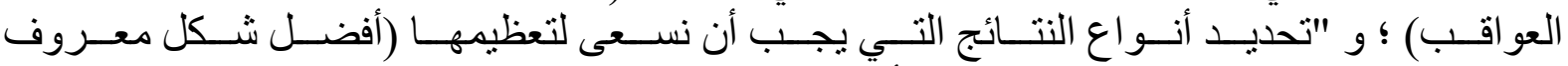

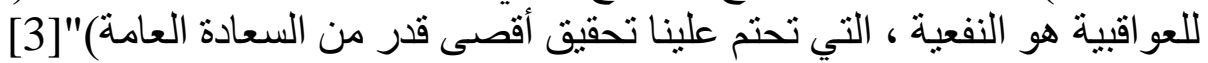

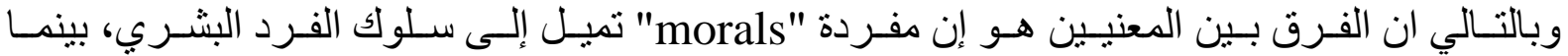

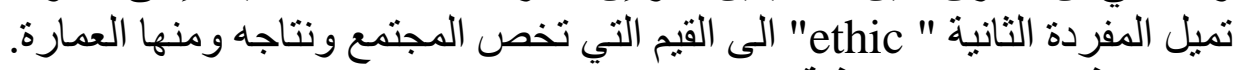

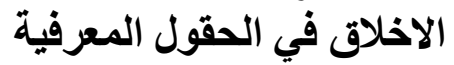

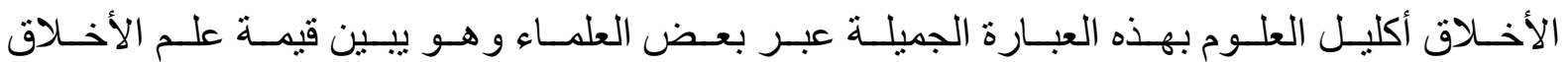

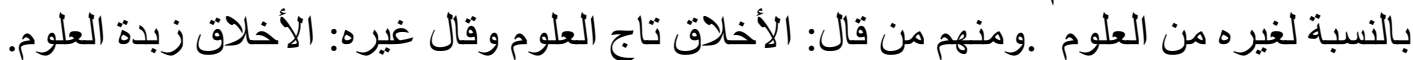

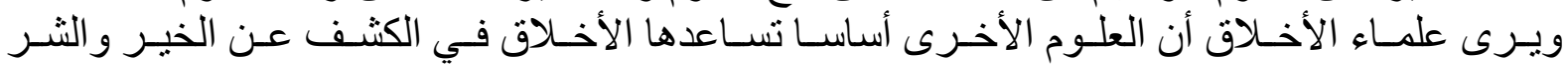

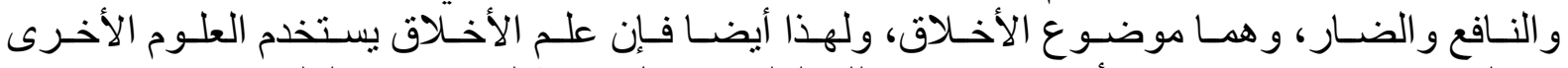

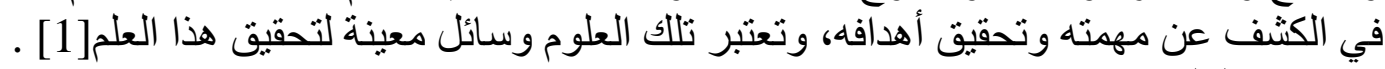

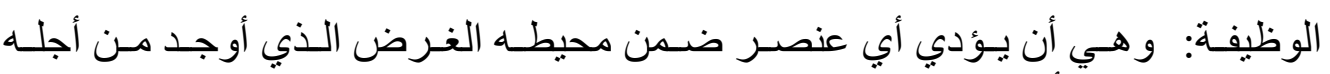

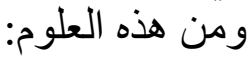

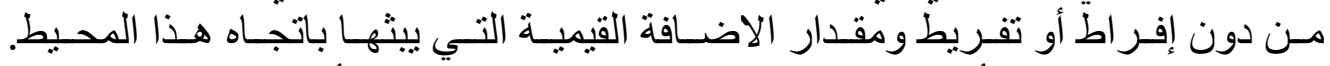

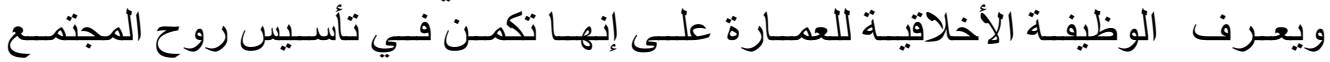

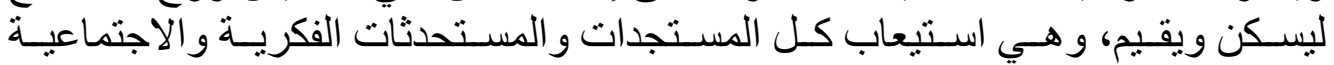

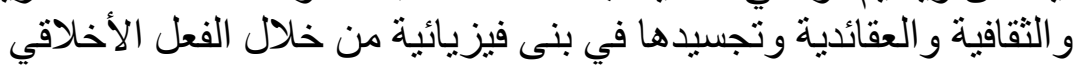

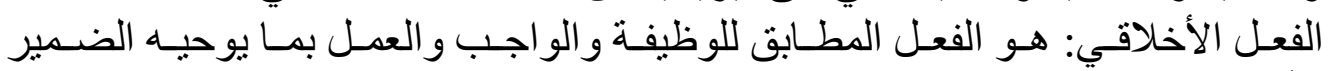

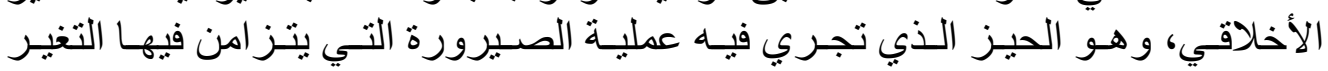
المستمر لعدم وجود حلول مطألقة دائميه.

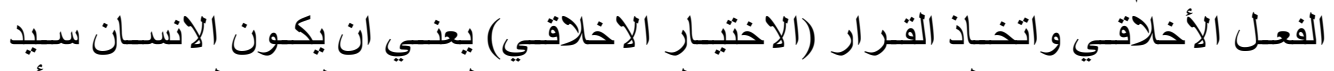

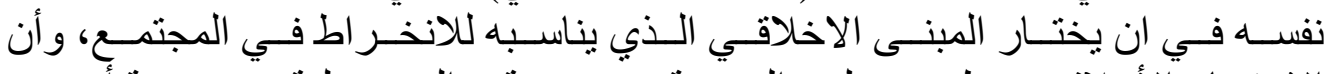

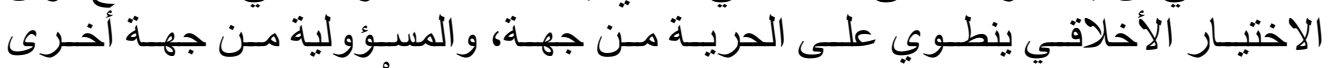

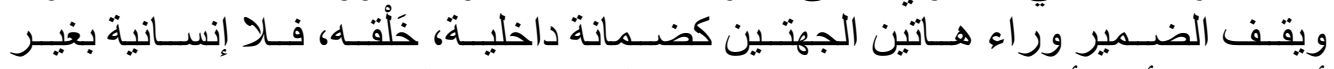

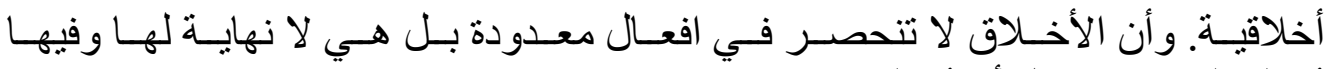

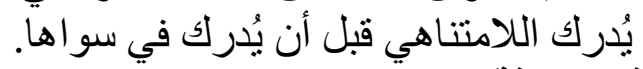
مفهوم الاخلاق في الثقافة والفن

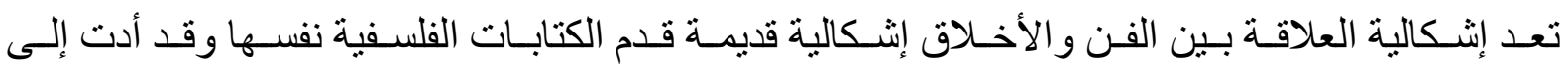

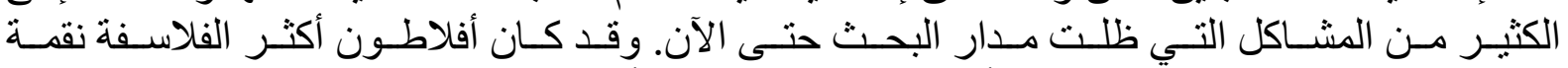

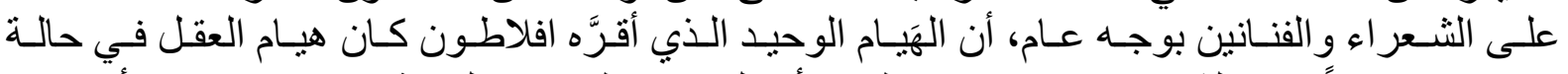

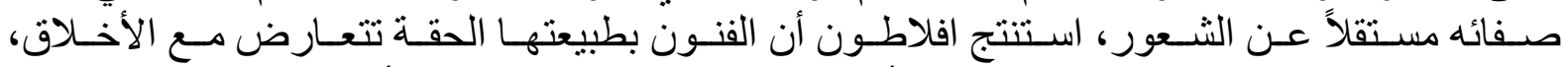

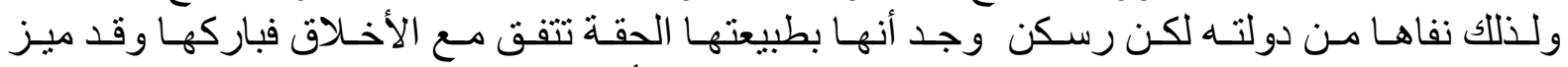

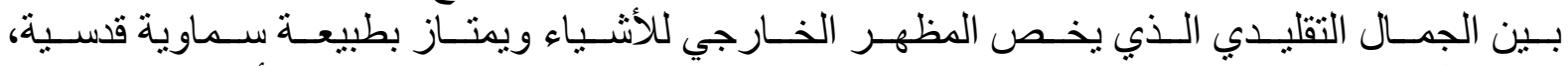

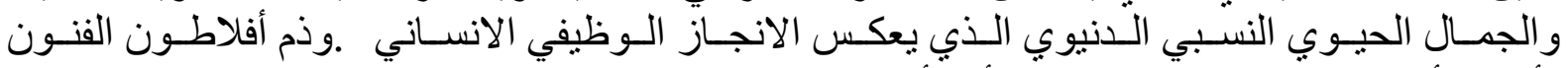

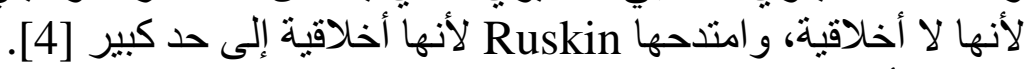

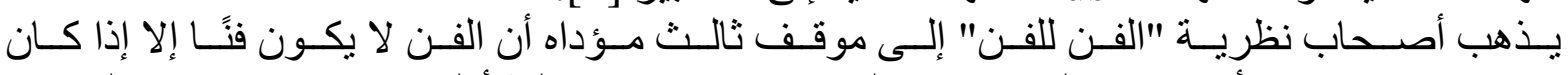

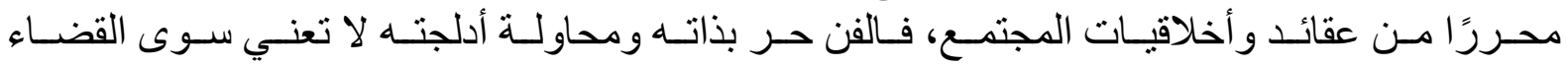
عليه من المهذ. 


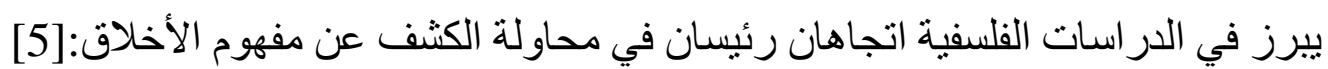

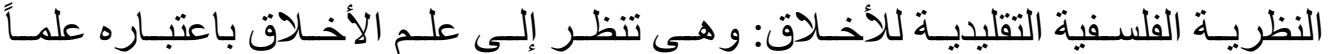

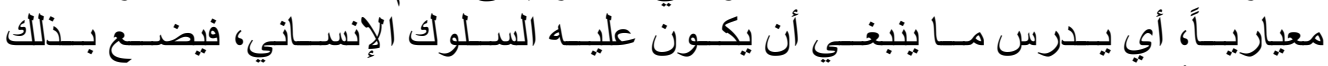

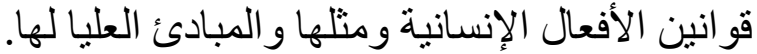

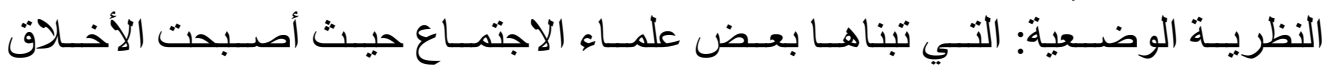

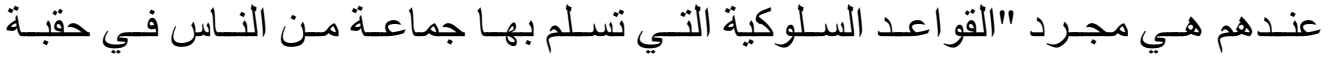

$$
\text { من حقب التتاريخ." }
$$

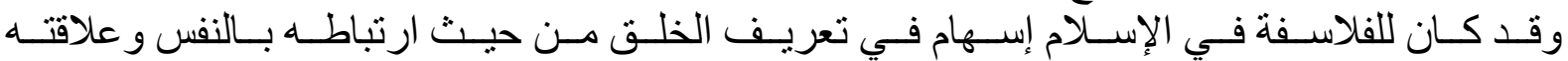

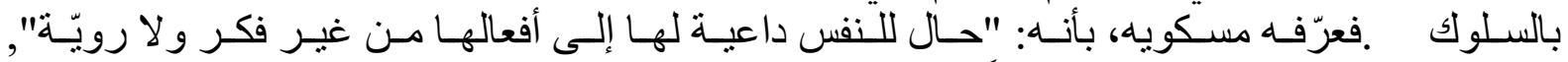

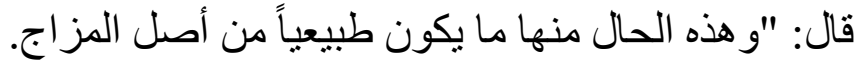

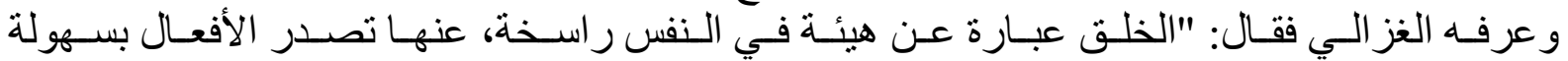

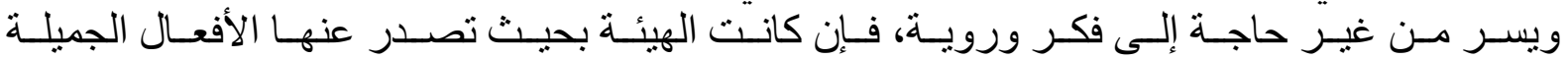

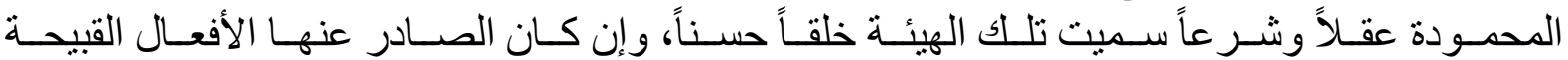
سميث الهيئة التي هي المصدر خلقاً سيئًا.

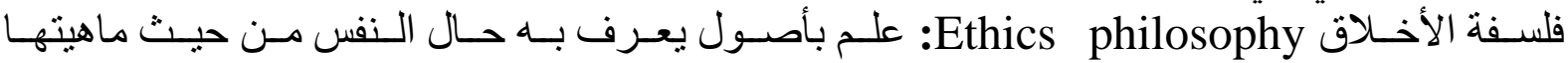

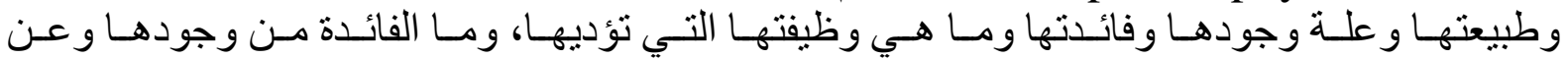

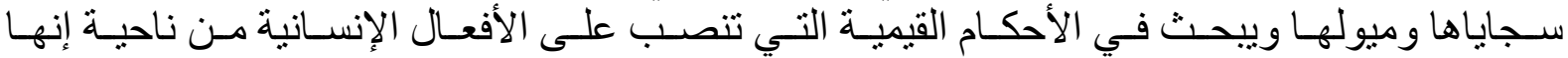

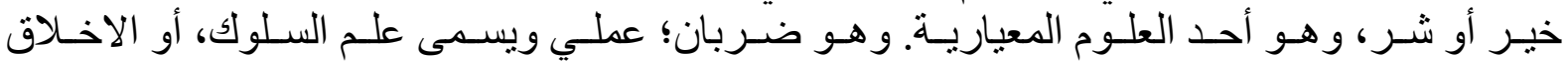

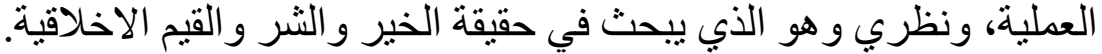

\section{التوجهات الفلسفية العربية الإسلامية للأخلاق}

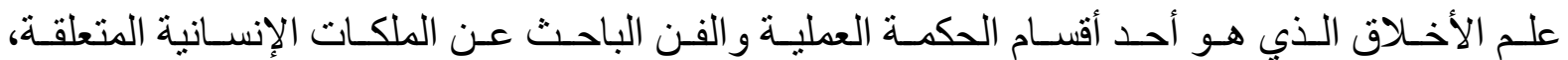

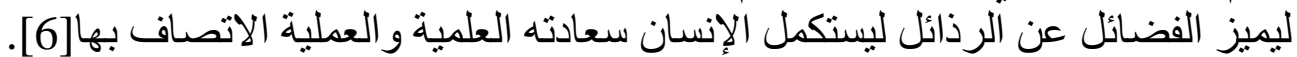

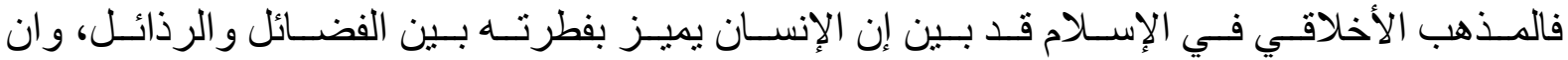

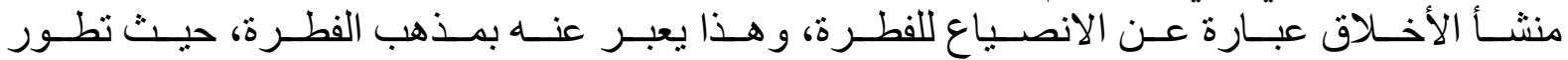
السجال في تمييز الفعل الاخلاقي عن غيره، واسفر عن تأسيس مذاهب ألبان أخلاقية.

\section{الفعل الأخلاقي كسلوك انساني}

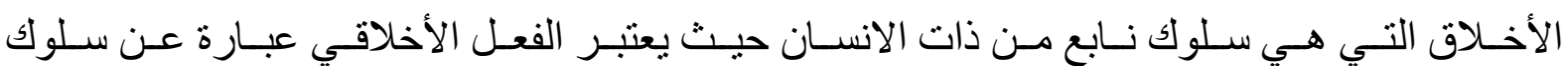

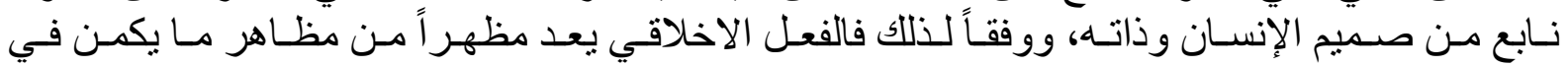

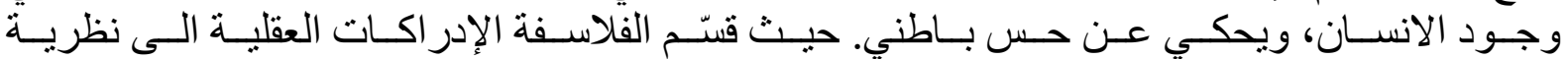

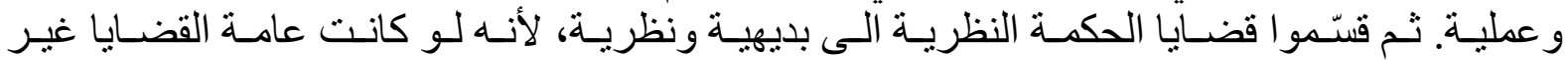

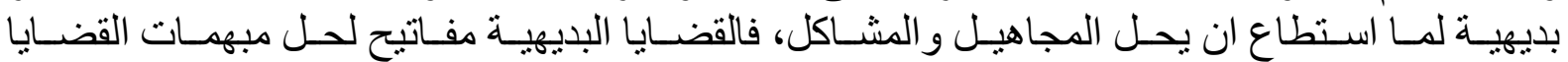

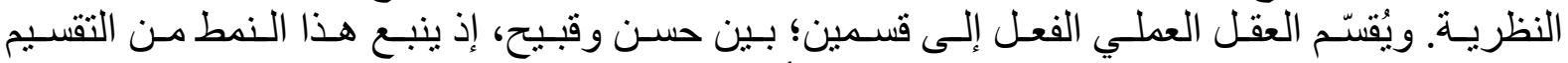

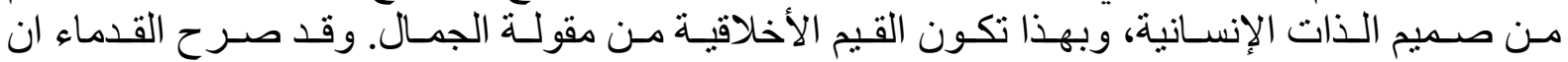

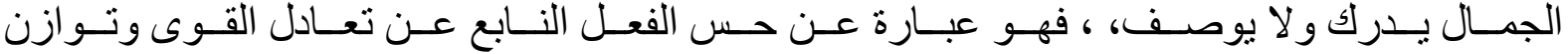

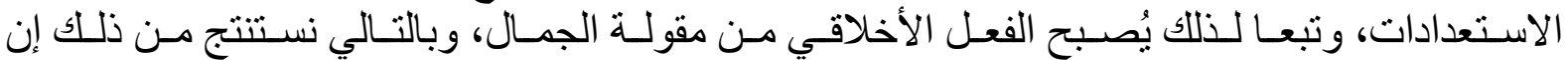

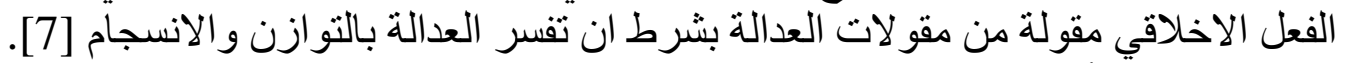

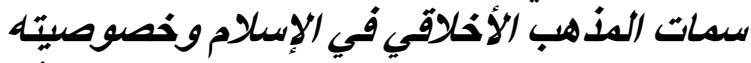

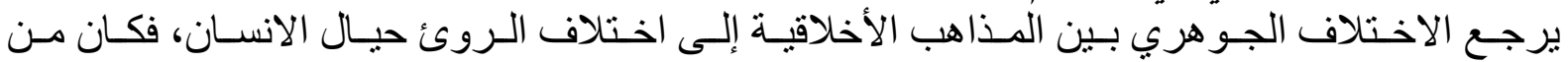

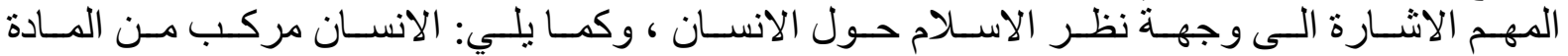

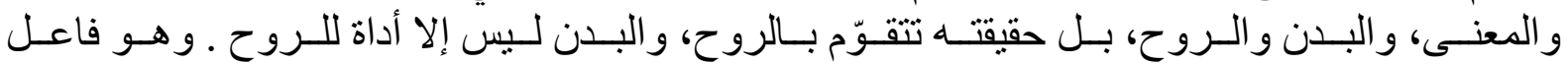

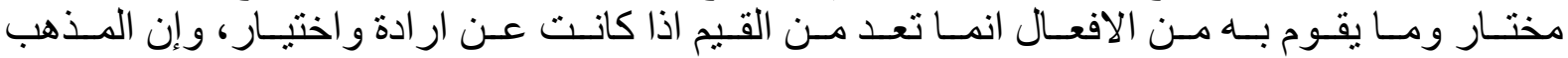




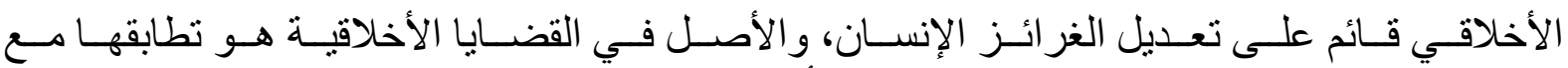

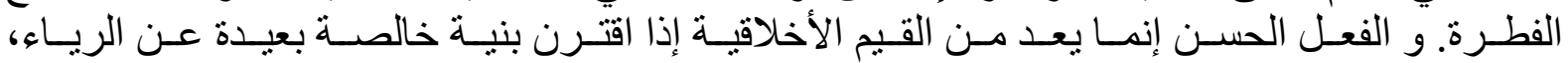

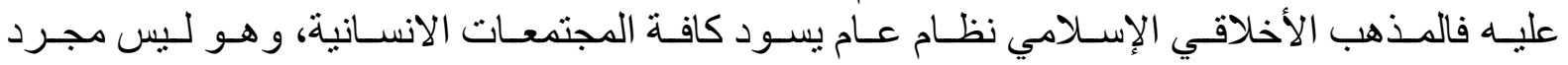

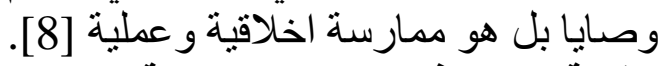
نظرية الكمال في الكليات الثرعية

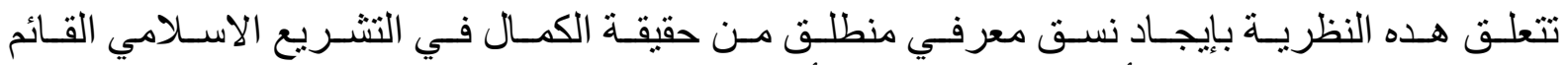

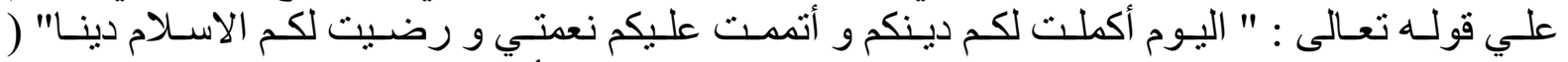

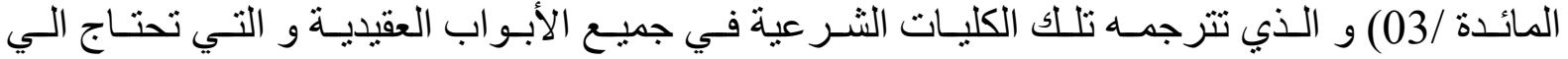

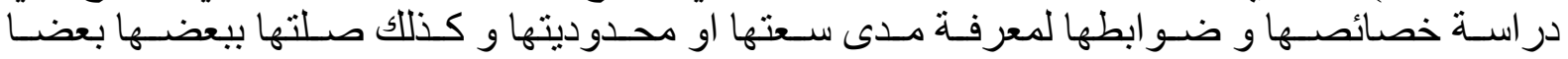

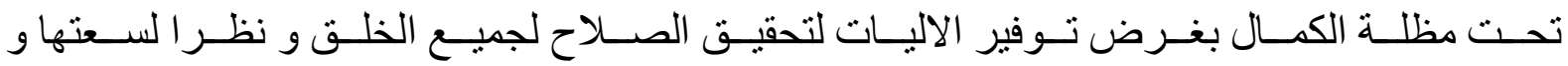
شموليتها استحقت ان تدرس في معنى النظرية الطروحات الفلسفية للكمالية:

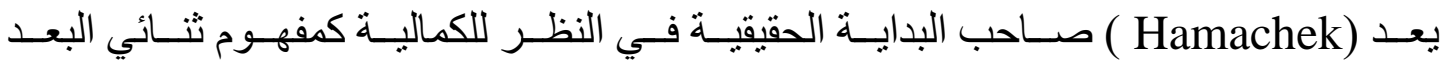

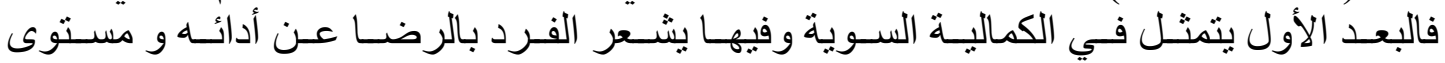

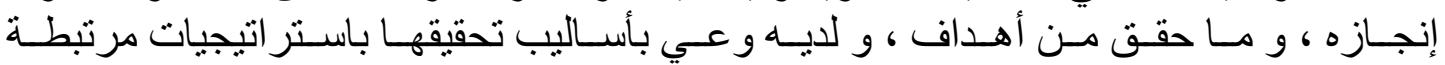

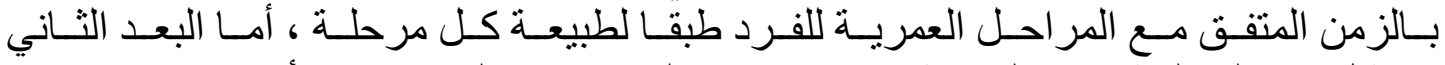

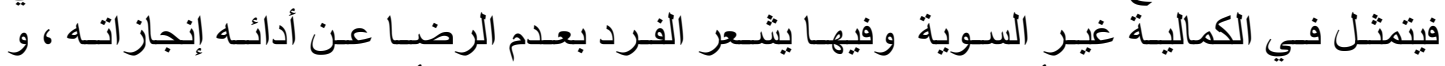

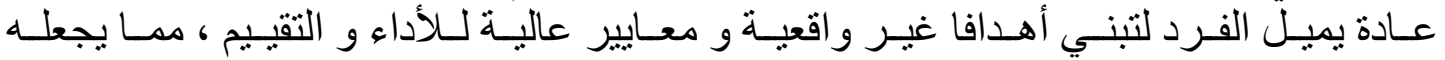

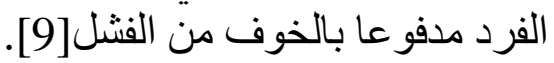

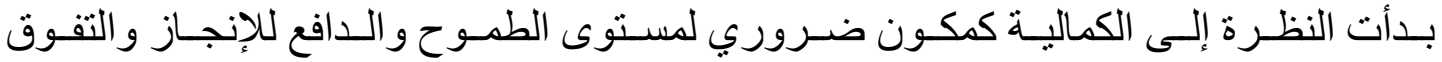

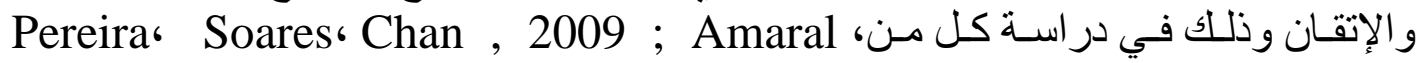
Marque, ، Bos،

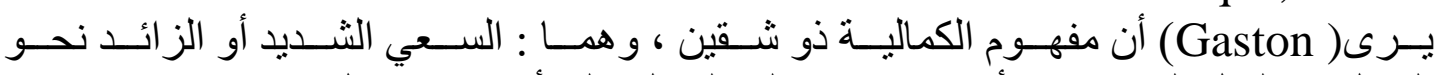

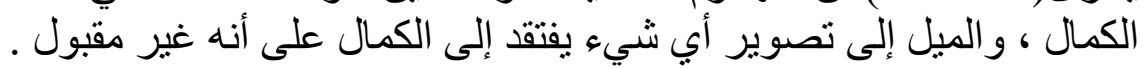

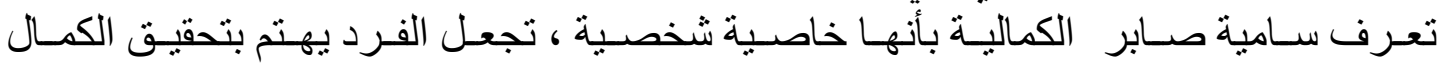

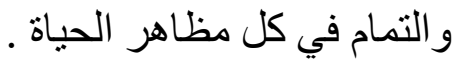

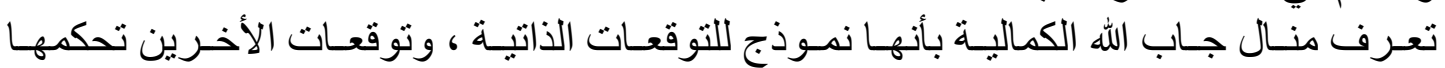
معايير غير و اقعية ، ومحددات صار مة الاستحقاقية الذات من خلاتل الأن الأداء

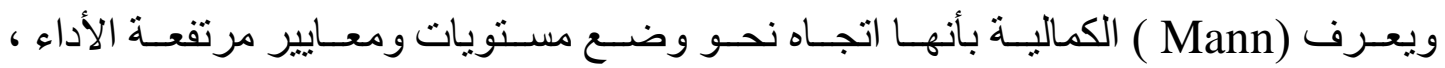
تكون مصاحبة لاتجاهات الفرد كي يكون مضبورة بانسات بصورة شديدة في سلوكه.

الار اسـات المعمارية

نظرية الكمال المعماري

ترتبط هذه النظرية بأربع خصائص أساسية لكل مبنى ((الجمال و الوحدة و الثمولية الكلية ))

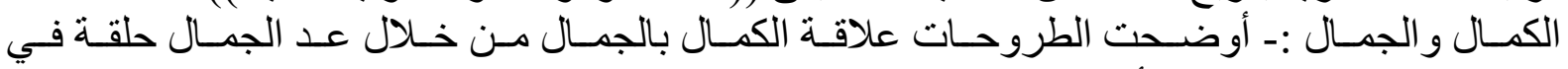

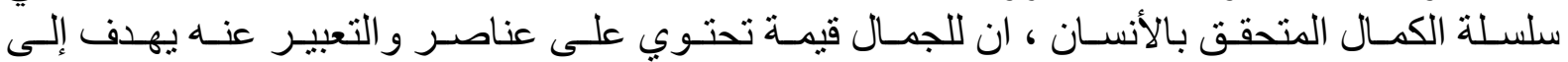

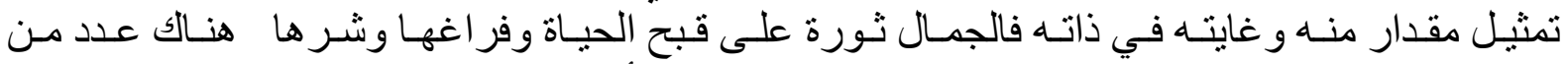

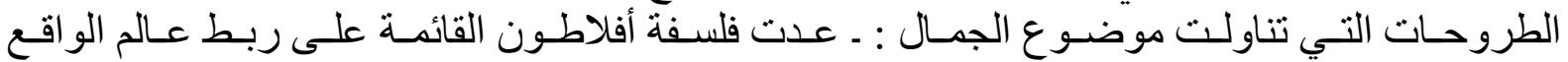

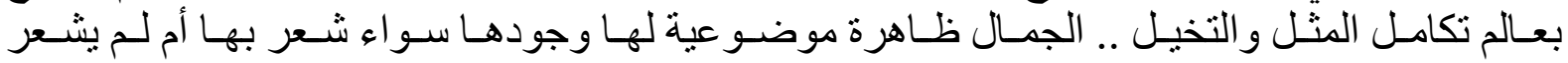

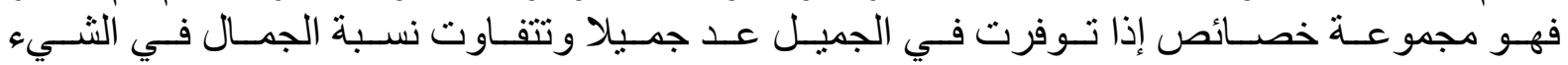

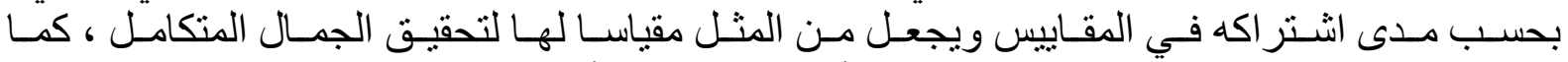

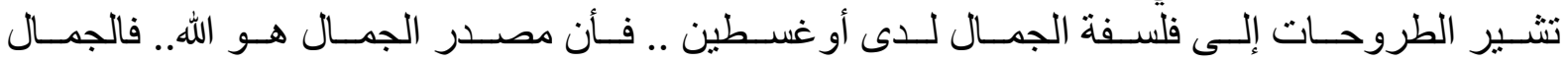

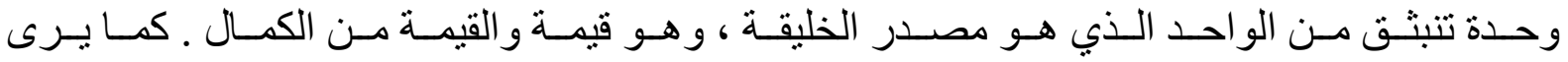




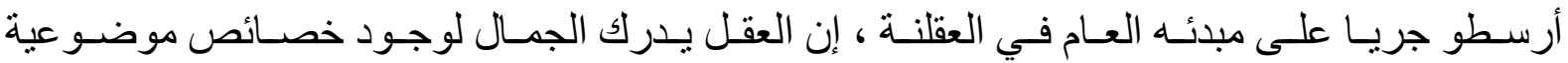

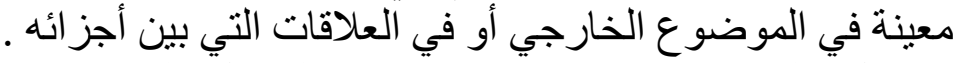

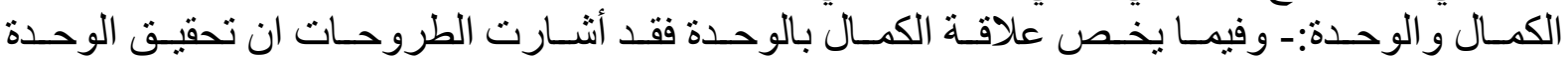

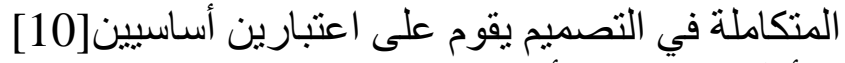

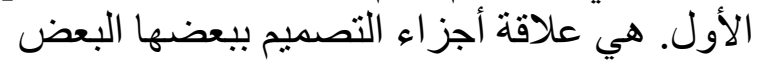

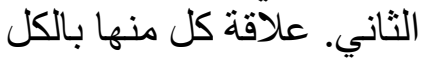

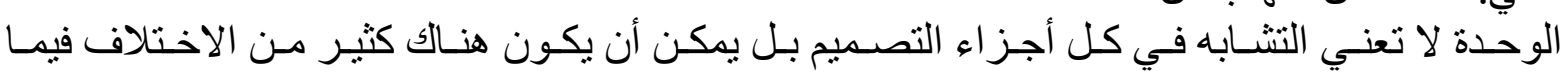

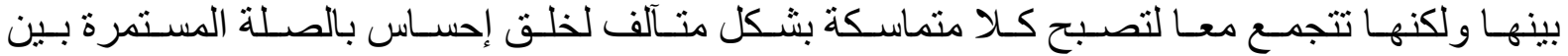
الأجز اء ، ويتم ذلك:-

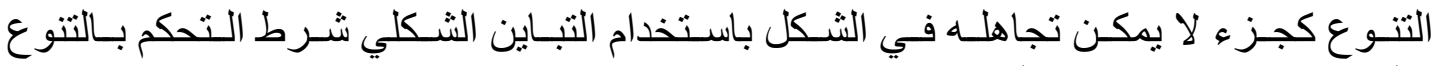

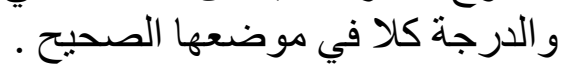

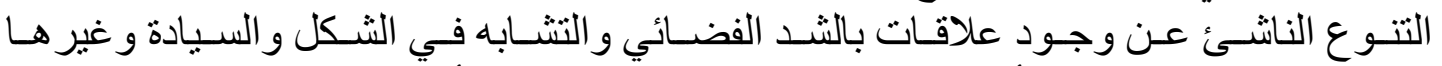

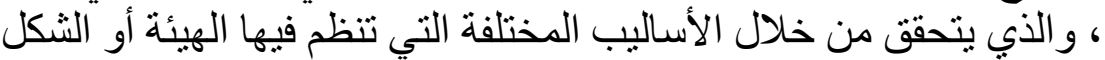

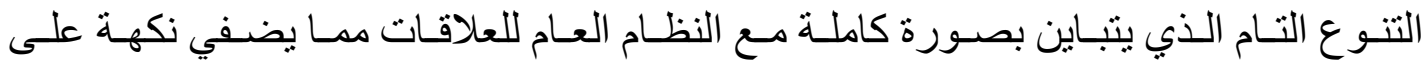

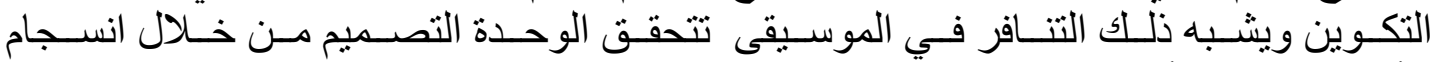

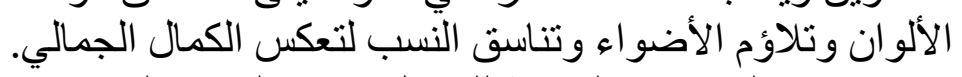

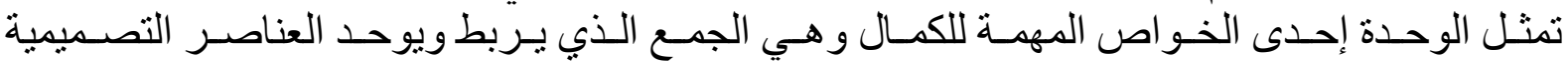

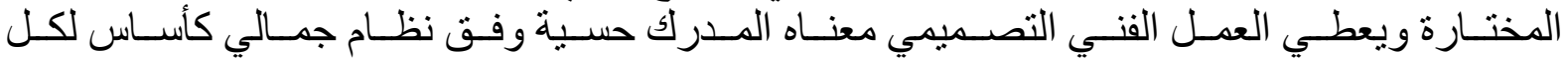

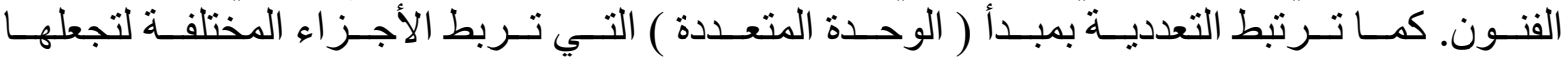

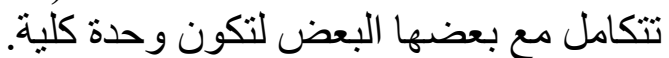

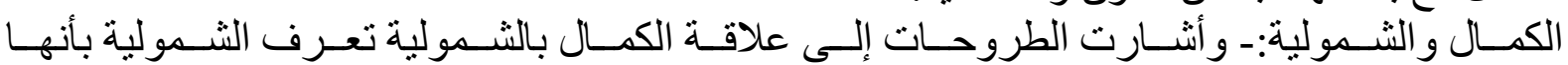

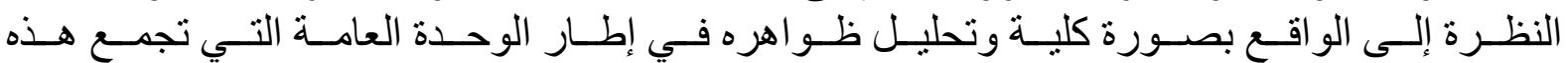

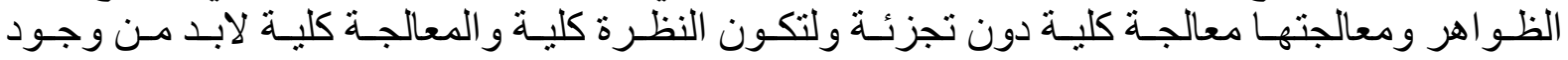

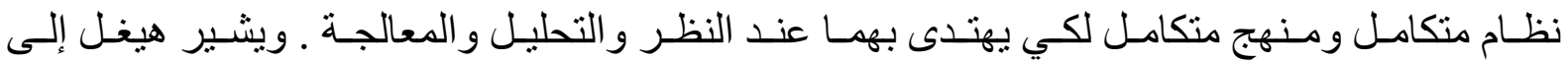

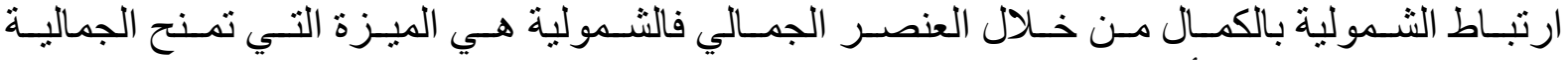

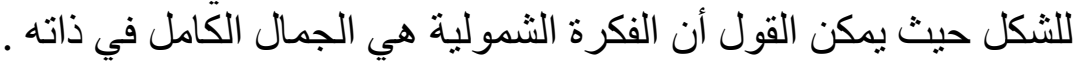

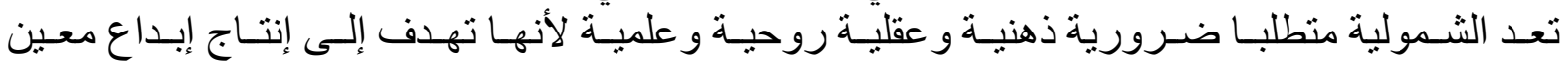

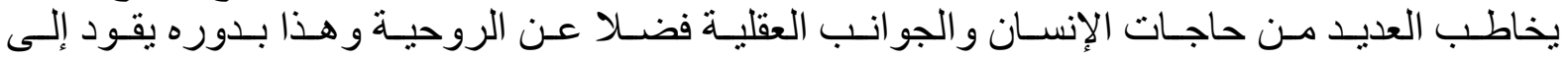

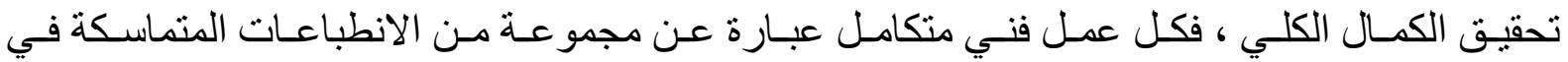
ترتيبها وليس ذللك الترتيب مفككة بل متماسكة

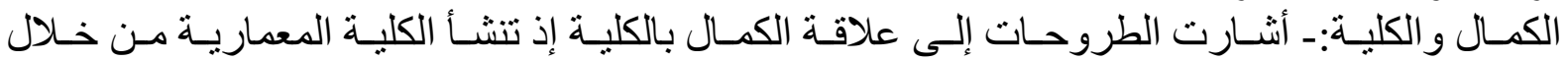

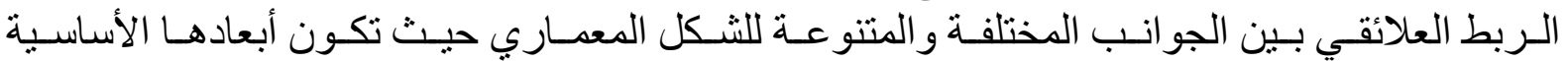

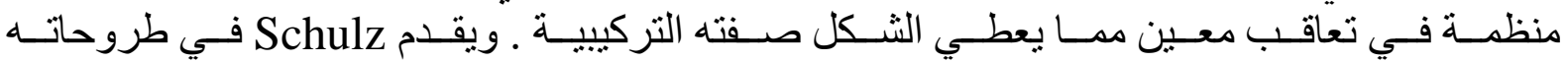

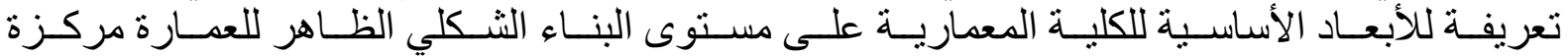

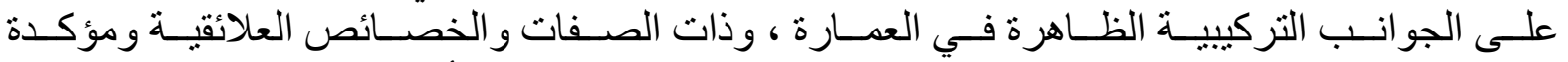

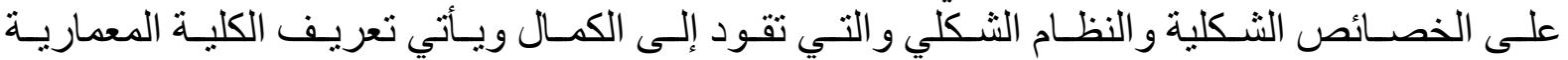

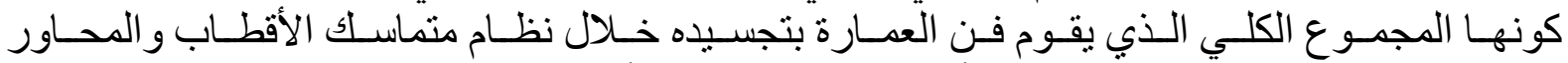

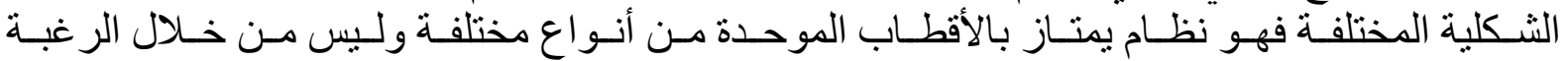

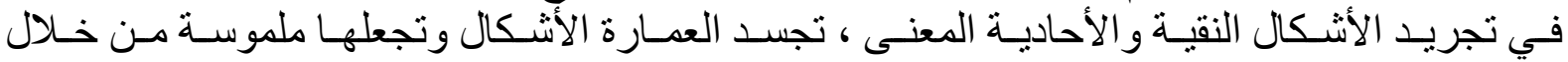

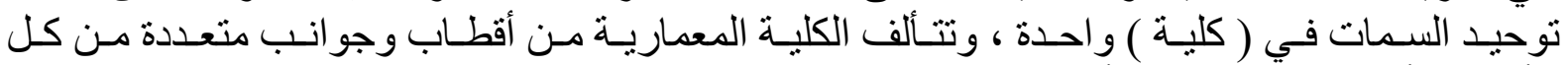

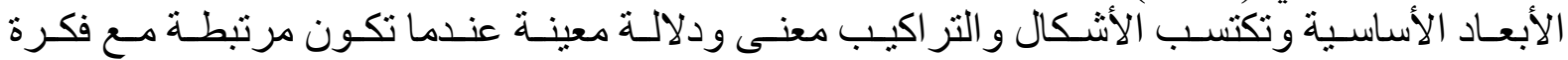
المبنى ، ويتم تحديد الكلية المعمارية بواسطة سماتها لإنها العلائقية. 


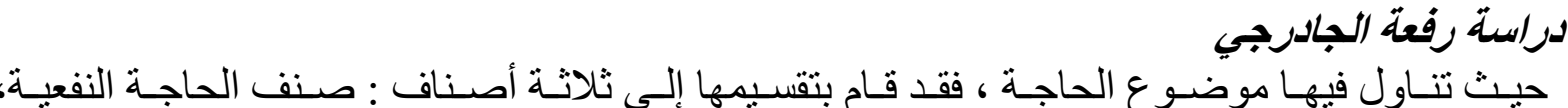

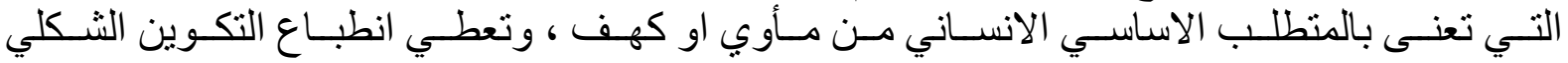

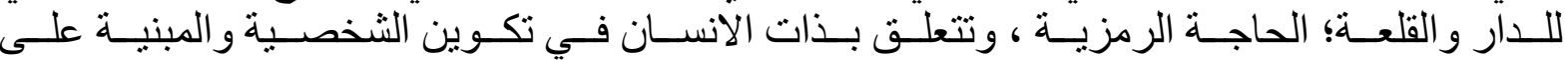

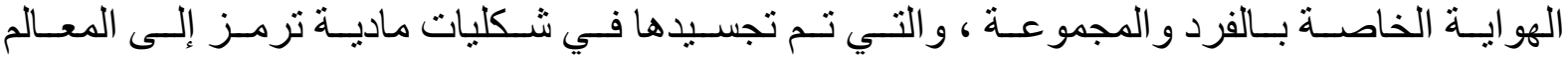

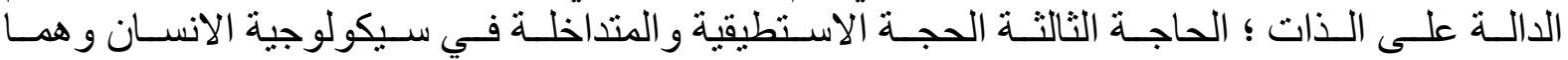

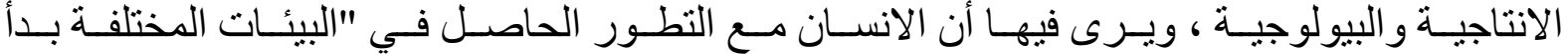

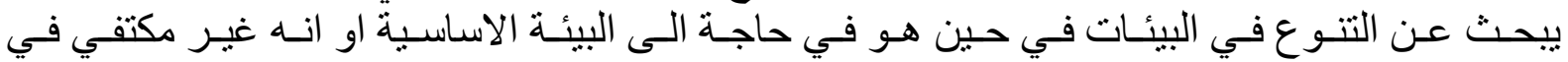

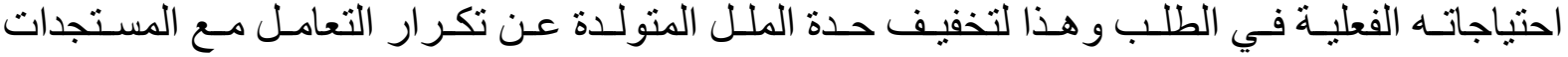

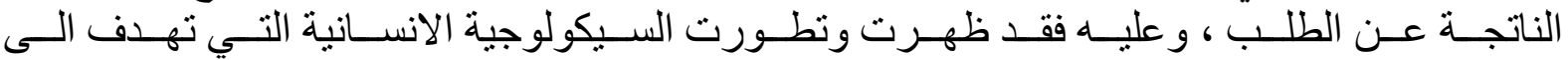

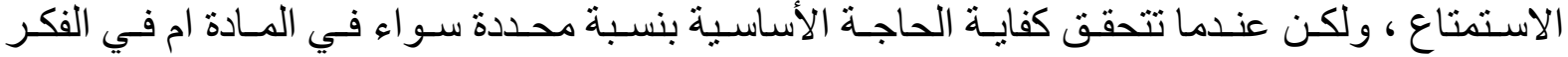

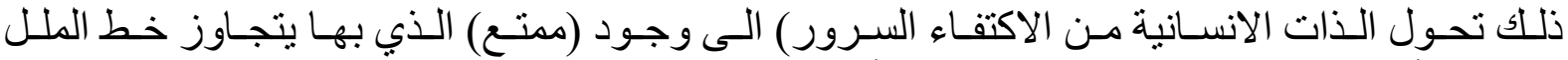

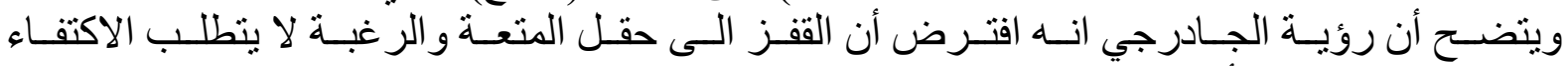

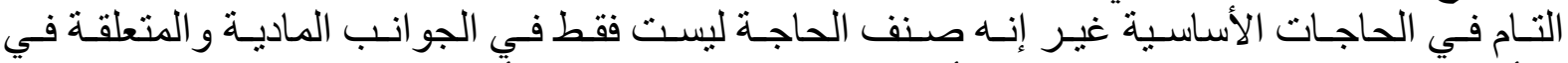

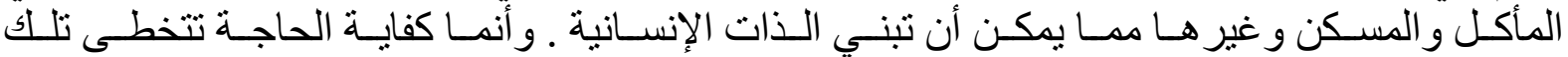

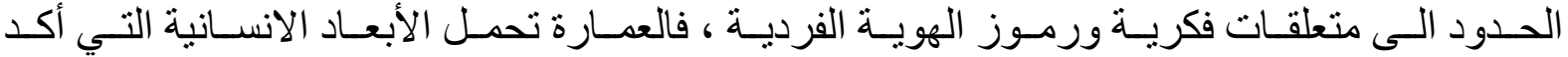

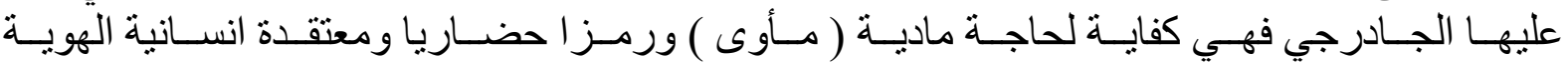

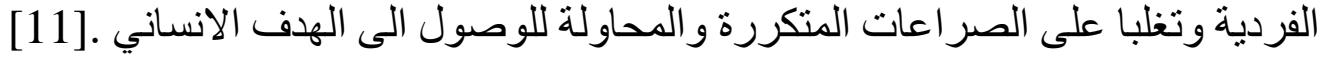

الدارسات المعدارية للأخلاق

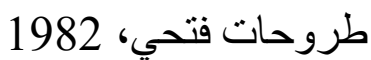

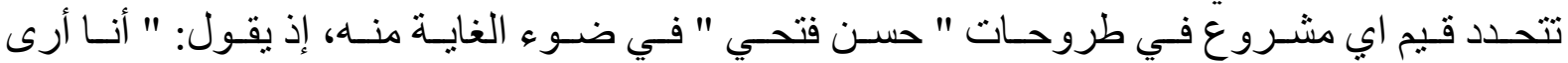

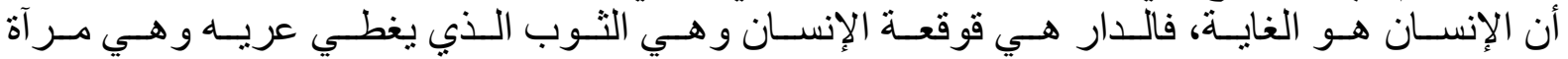

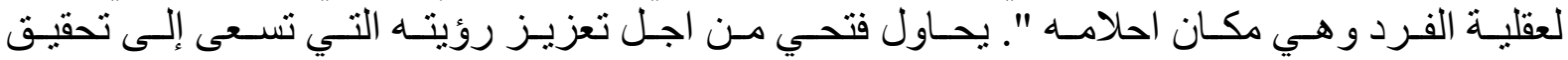

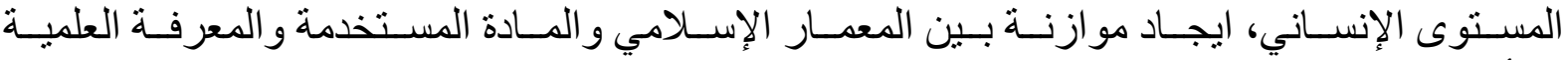

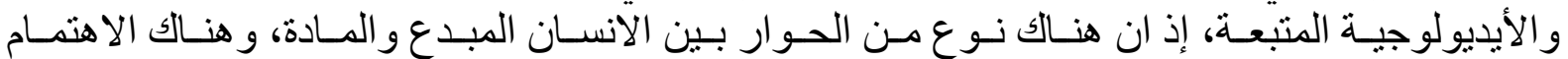

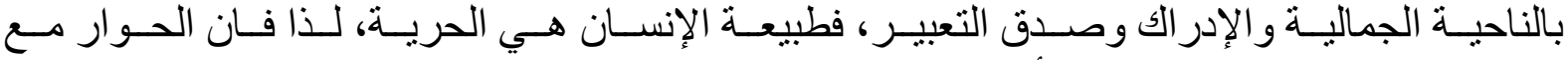

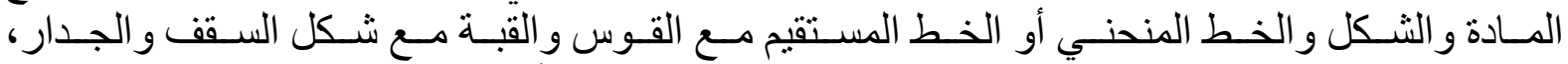

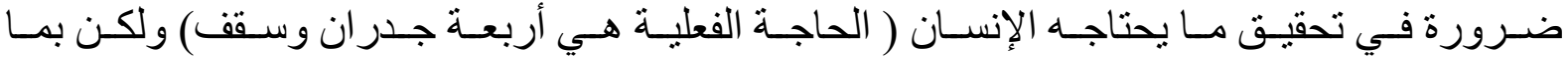

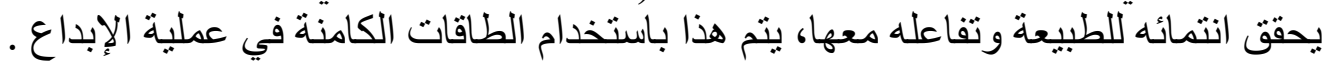

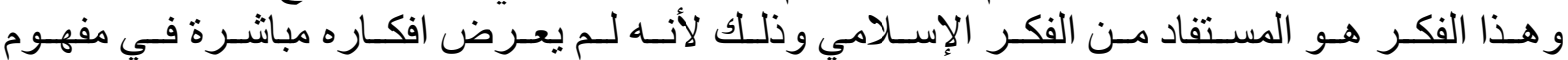

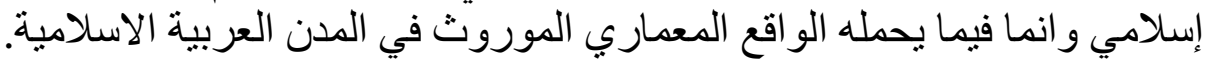

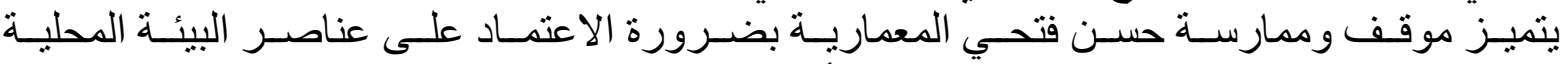

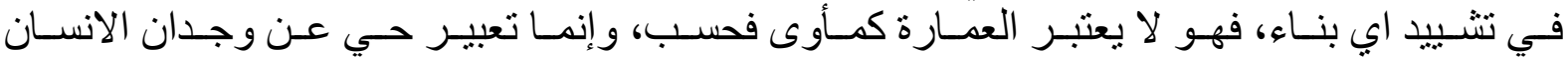

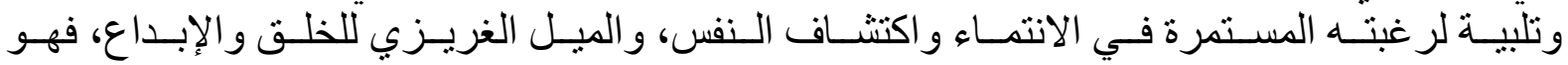

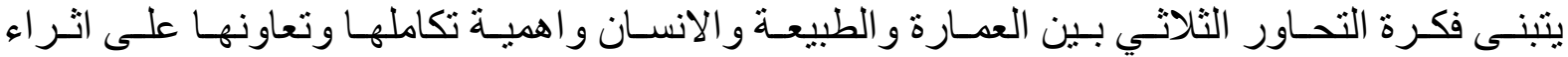

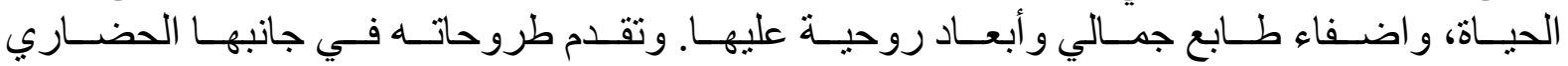
مساهمة في الجدل حول الذاتية ومحاربة التغريب في العمارة

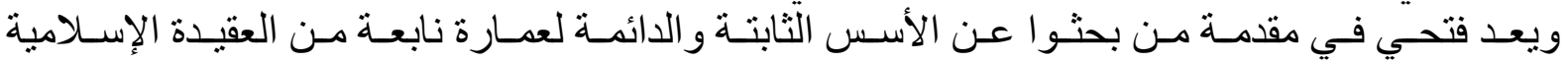

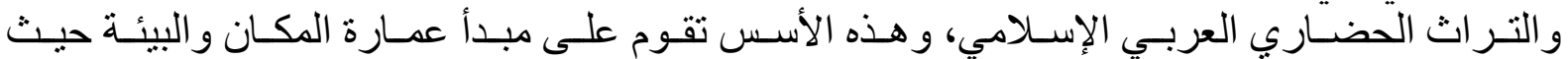

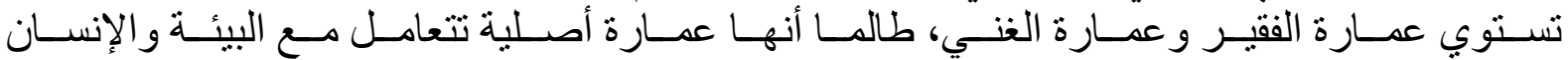

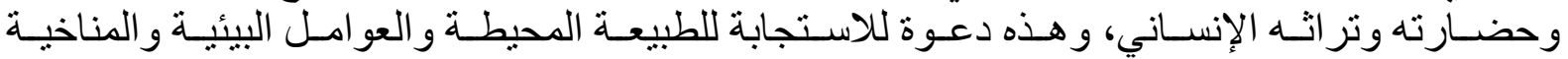

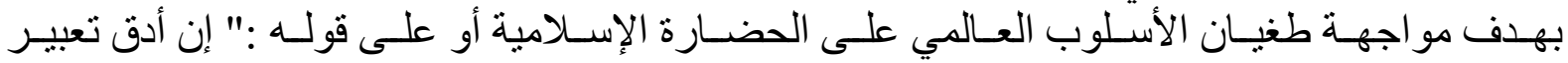




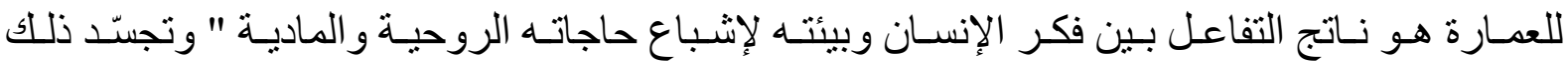

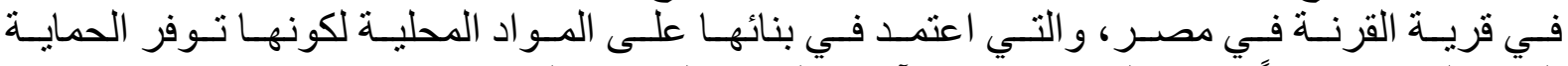

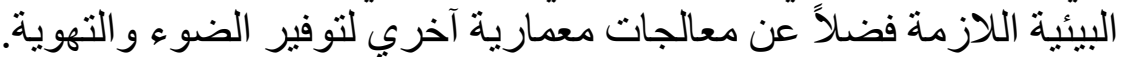

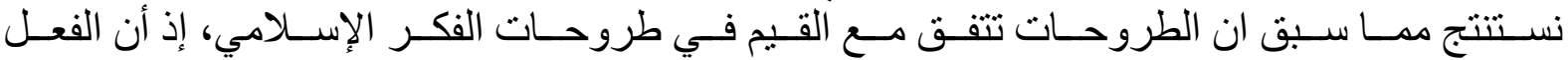

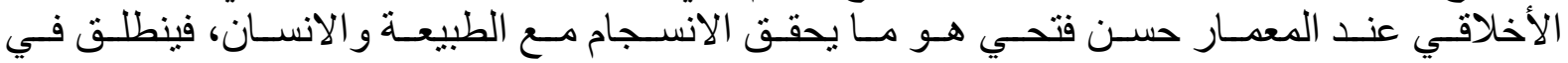

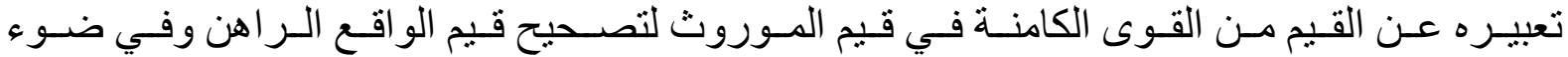

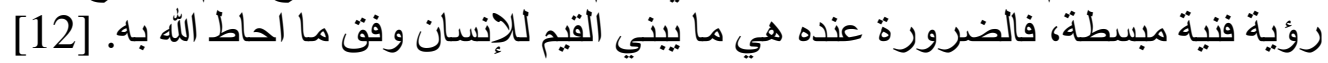
طروحات مكية 1982- 1983

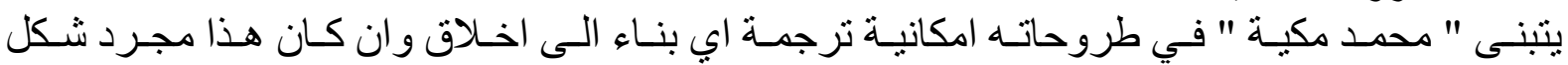

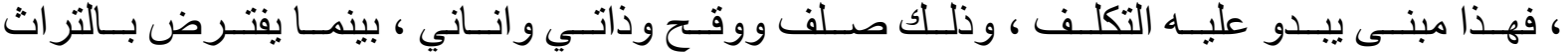

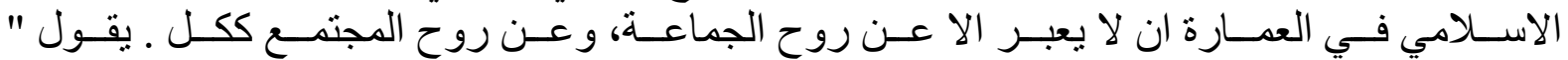

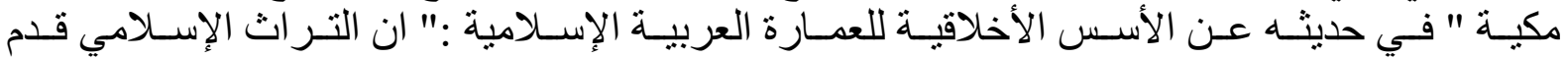

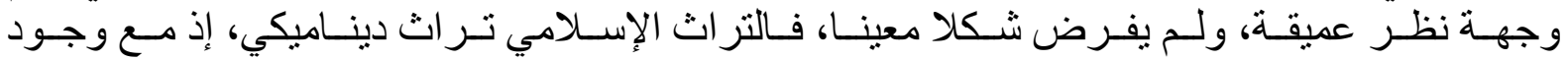

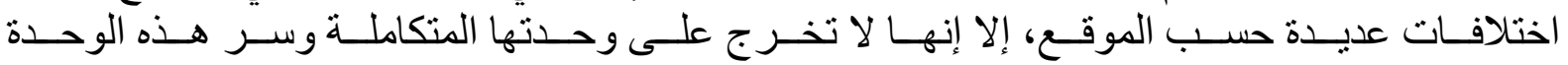

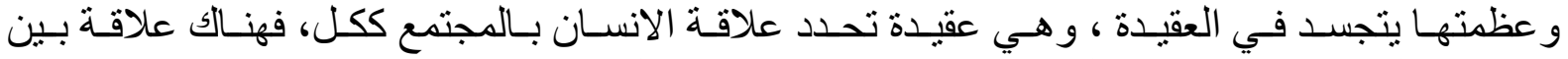

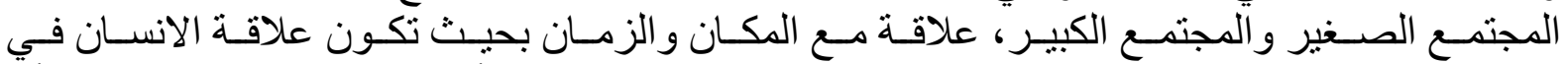

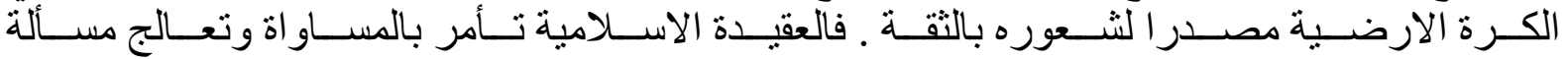

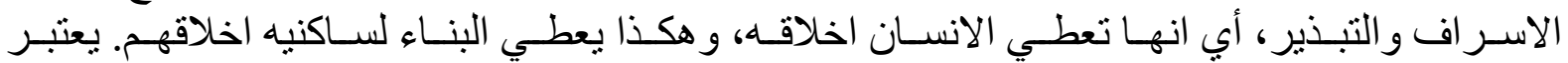

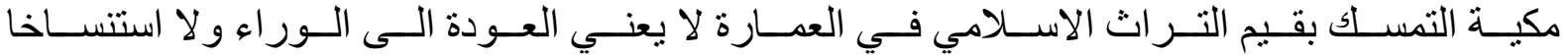

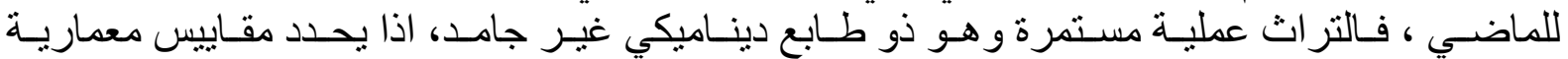

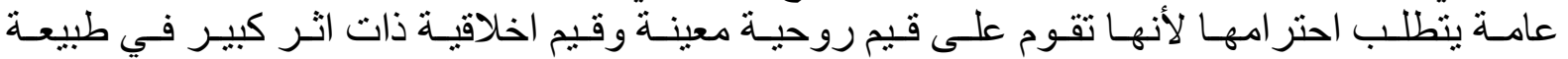

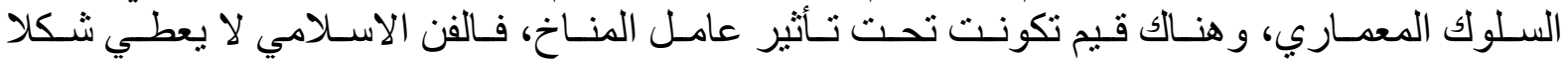

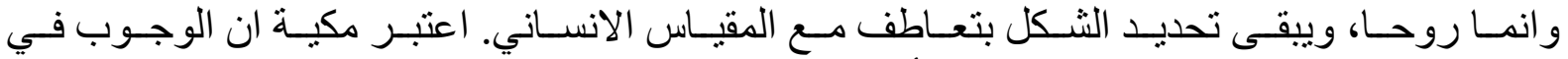

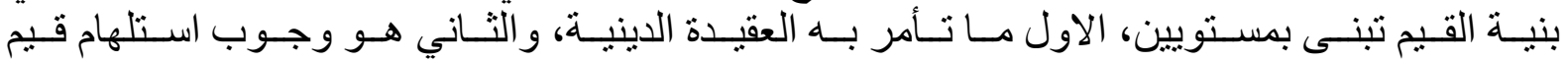

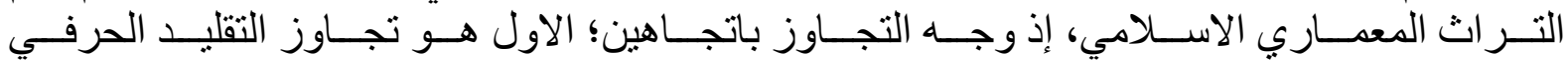

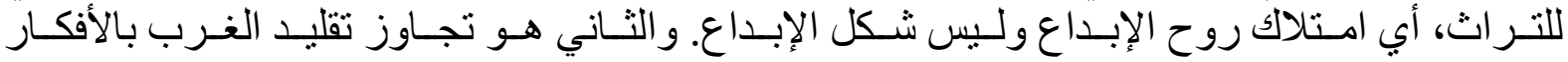

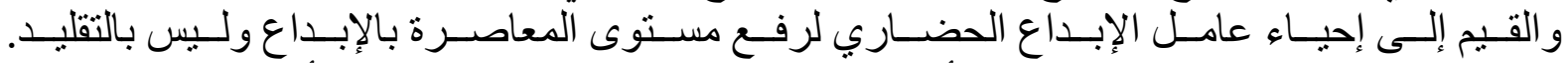

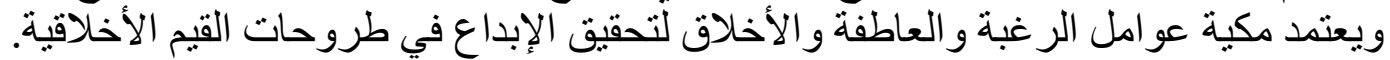

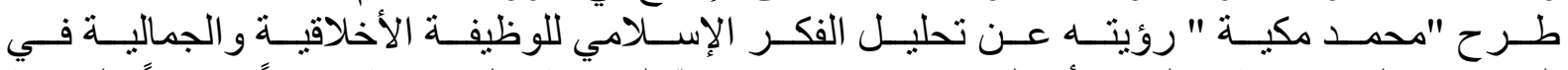

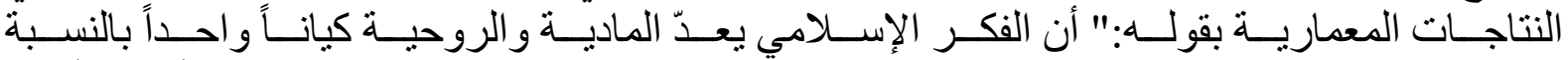

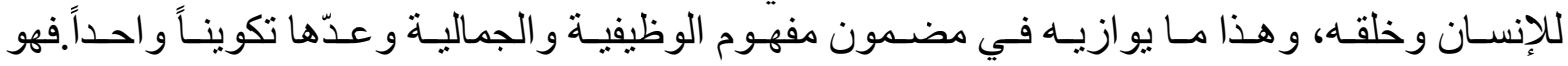

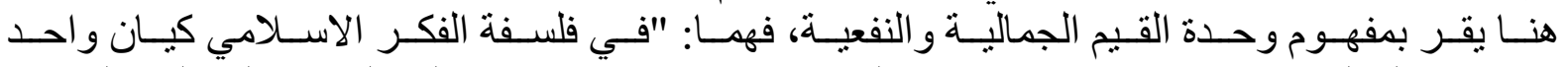

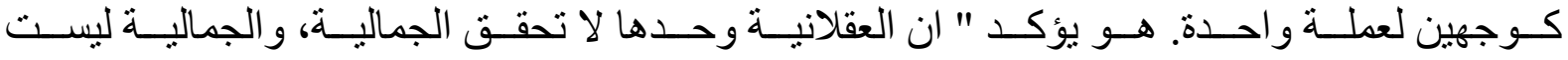

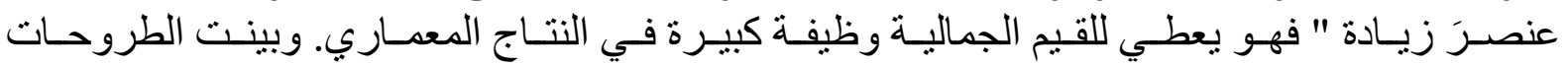

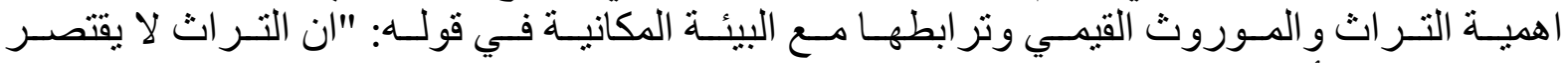

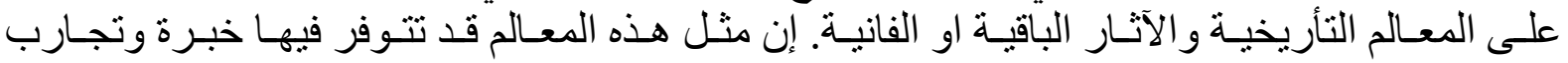

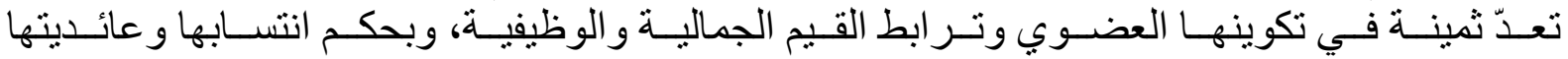
وتفاصيلها المتر ابطة تدينة

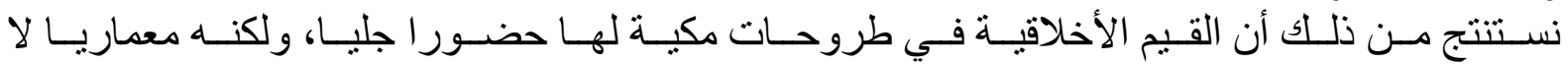

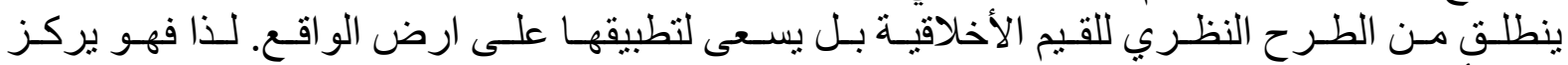

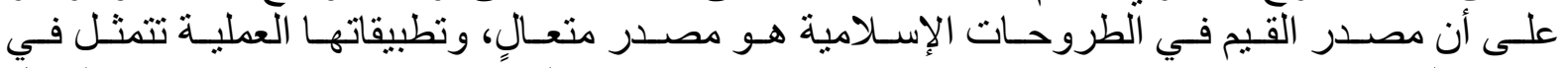

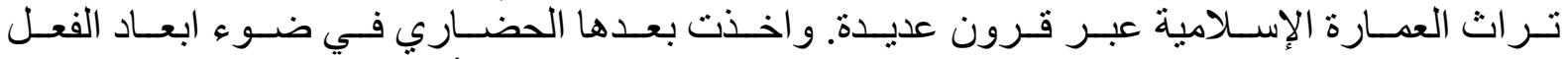

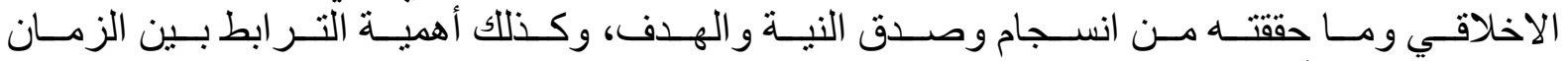
و المكان والقيم الأخلاقية [13]. 


\section{الفكر الأخلاقي وضرورة المبادئ الأخلاقية}

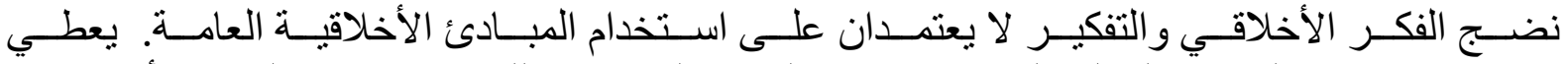

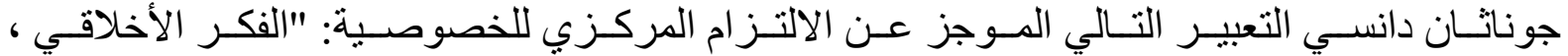

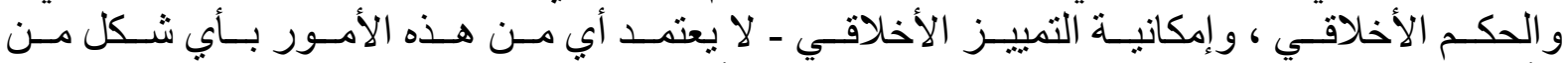

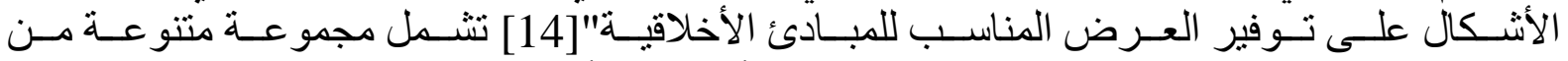

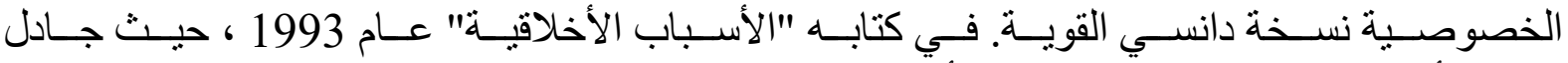

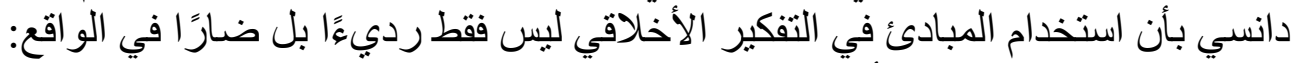

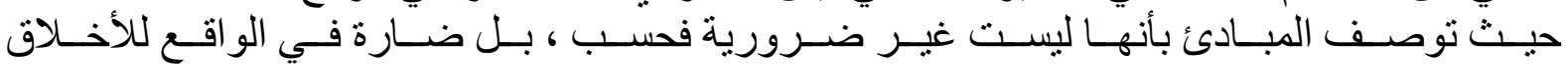
الحميدة.

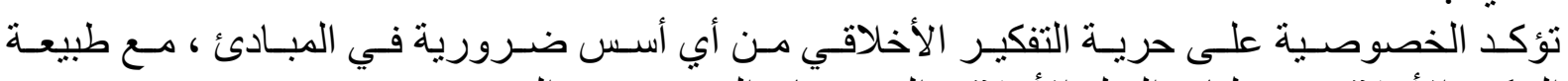

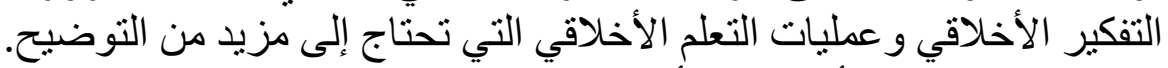

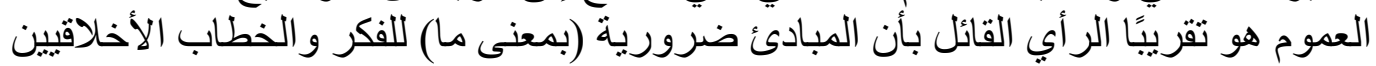

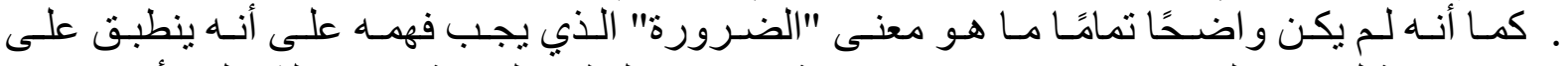

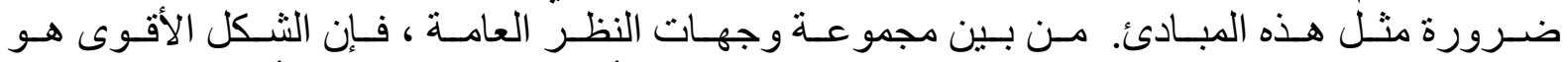

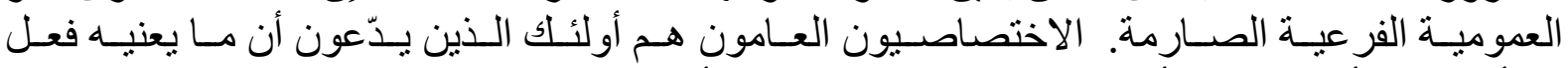

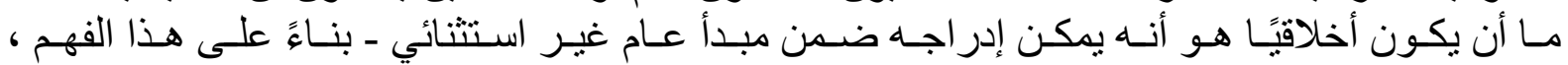

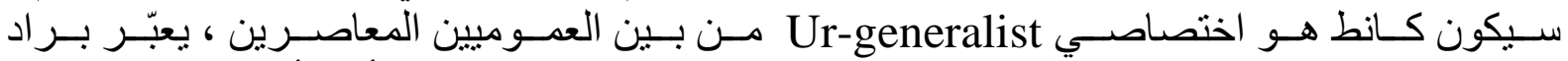

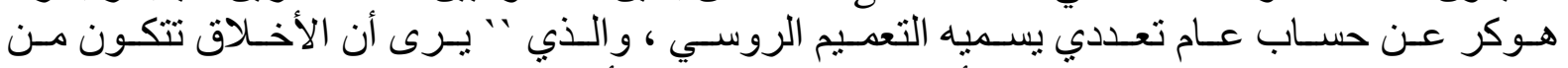

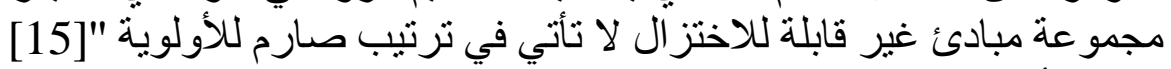

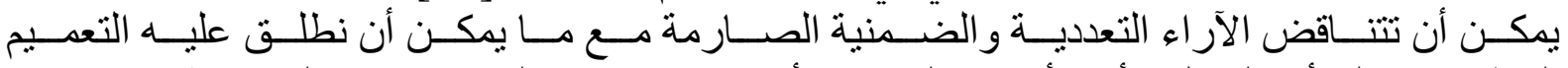

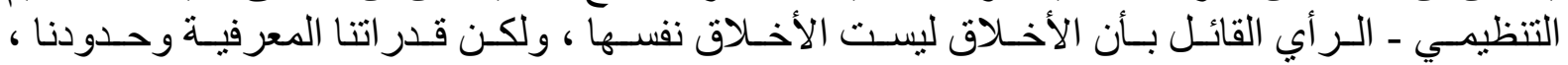

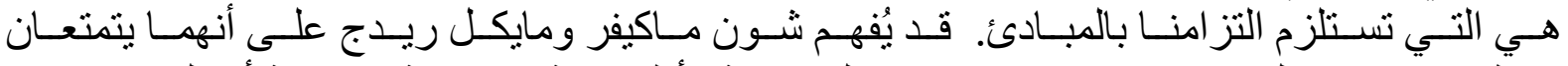

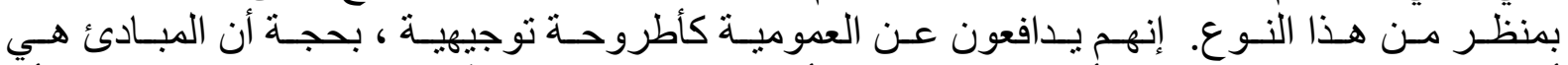

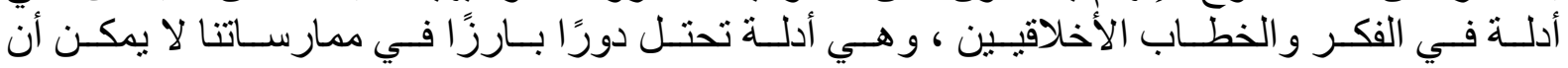

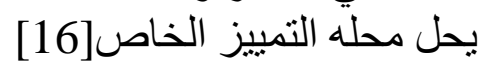

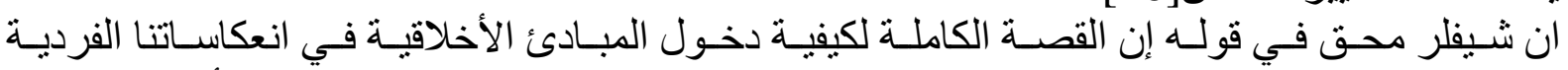

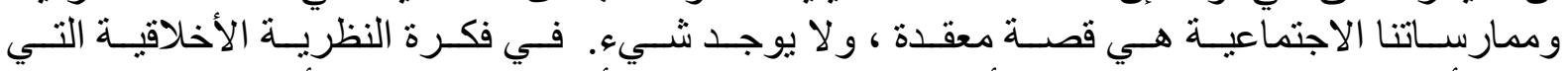

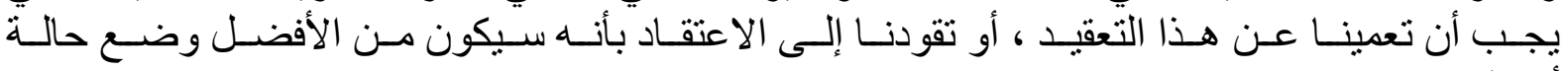
[17]. أبسط

\section{تجاوز الأخلاق}

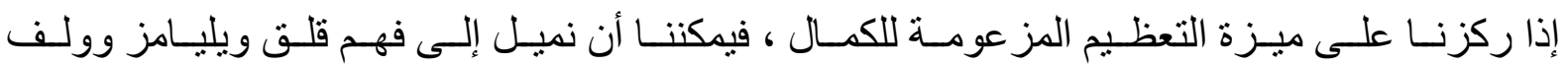

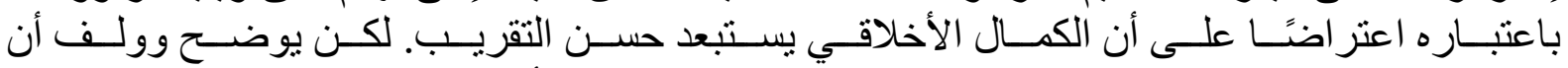

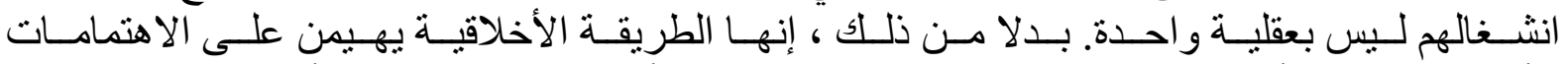

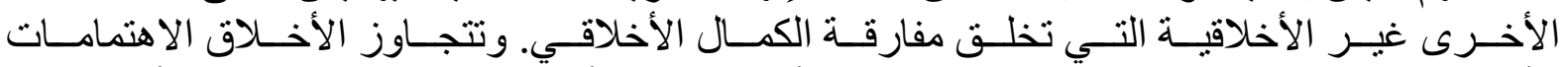

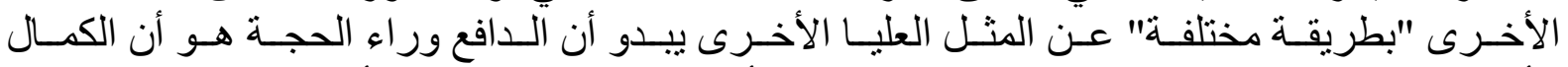

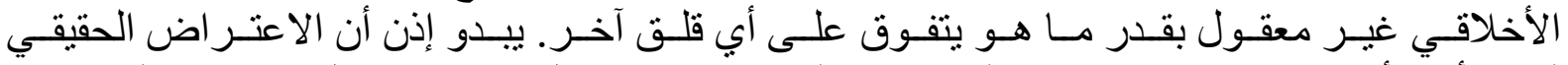

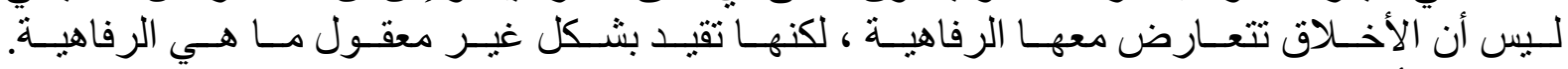

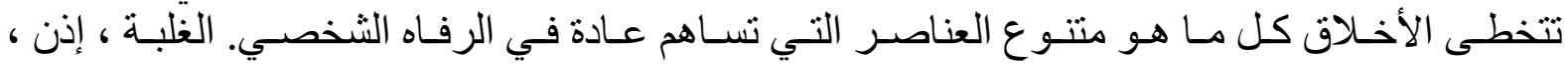

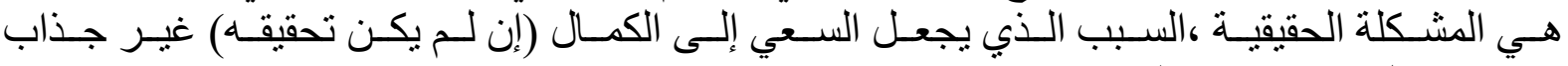
و غير معقول كثخصي مثنالي. 


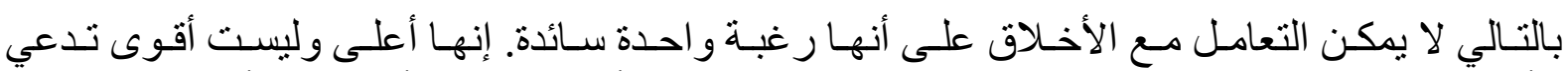

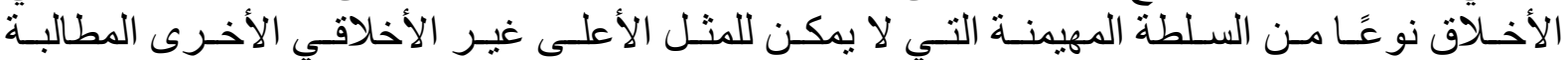
نظريات الكمال الأخلاقي

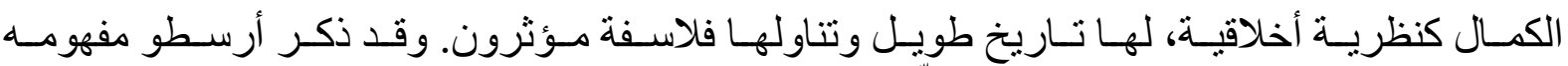

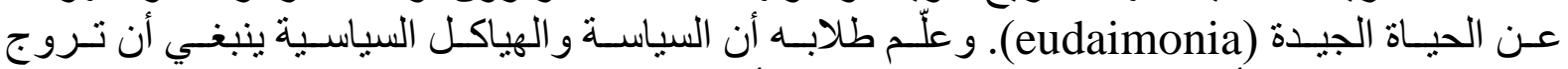

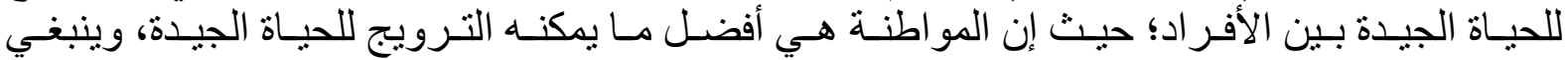

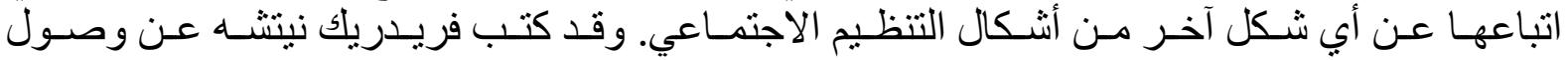

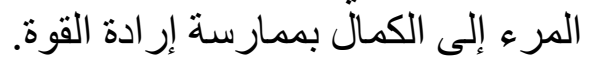

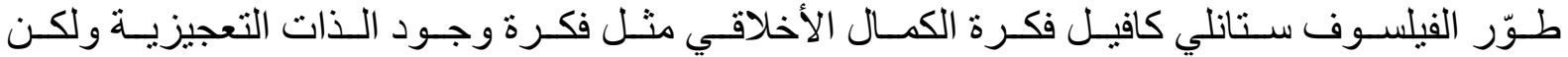

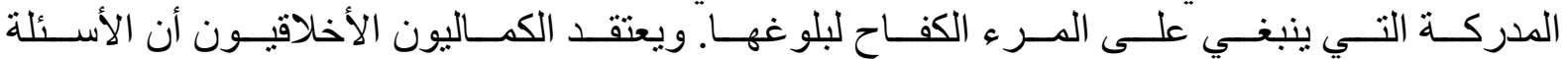

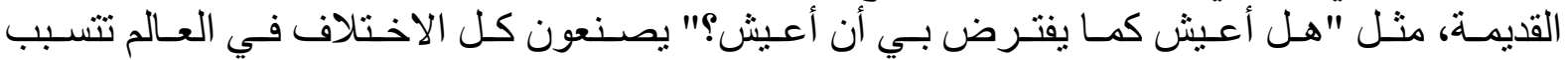

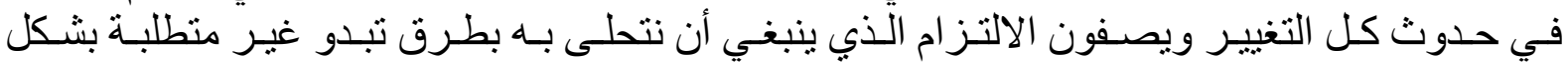

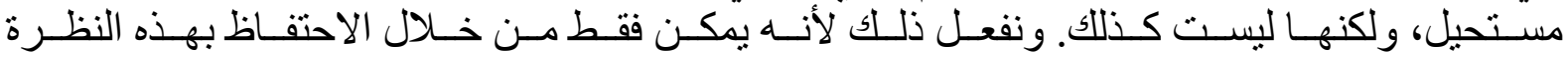

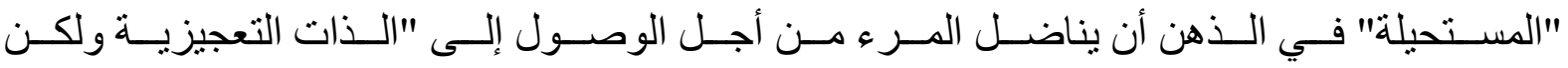

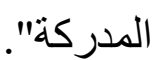

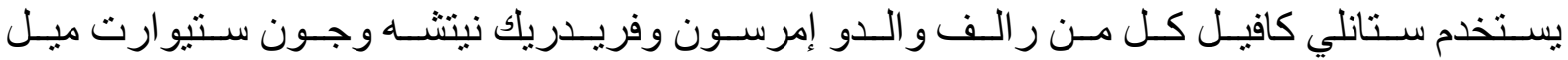

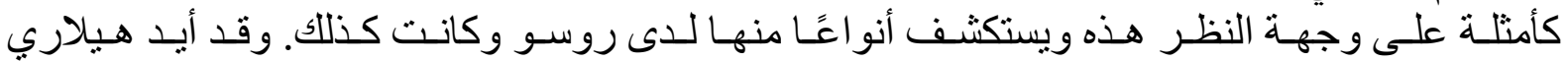

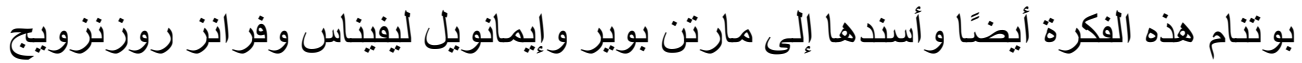

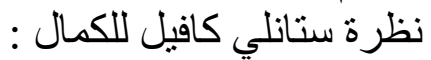

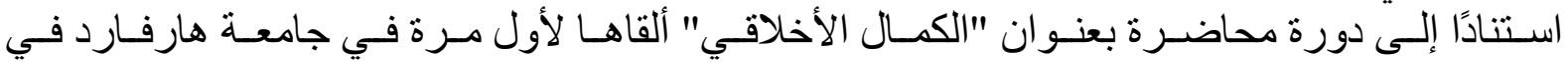

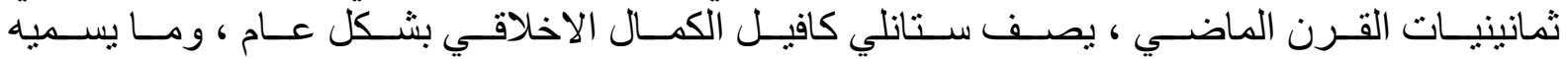

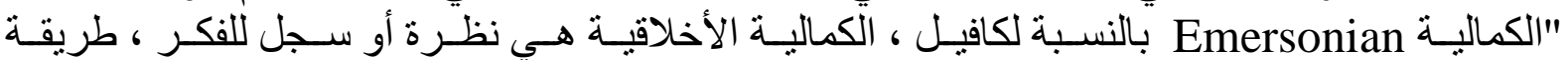

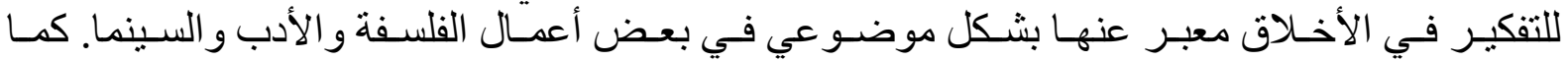

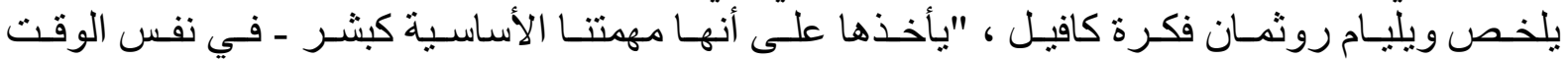

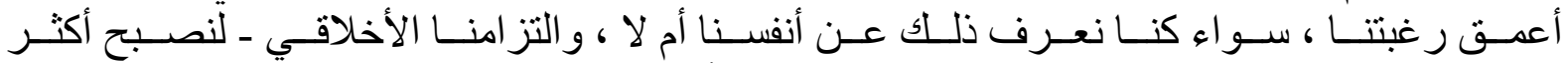

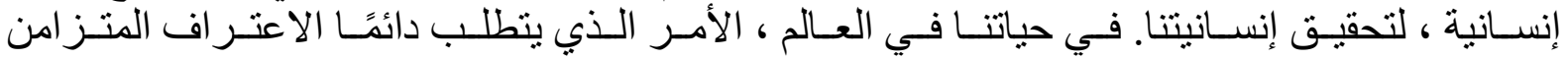
بإنسانية الآخرين (اعتر افنا بهم و إيمانهم بنا). مؤشر ات الوظيفة الأخلاقية للعمارة

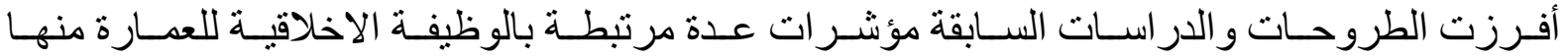

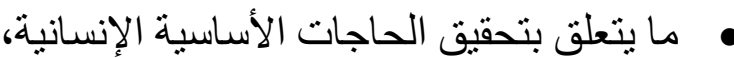

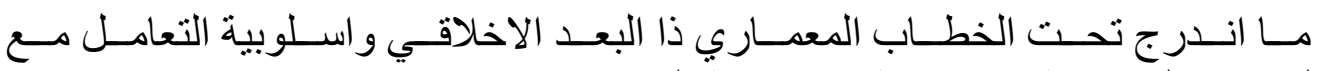

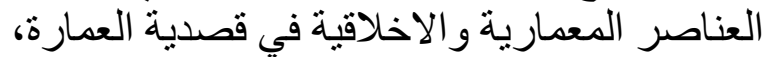

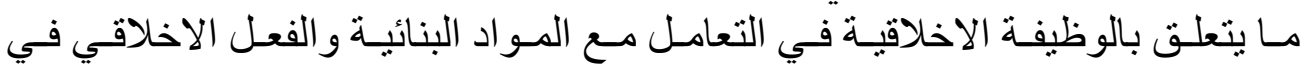

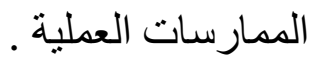

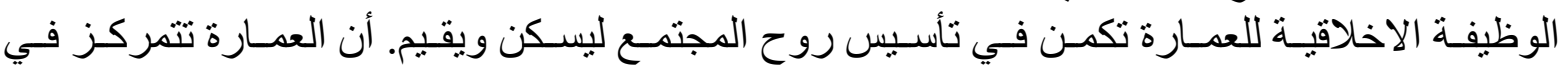

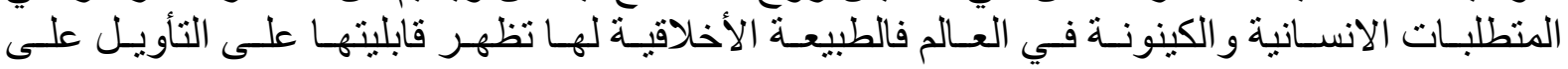

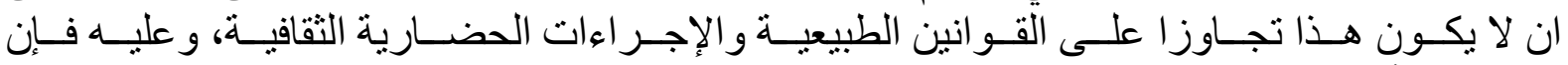

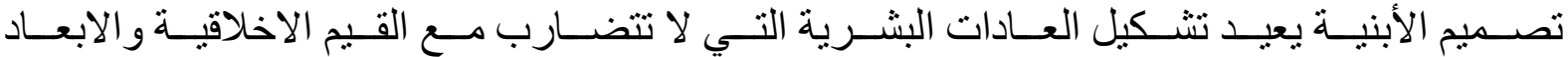
المكانية.

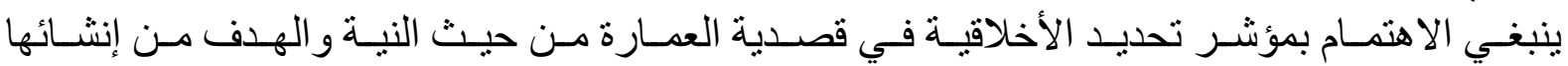

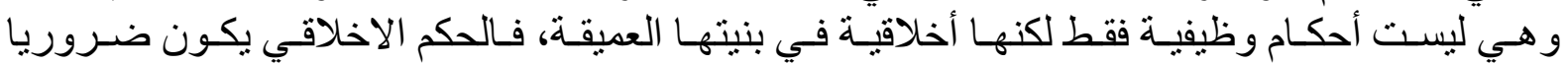




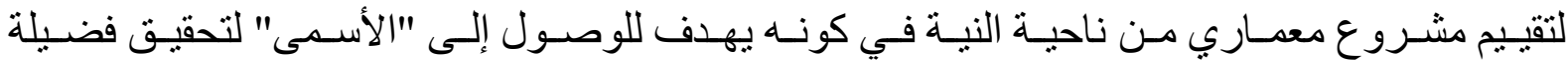

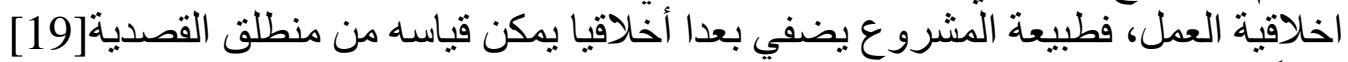

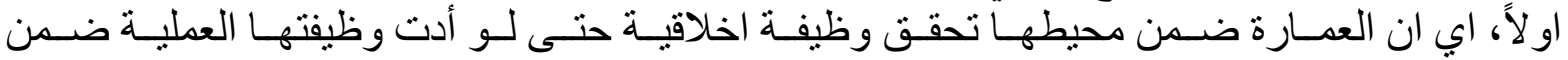

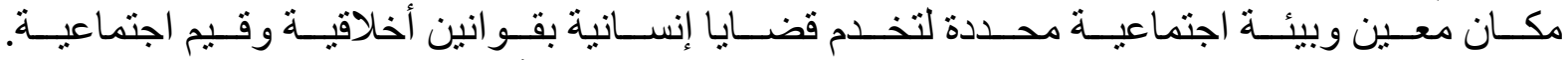

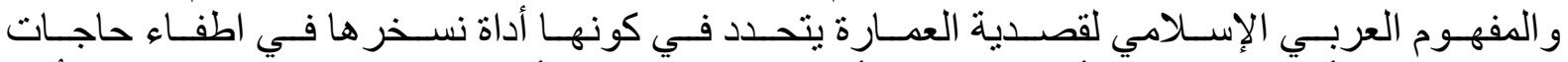

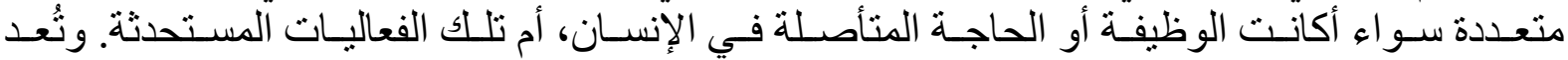

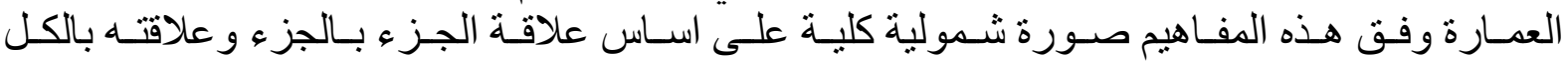
لتحقيق الوظيفة الاخلاقية للمبنى . [20]

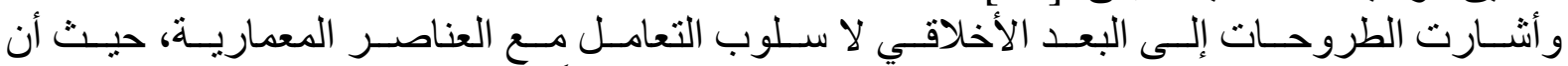

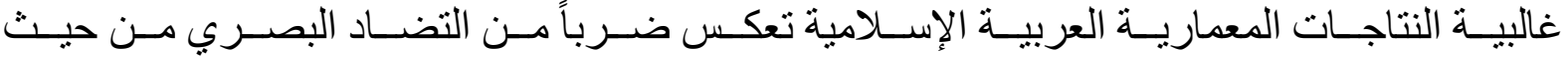

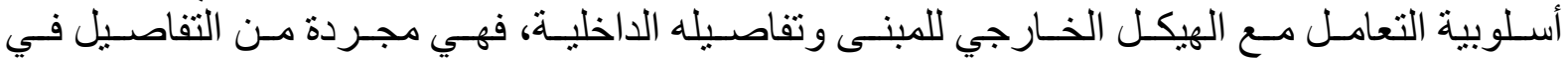

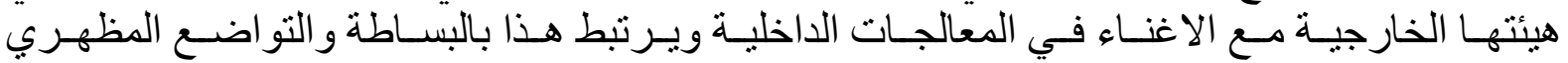

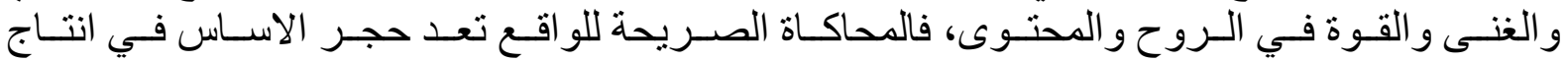

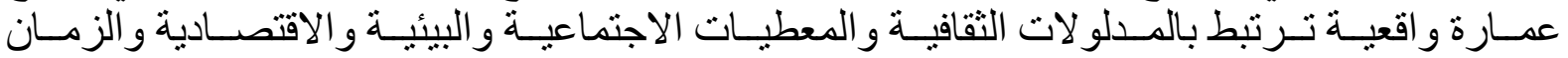

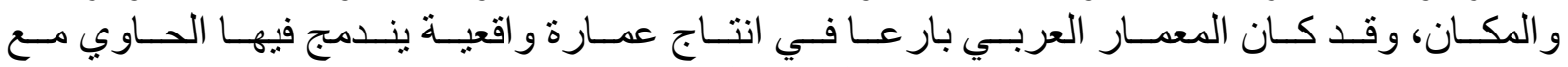

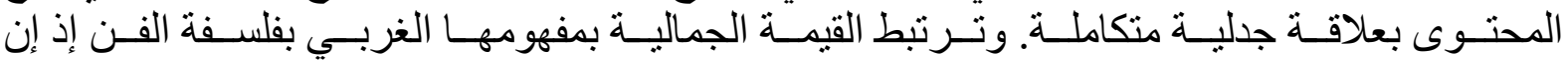
اضافة شكل جميل ذا بعد خيالي يتطابق مع معتقدات المجتمع ستكون خاصية جمالية بقوة [21]

النقد الأخلاقي في العمارة

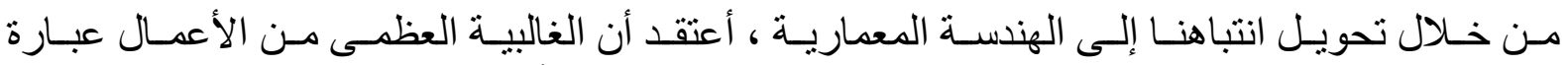

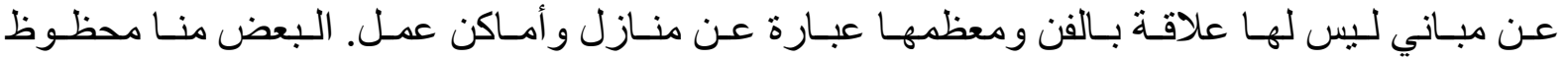

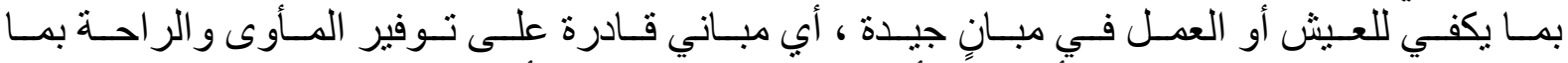

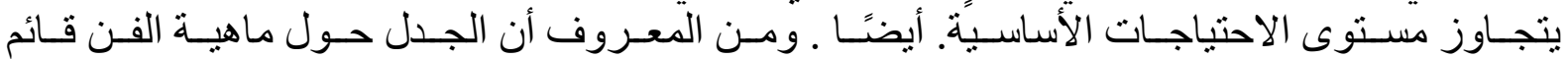

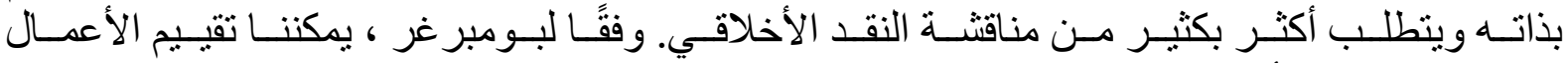
الفنية من الناحية الأخلاقية بطريقتين:

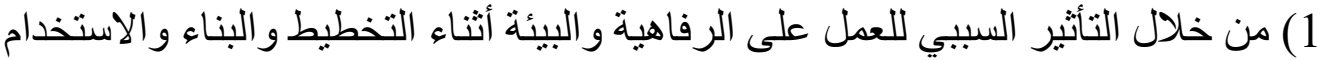
2) ومن خلال معناه الرمزي أو تأييد المو اقف الفي الأخلاقية.

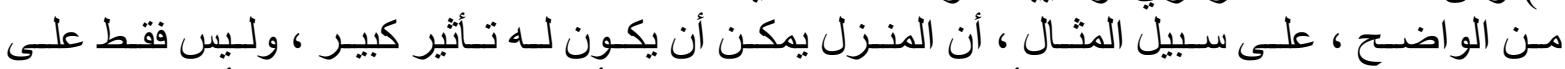

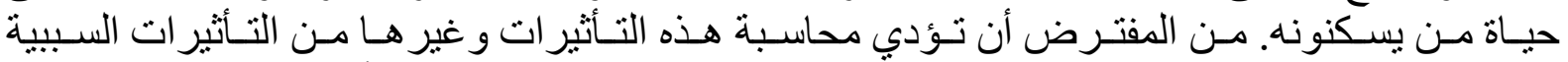

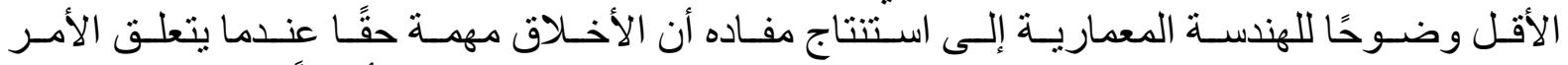

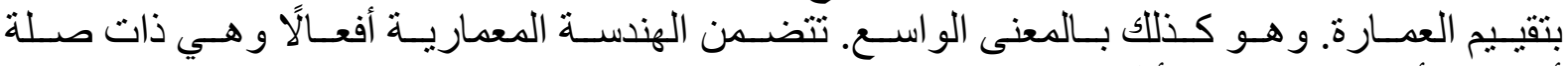

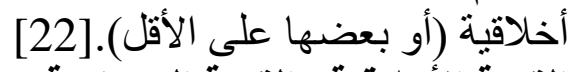

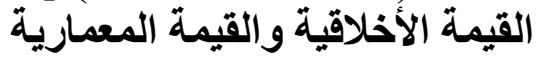

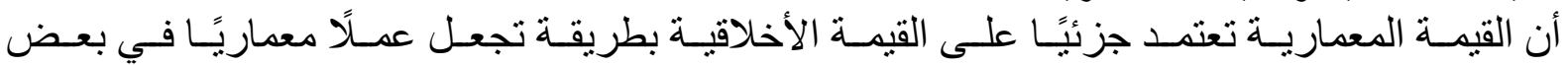

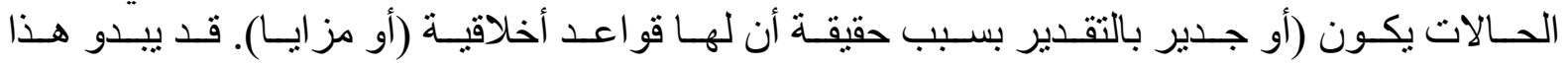

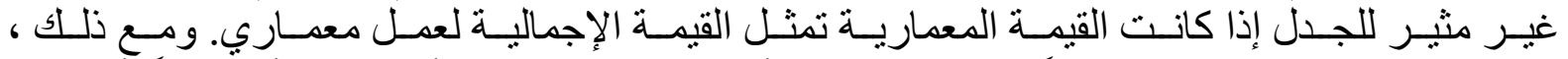

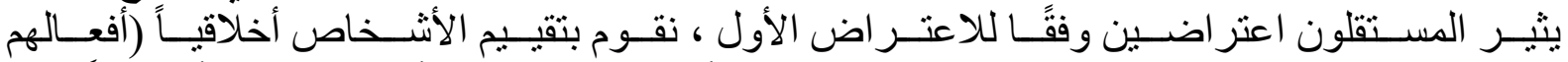

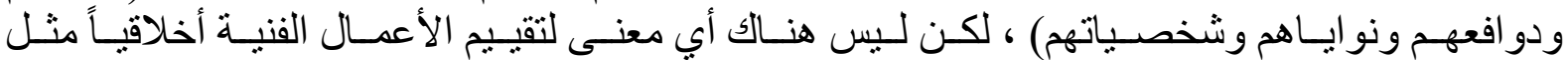

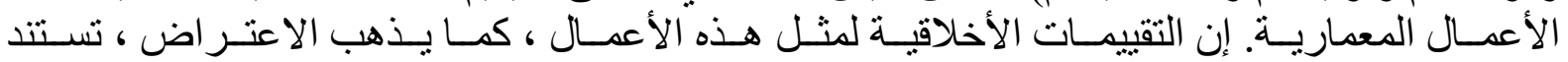

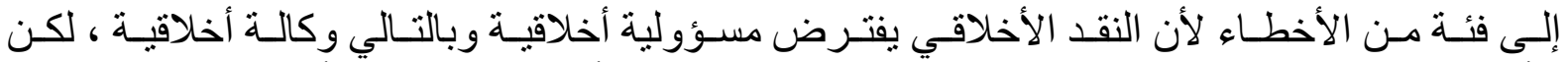

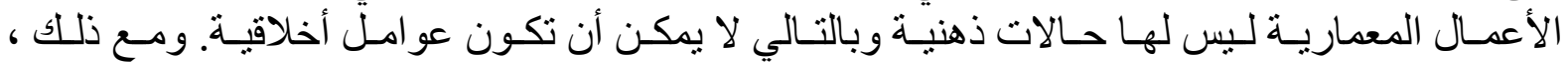

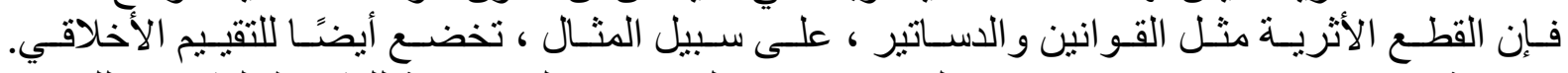

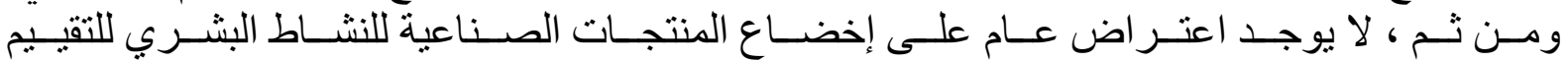

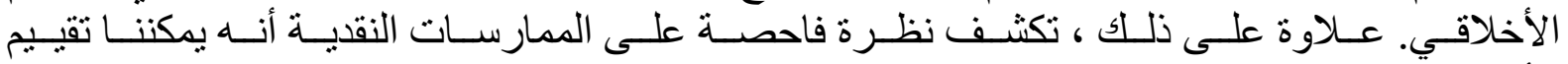

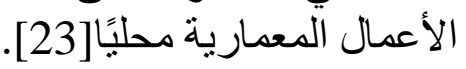




\section{يشمل التقييم الاخلافي مايلي :-}

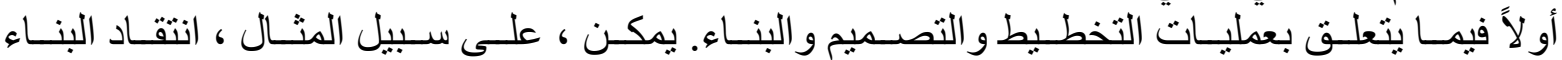

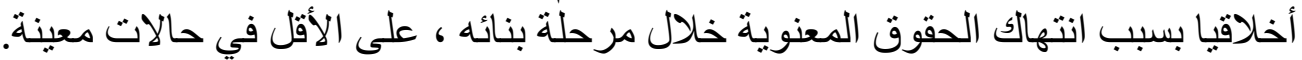

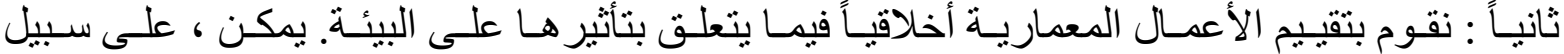

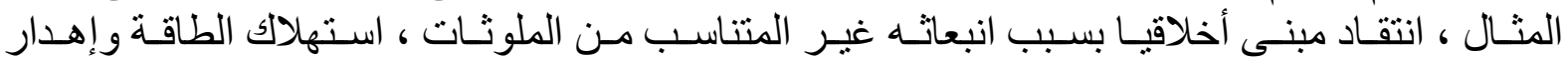

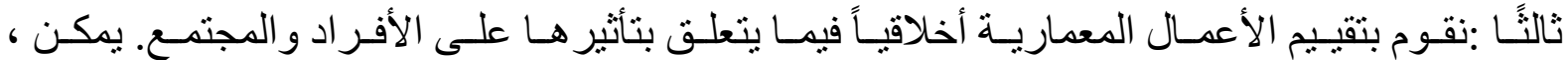

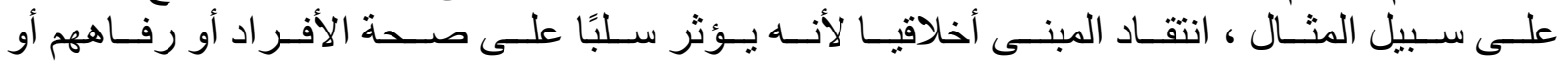
سلوكهم ، وبسبب التثويش الاجتماعي السلبي.

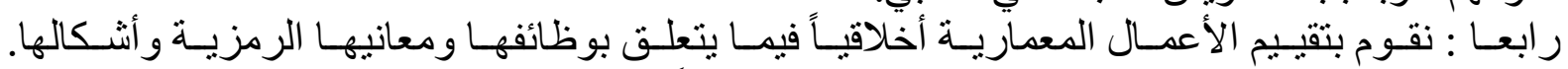

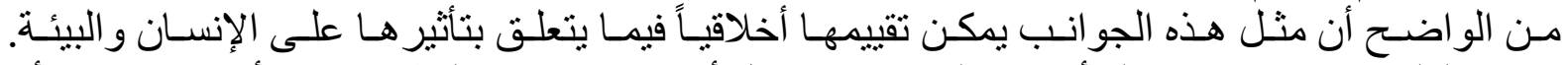

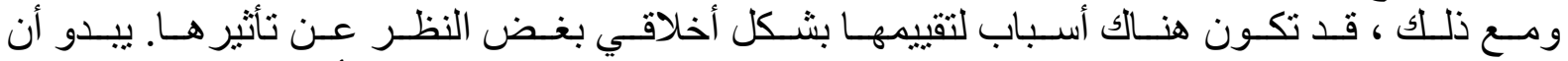

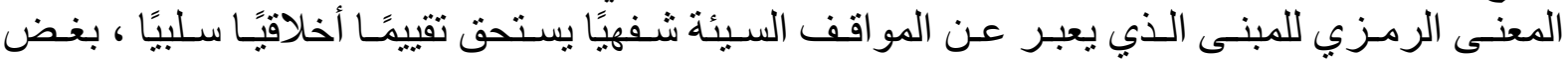

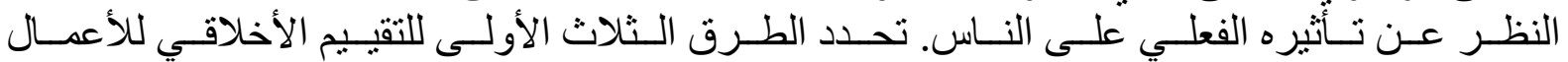

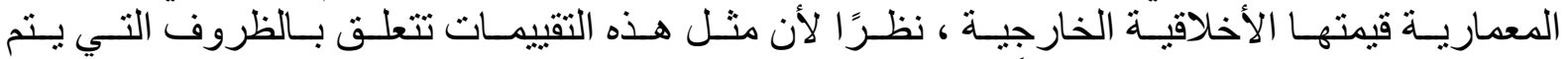

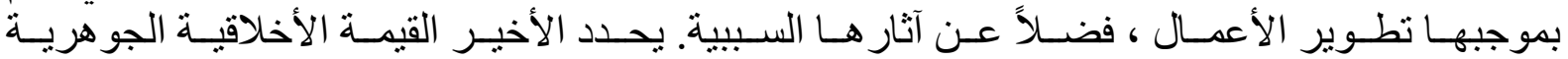

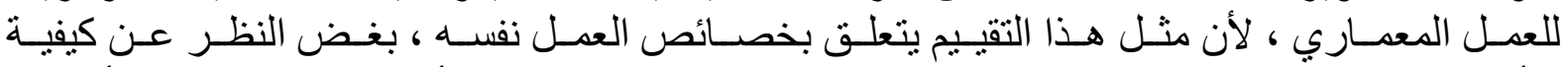

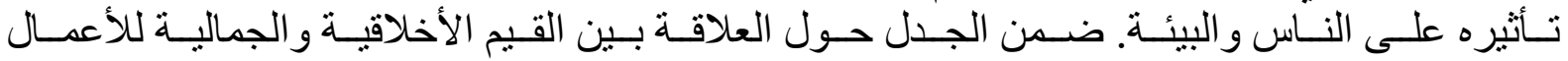

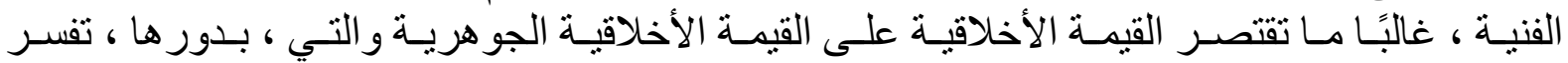

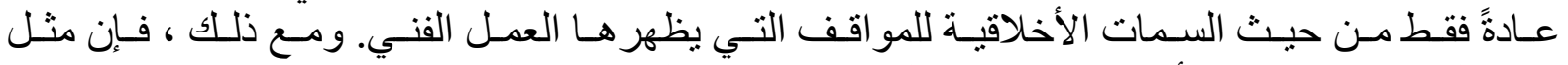

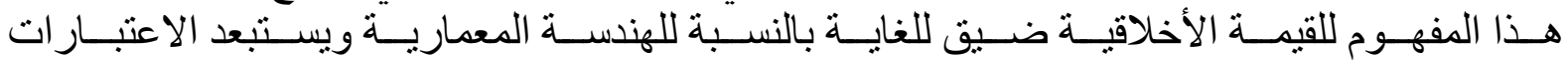

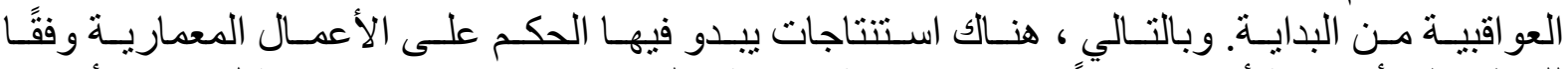

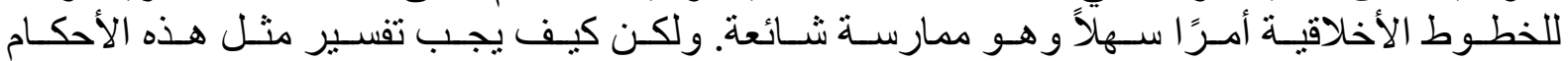

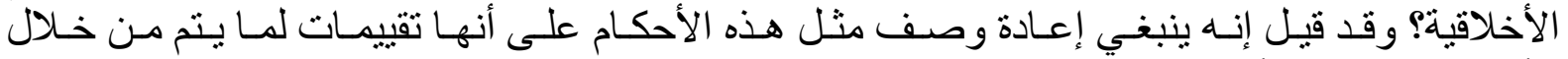

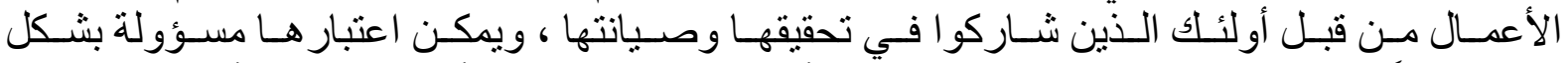

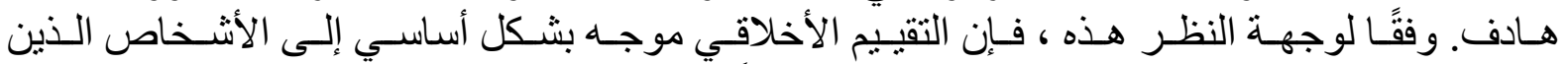

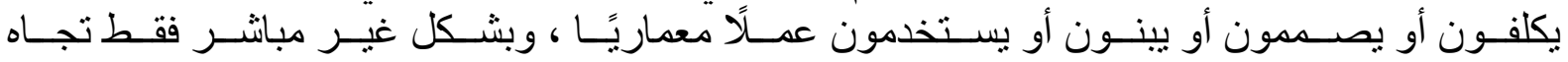

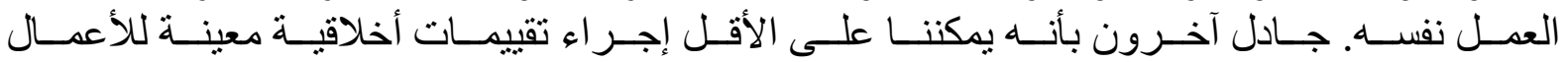

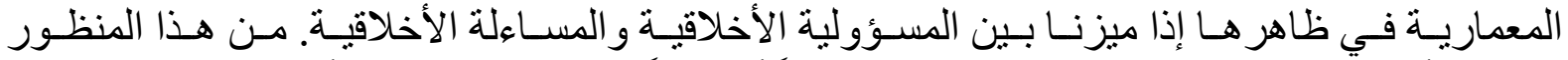

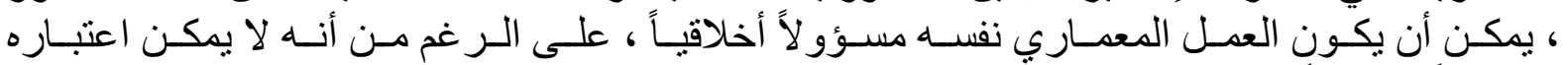

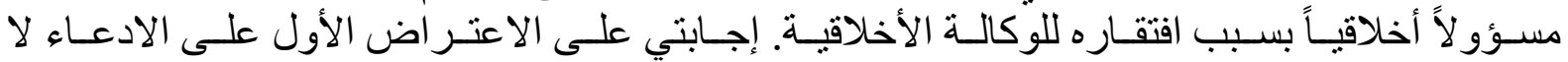
يتطلب أي قرار بشأن الاستر اتيجية الواعدة أكثر [24].

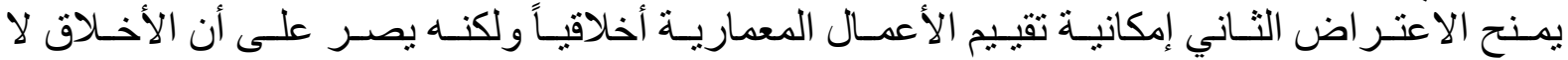

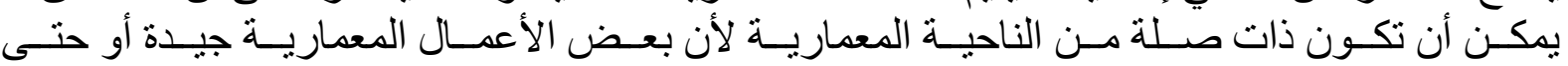

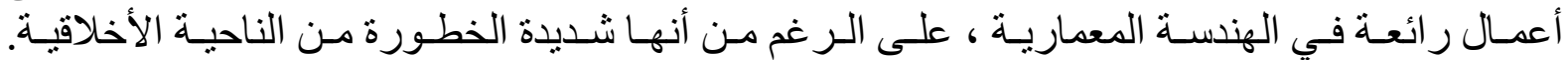

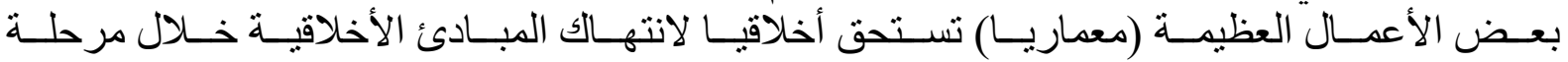

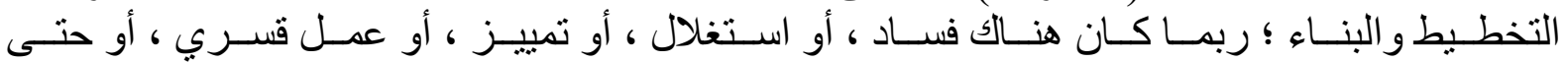

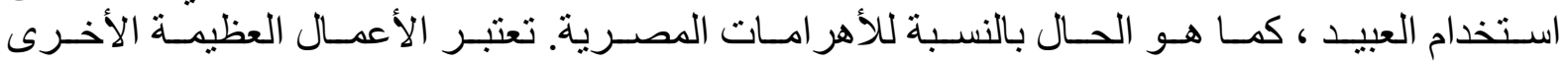

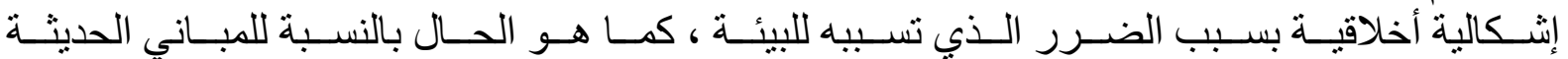

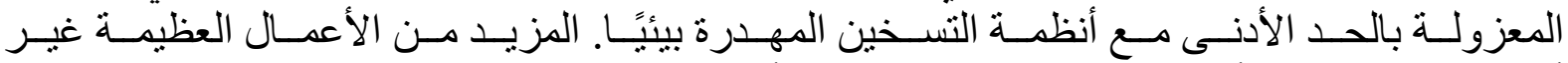

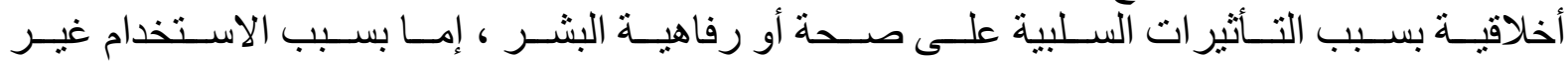

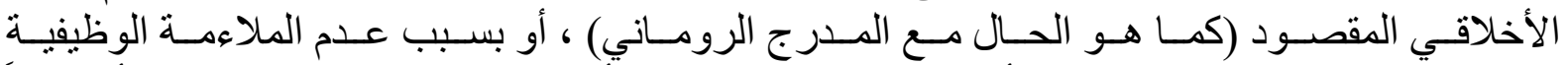

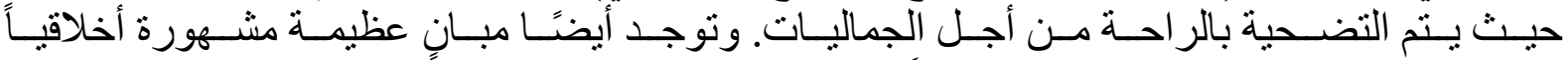

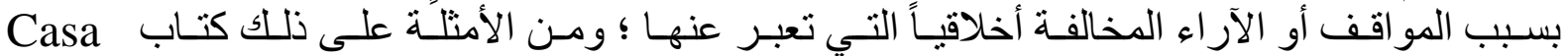
del Fascio 


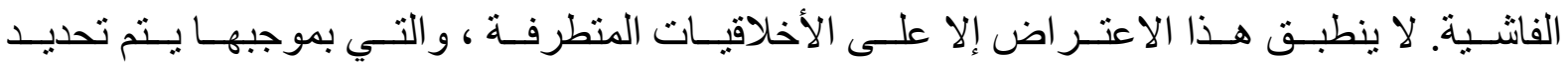

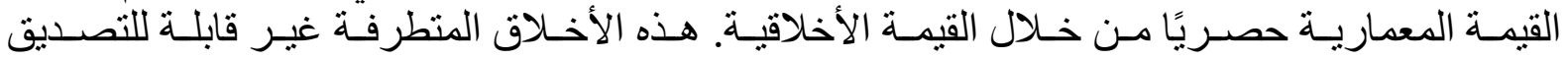

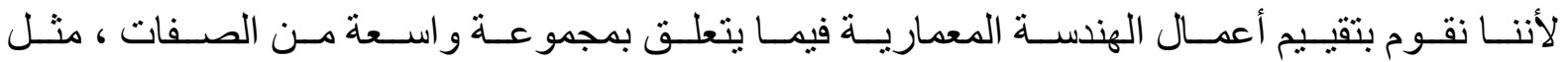

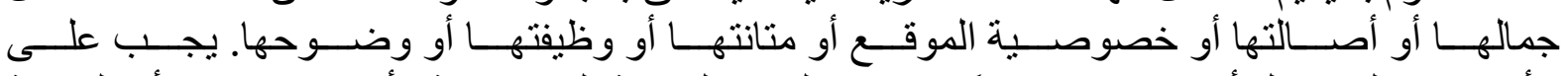

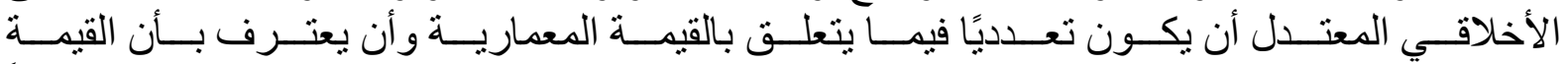

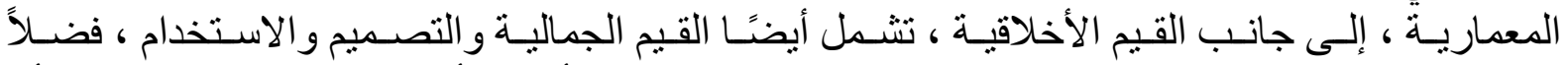

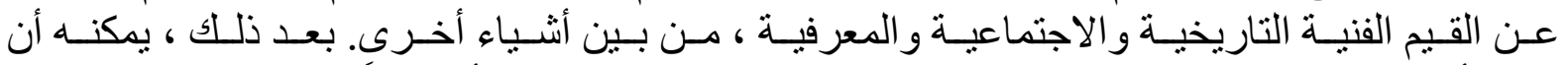

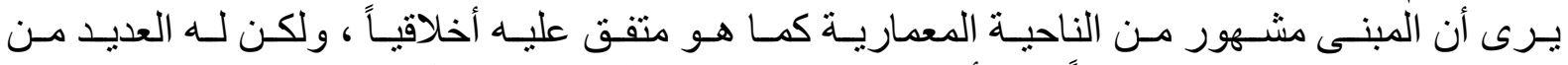

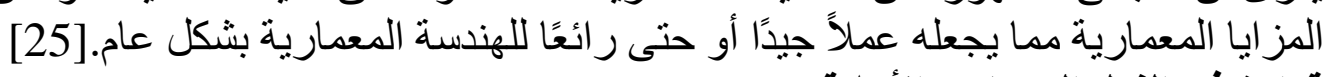
قراعة في الفعل المعماري الأخلاقي

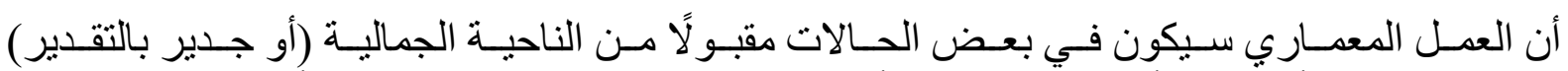

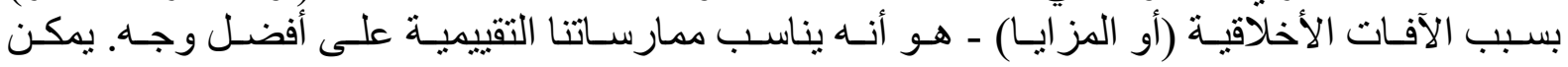

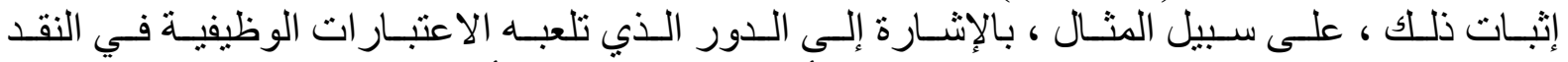

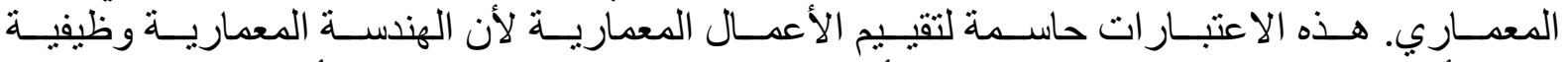

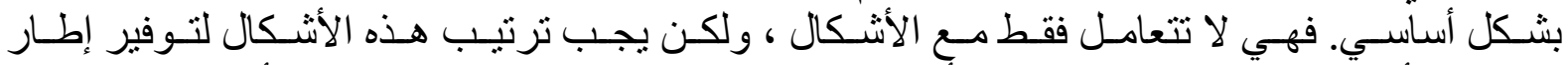

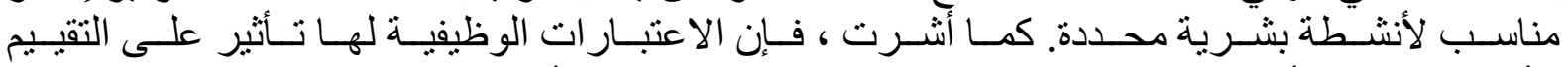

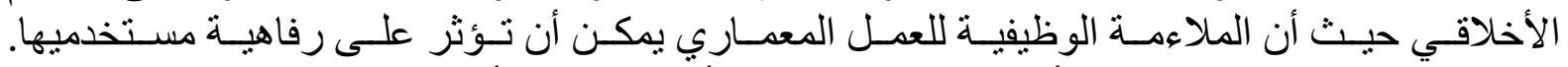

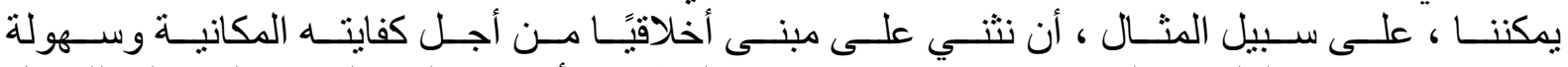

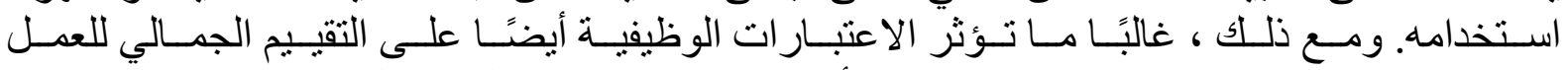

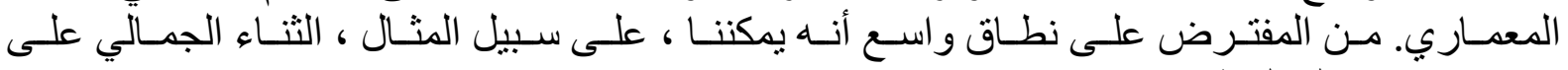

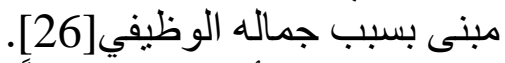

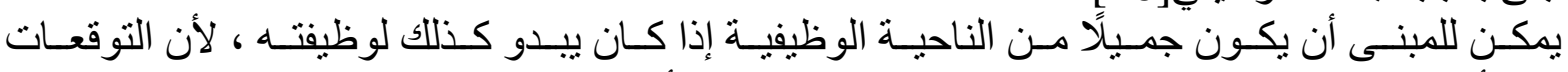

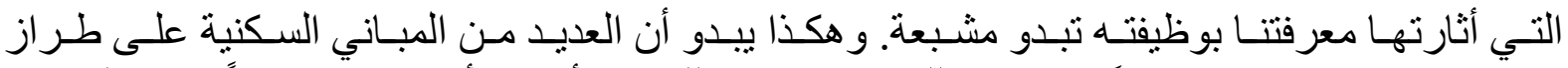
Art Nouveau

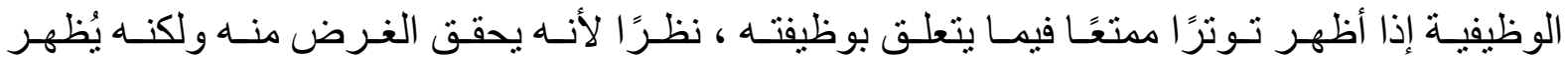

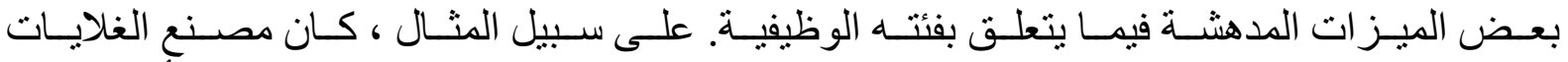

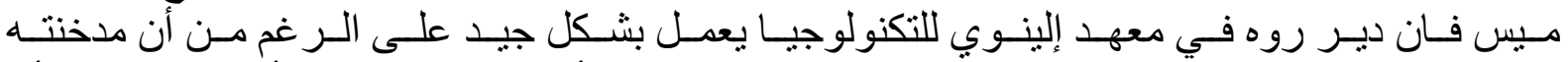

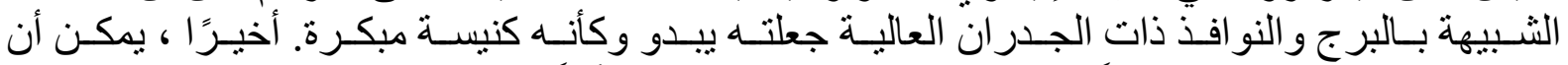

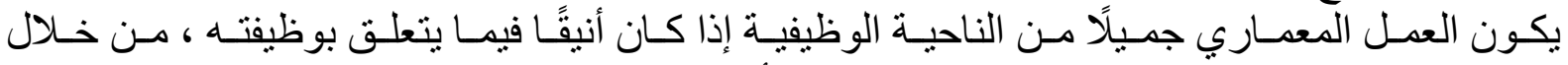

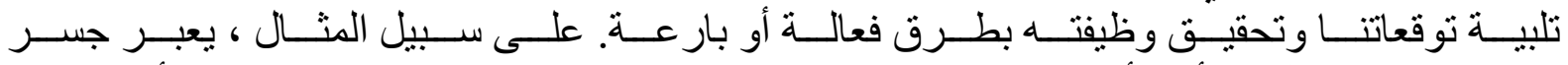
Salginatobel

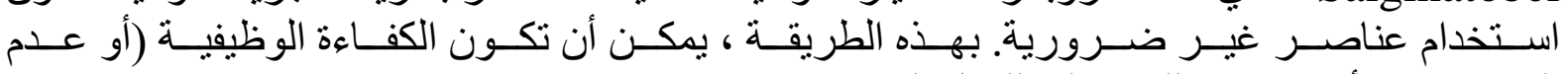

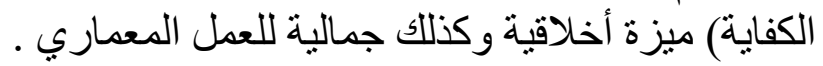

العدارة الأخلاقية

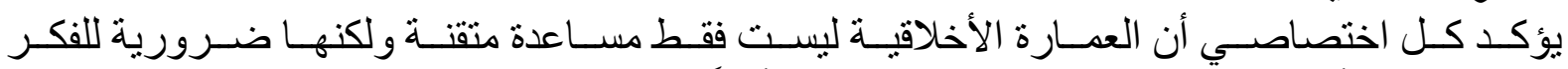

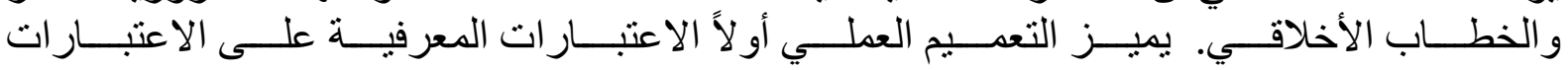

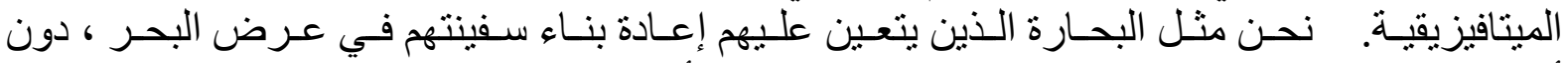

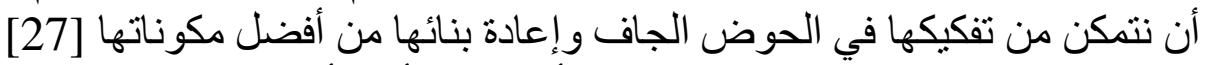

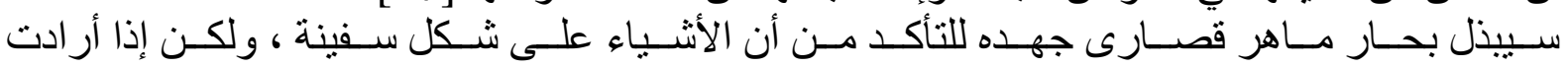

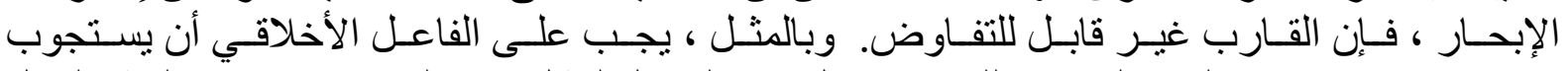

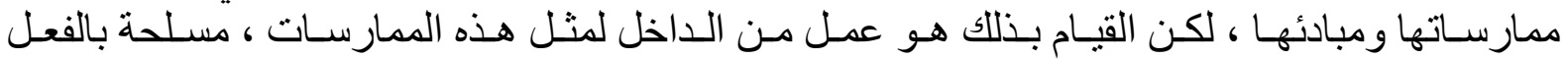

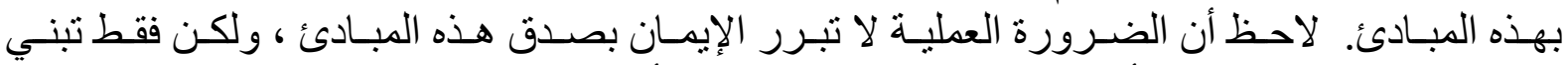

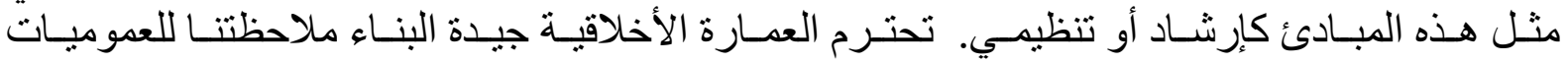




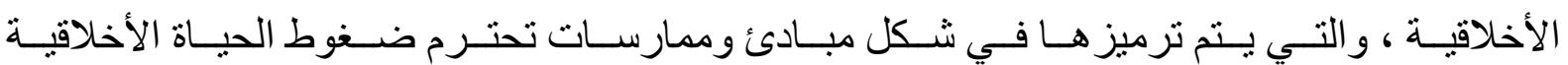

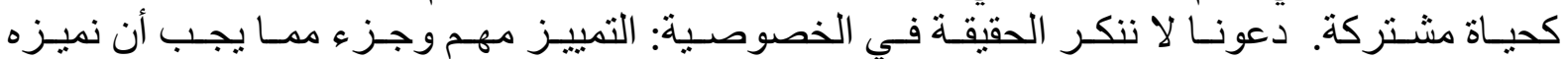

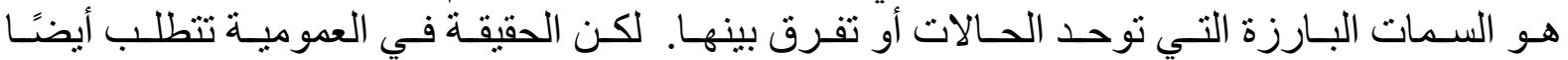

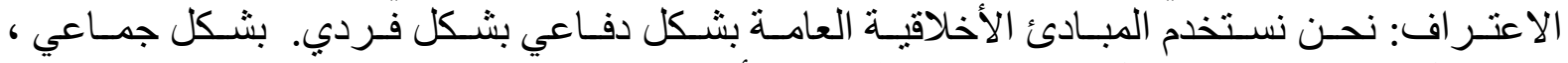

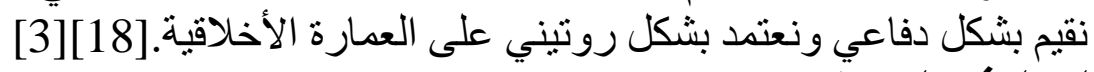
الكمال في العمارة

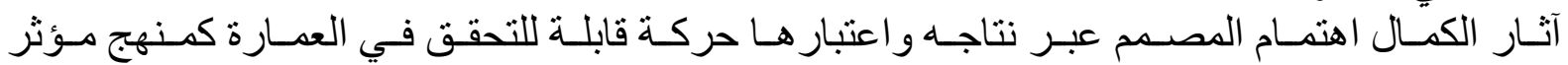

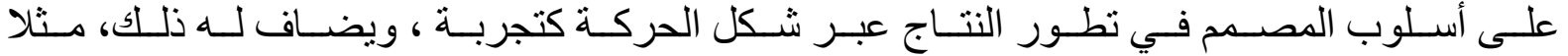

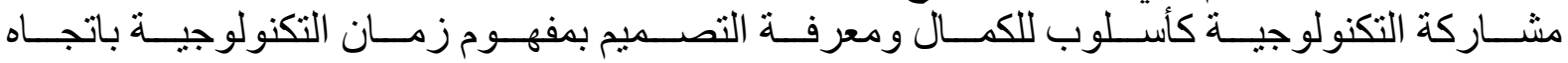

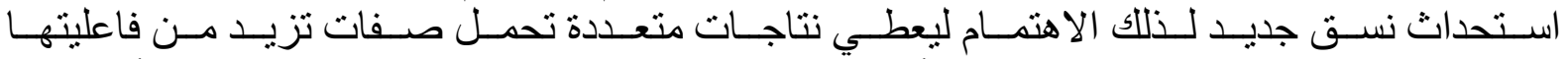

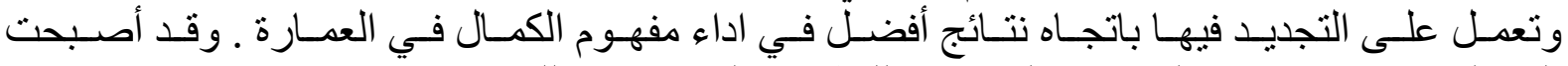

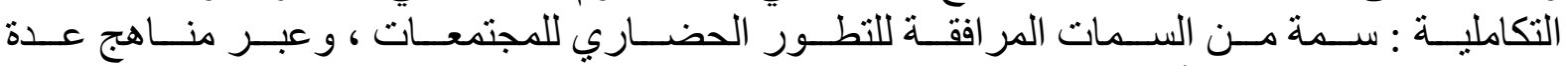

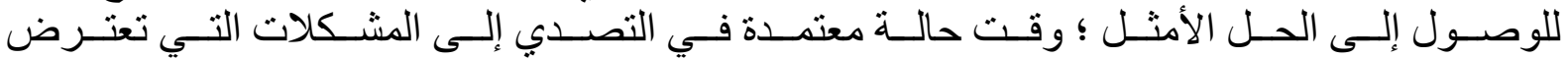

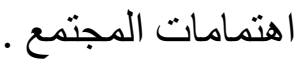

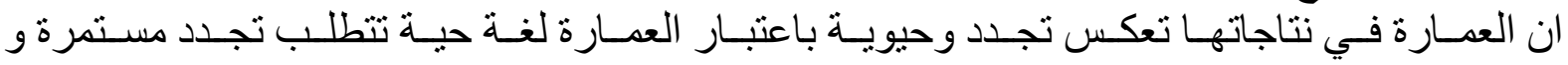

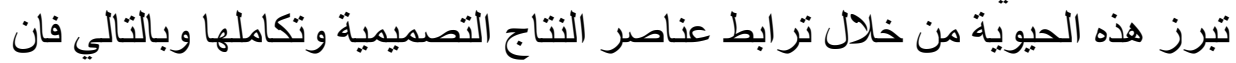

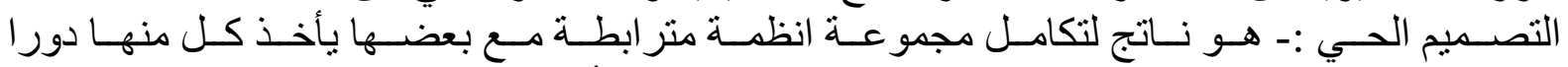

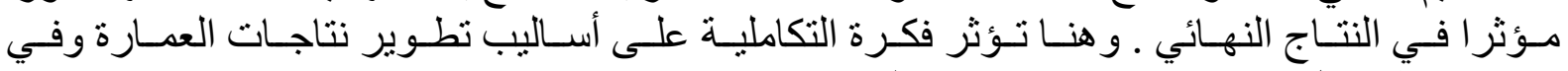

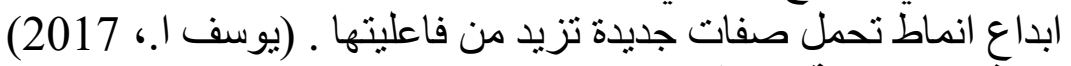

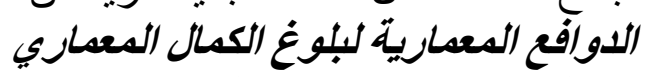

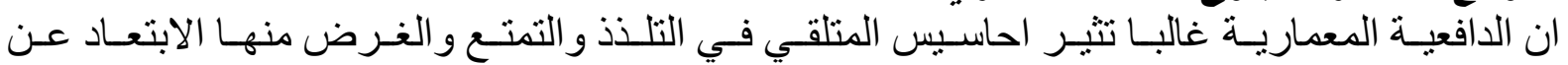

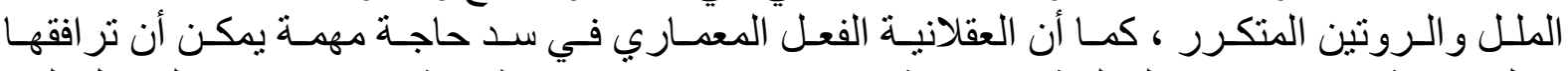

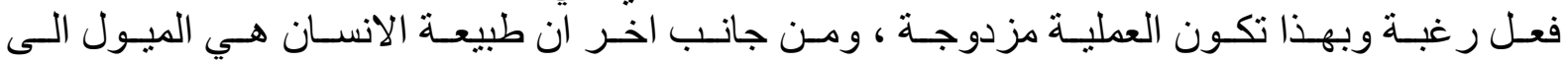

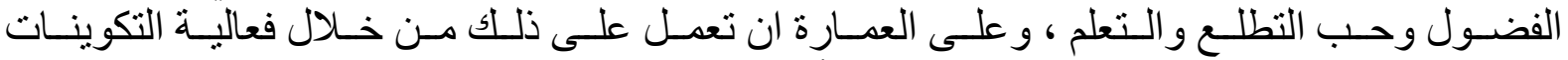

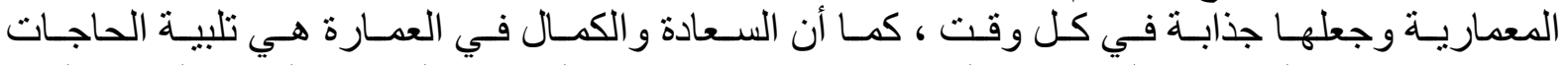

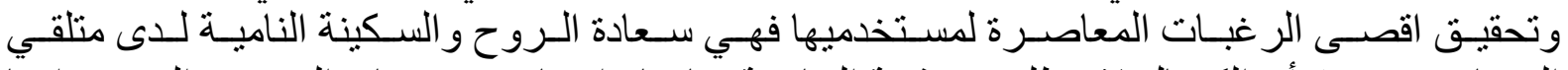

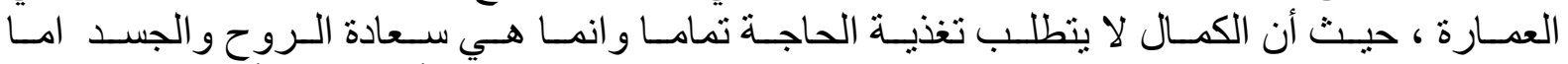

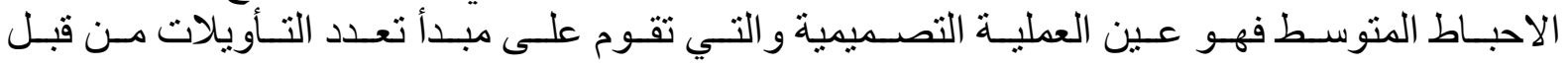

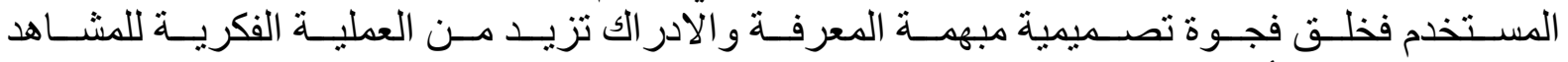

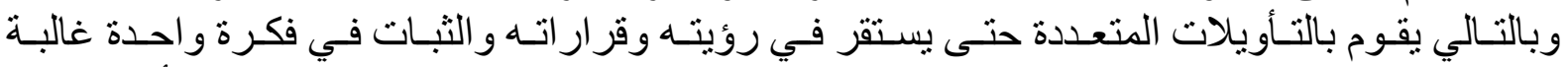

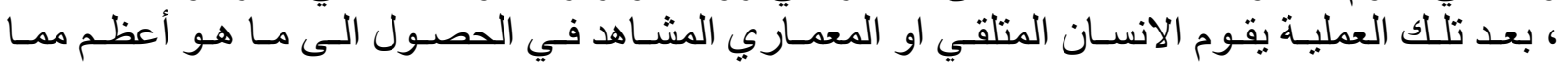

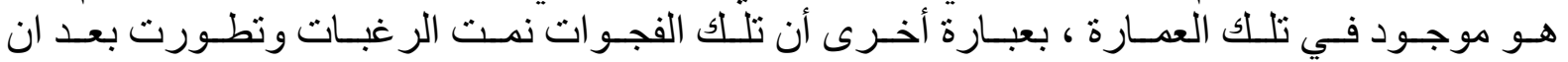

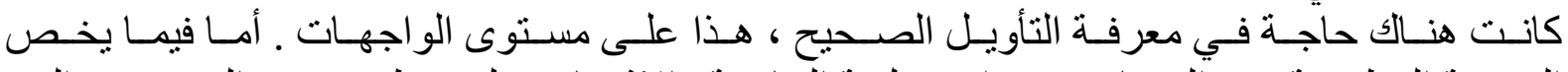

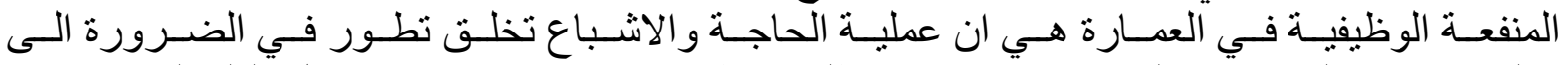

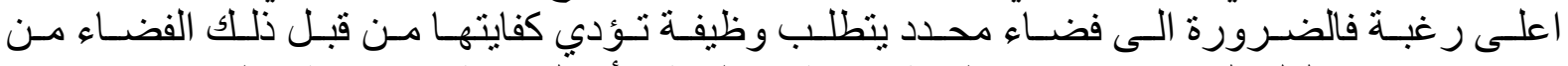

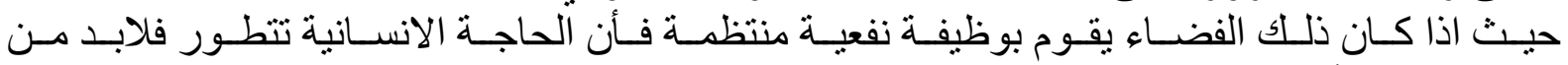

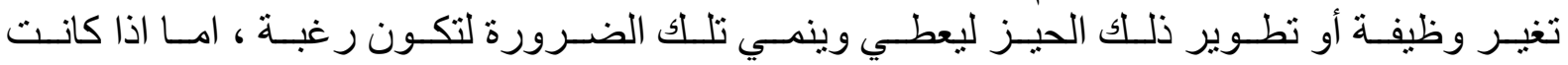

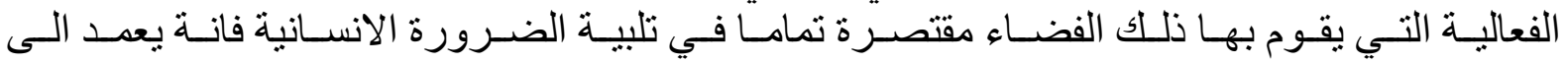

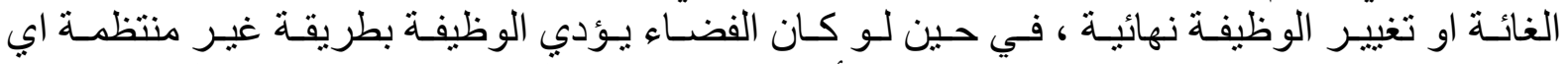

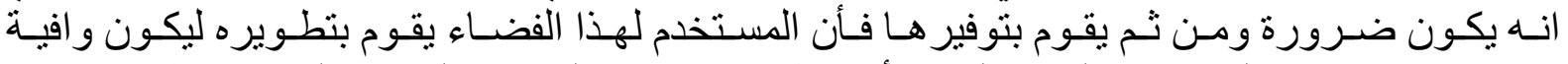

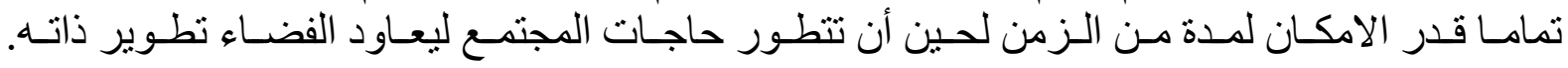
(رشيد، 2021) تعتمد فكرة الكمال المعماري على :-

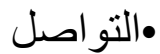
•تجربة التطوير 


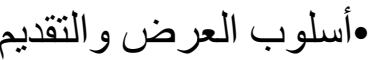
•الاسلوب الجديد للابنامكية

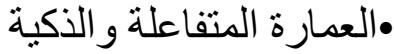

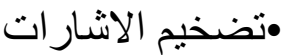

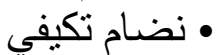

\section{اطراف الكمال المعداري: موضح بالثكل رقم 1}

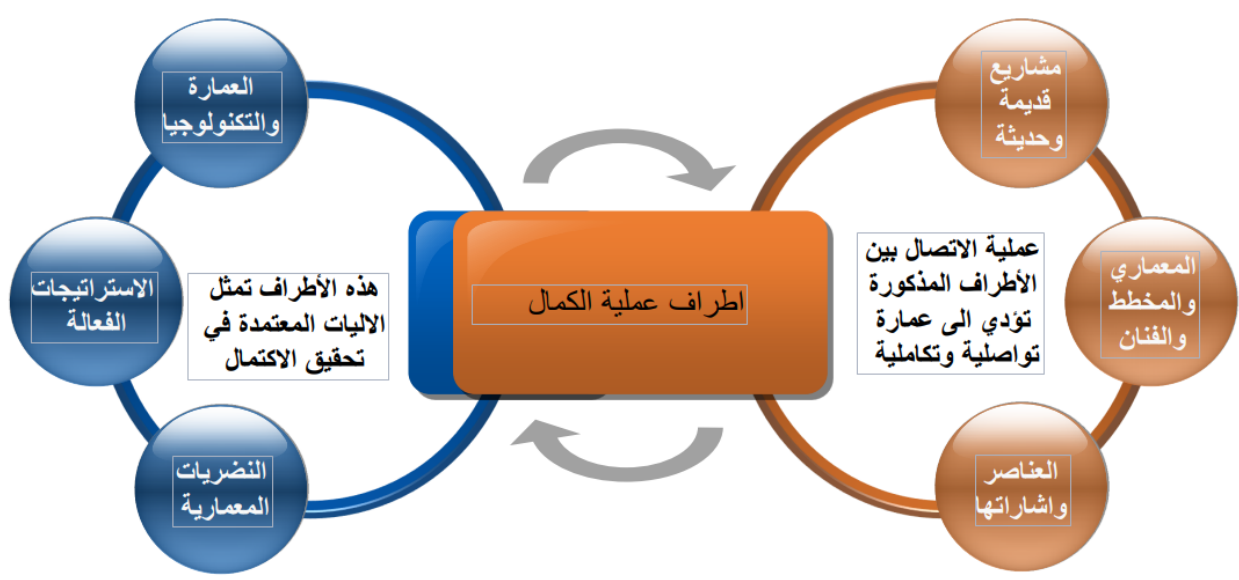

تخلق هذه الأطر اف حالتين للوجود و التكامل هما القوة و الفعل

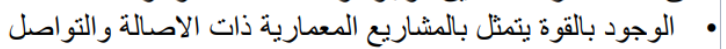

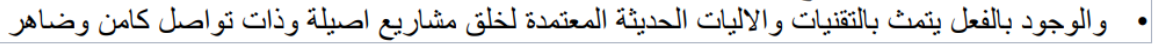

شكل ـ1. اطر اف عملية التكامل المعماري

اليات الكمال المعداري

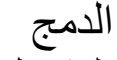

التشكيل

اللغة المشتركة التماثل الثكلي التماثلل مع الخصائص المفترضة التئة التجريد محاكاة النظام معايير الكمال المعماري كما موضح في الثكل 2.

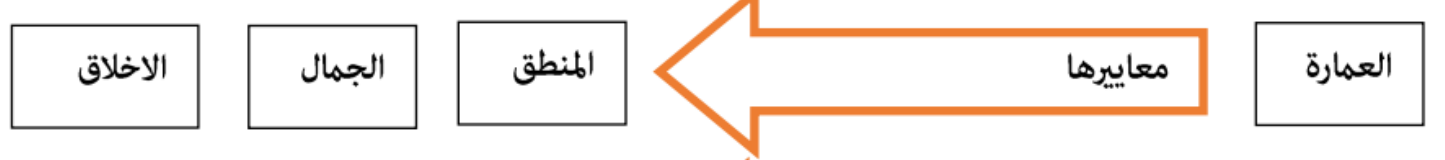

شكل .2. معايير العمارة

مستويات الكمال المعماري

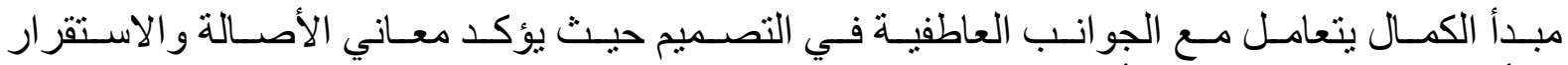

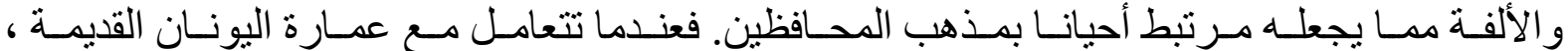

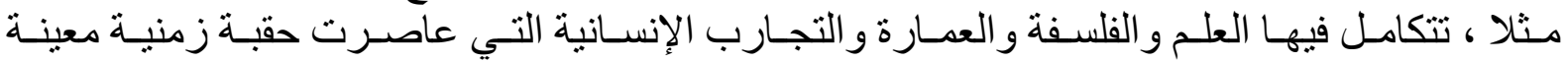




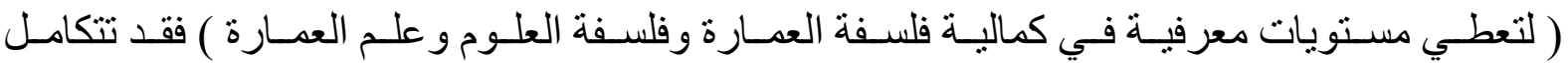

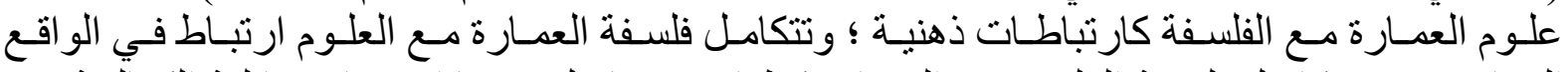

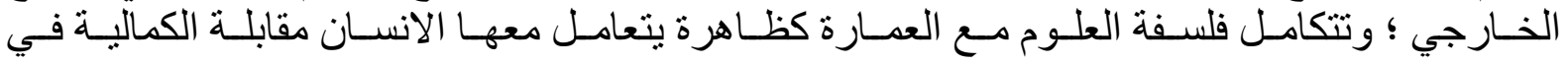

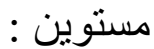
مستوى من تكاملية النتاج في الفلسفة التي يتحرك بها الإنسان من الخارج إلى الداخل. مستوى اخر في الاضمحلال من الداخل إلى الخارج .

\section{النتاج المعماري بين الضرورة والكمال}

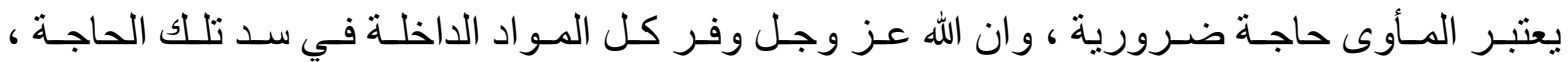

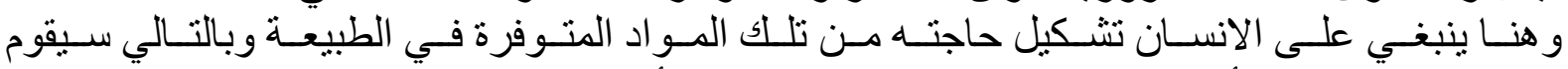

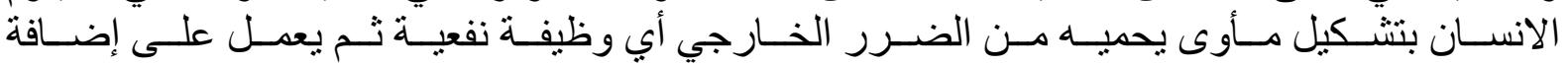

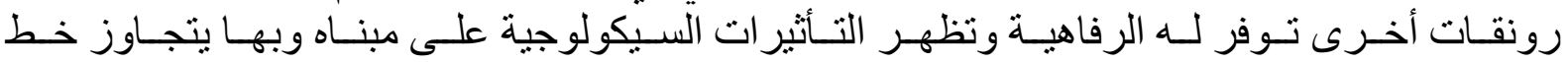

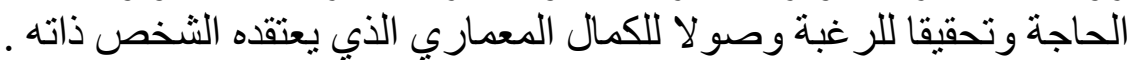

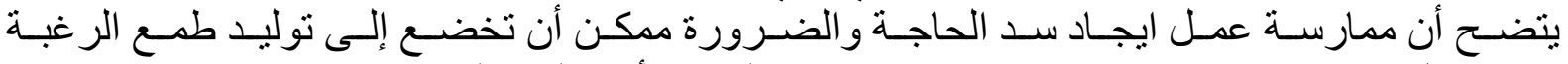

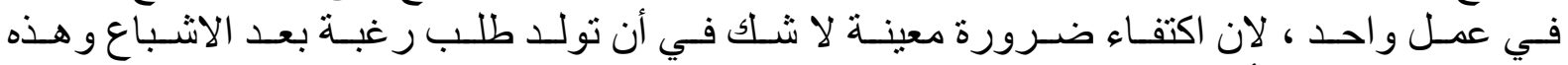

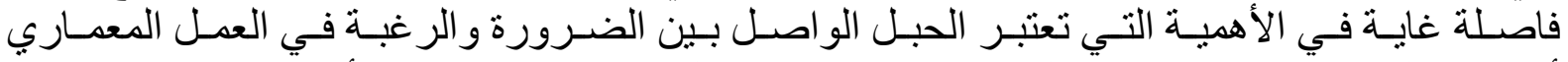

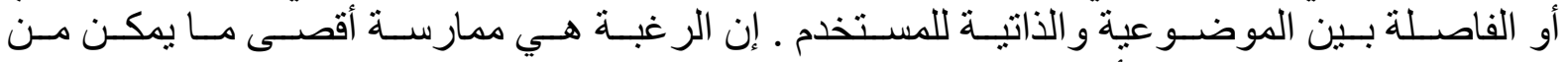

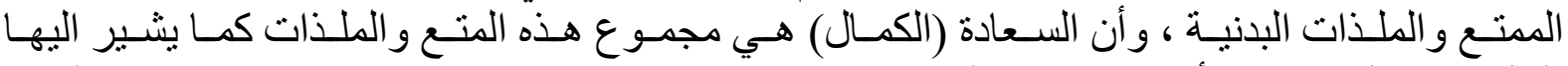

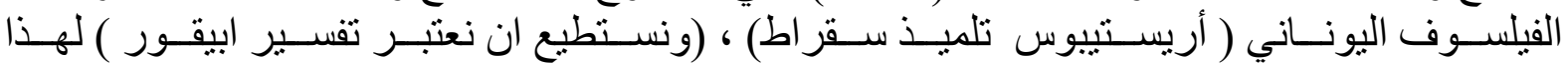

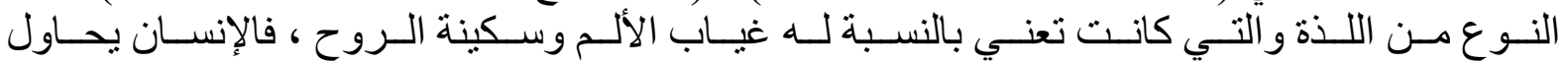

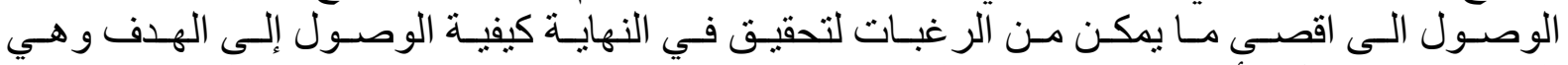

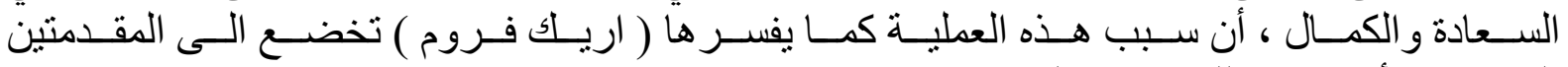

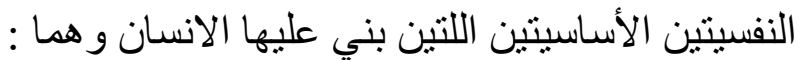

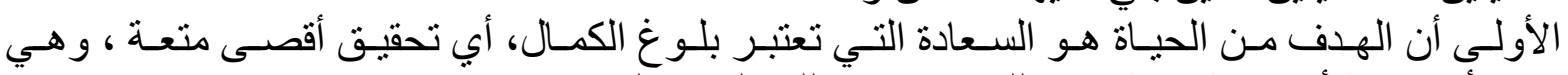

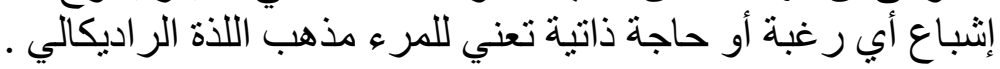

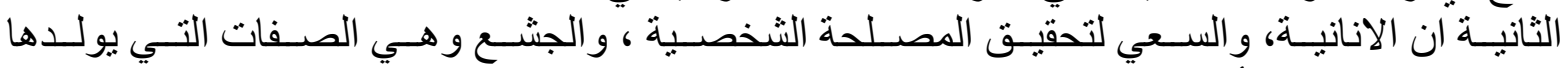

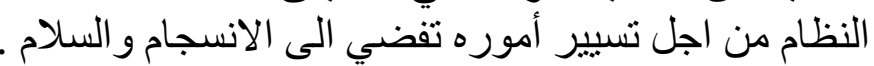

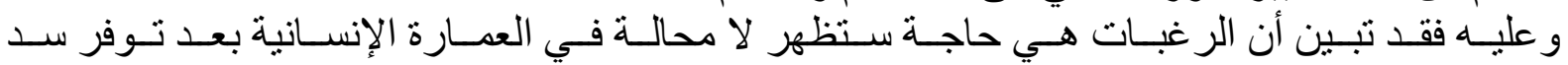

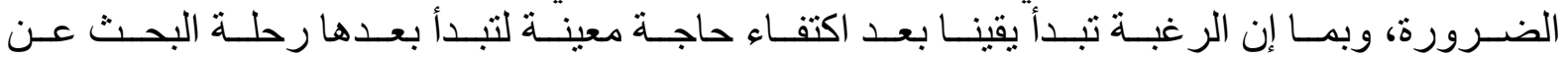

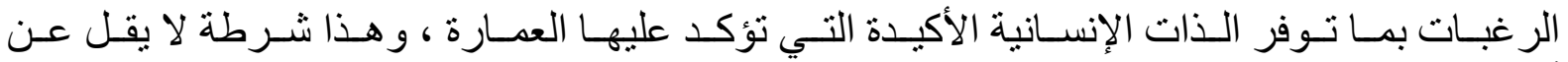

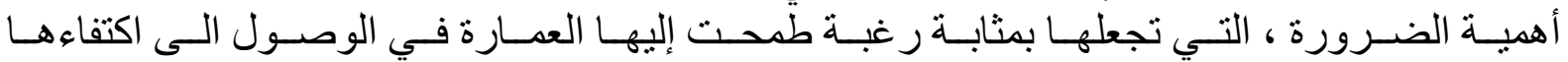

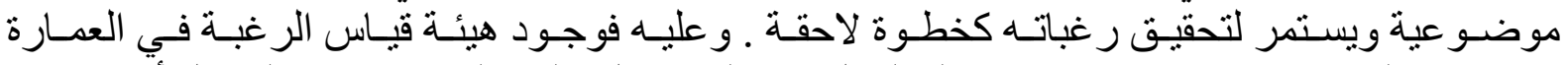

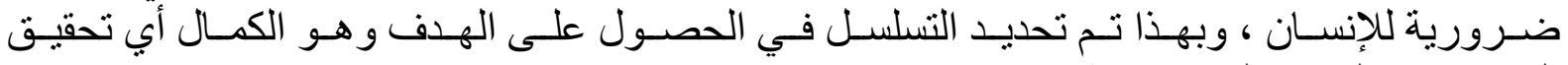

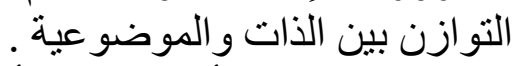

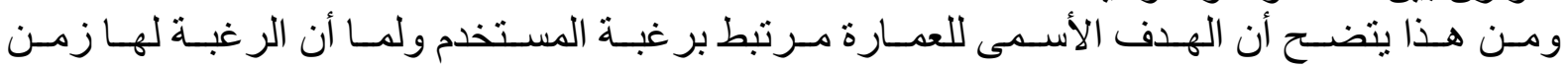

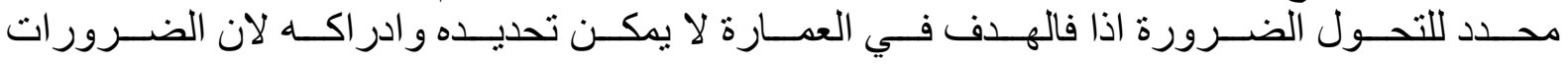

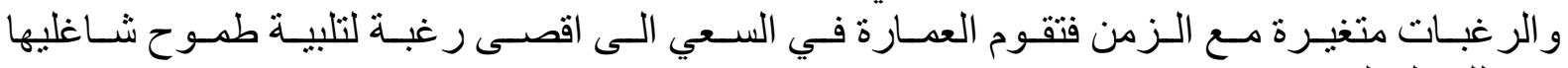

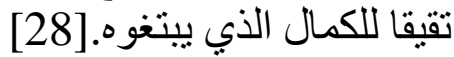




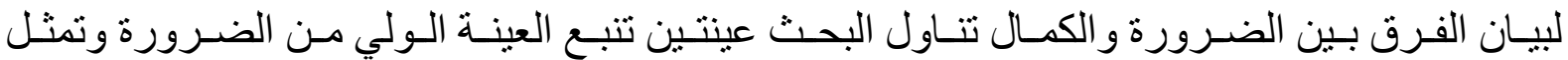

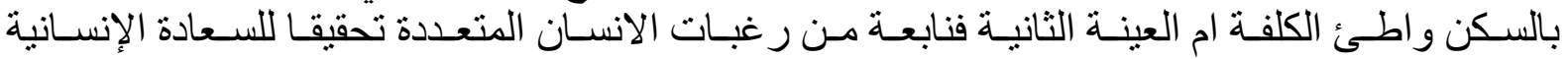

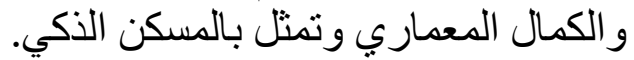

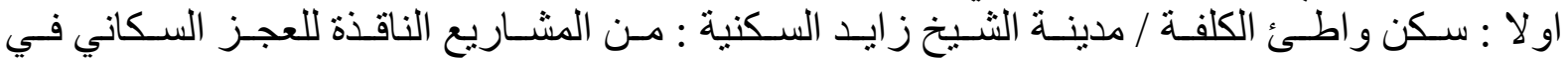

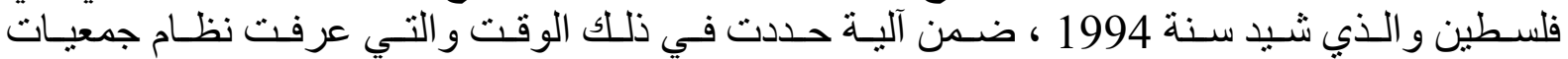

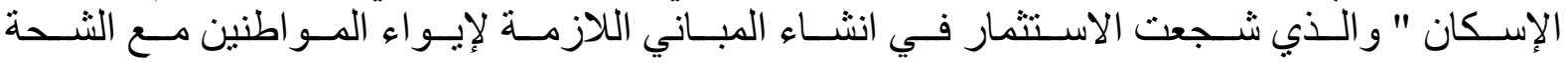

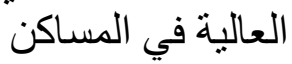

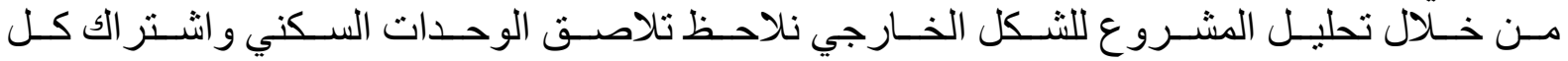

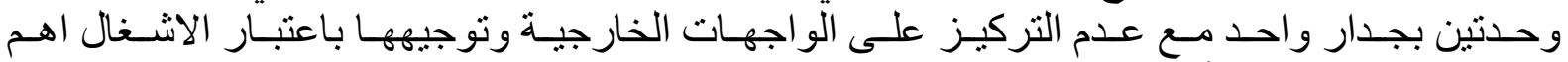

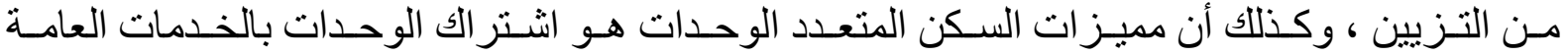

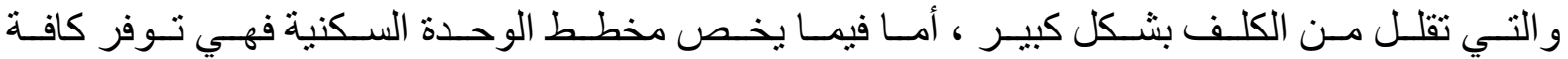

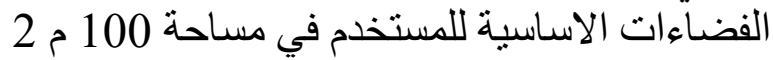

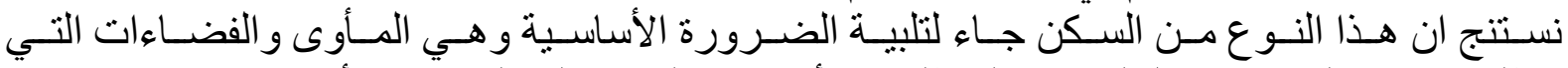

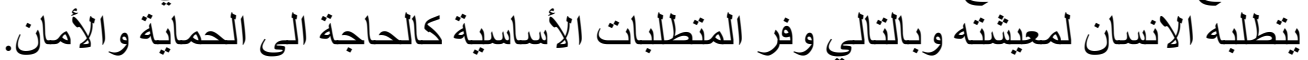

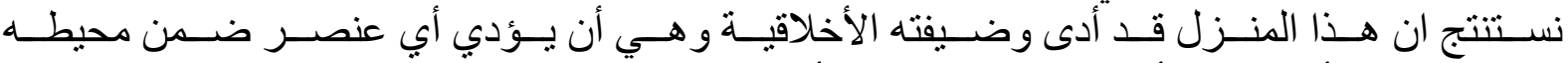

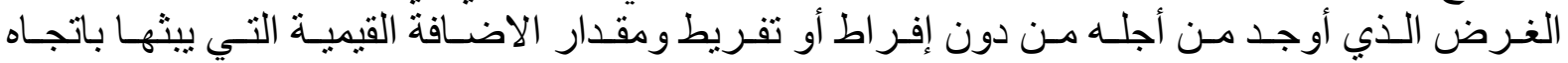

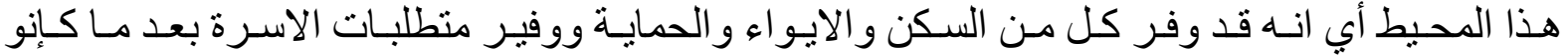
يعانون من التشرد.

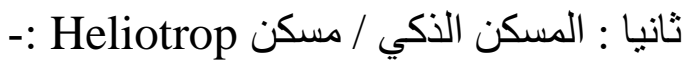

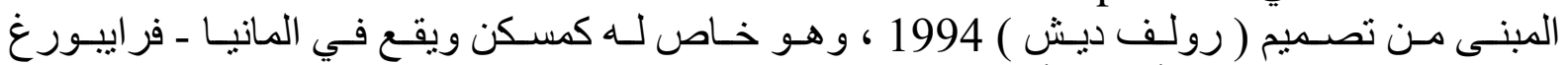

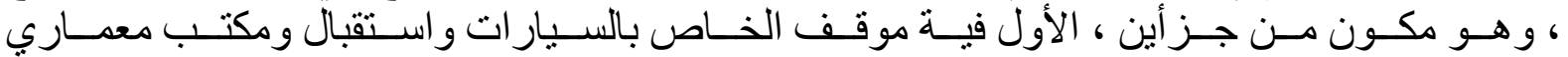

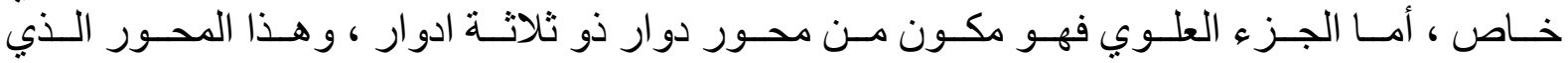

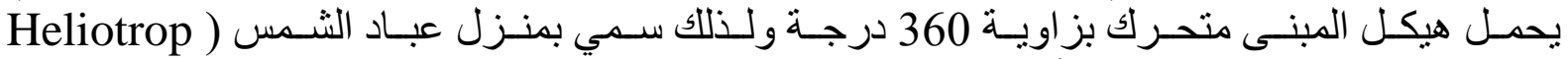

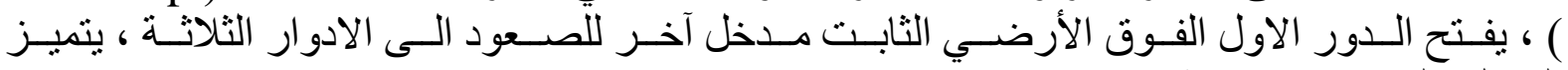

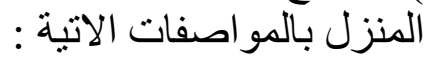

ـ ـاتية التحكم : توفر نظام ادارة

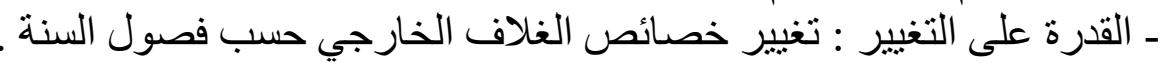
ـ التحكم عن بعد في انظمة المبنى وتجنهيز اتهانه .

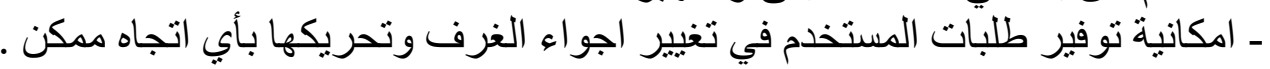

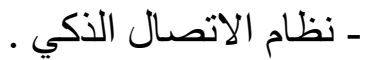
- بيئي ، فهو يتحكم بالّنظام الذاتي للطاقة الثمسية ، و اكساب الطقة الثمسية .

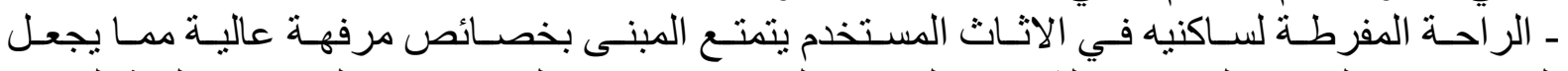

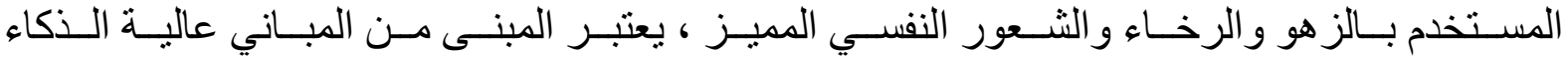

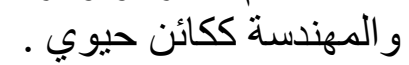

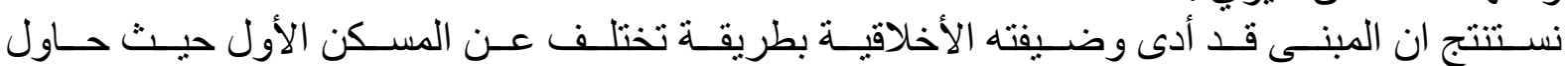

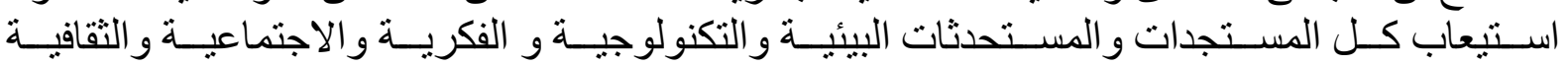
و العقائدية وتجسيد ها في بنى فيزيائية

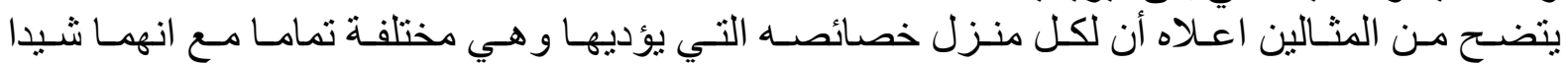

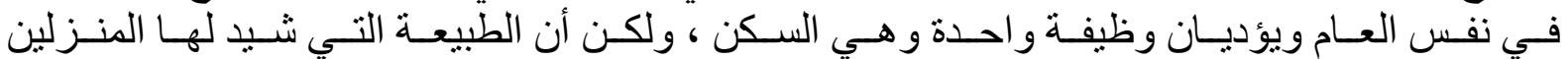

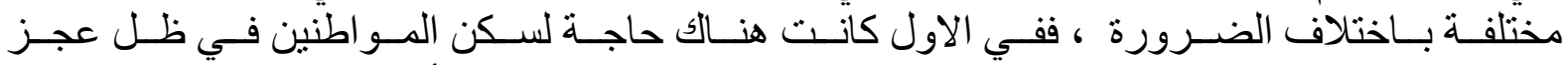

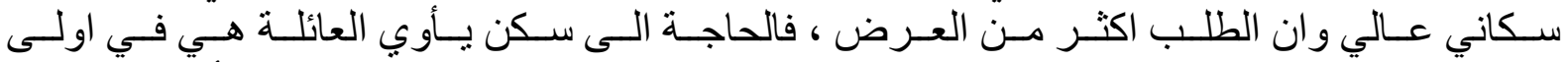

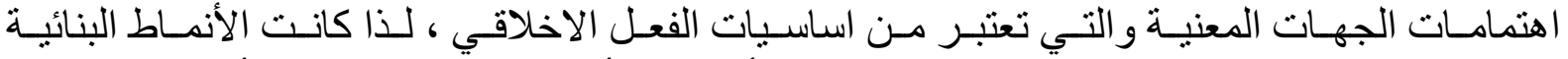

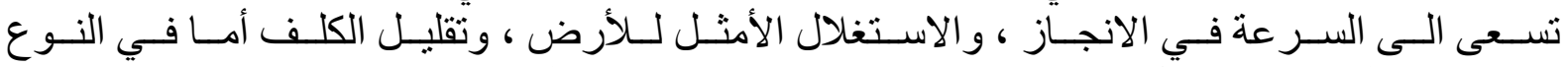

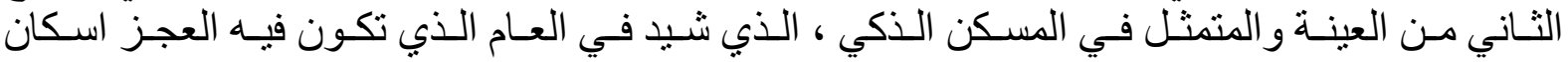




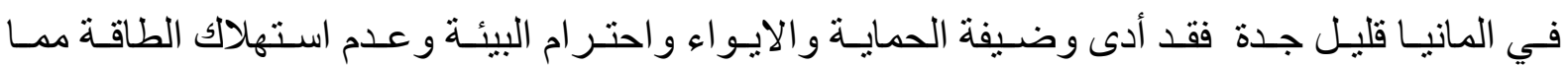

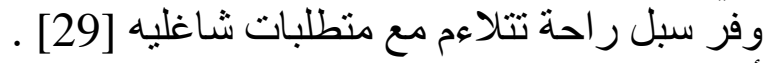
أساليب الكمال المعماري بين التشكيل القائم والمستجد ومدى لثنائ تطبيق القيم الأخلاقية في تلك الاساليب • أسلوب الكمال المعماري المتبع بين التشكيل القائم والمستجد في نفس الزمان و المكان المبان

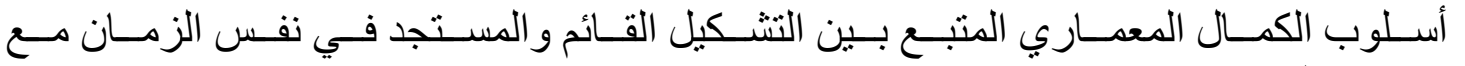

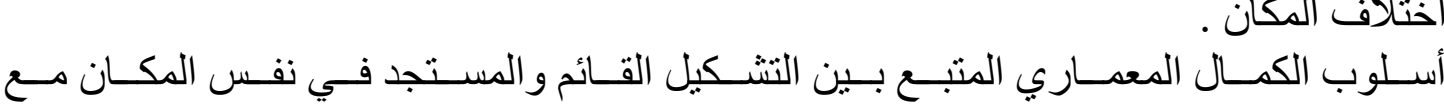

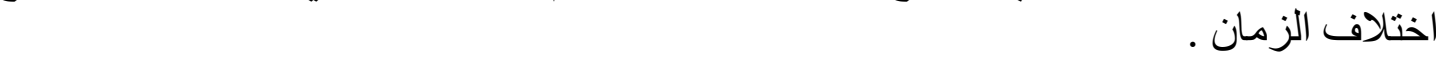

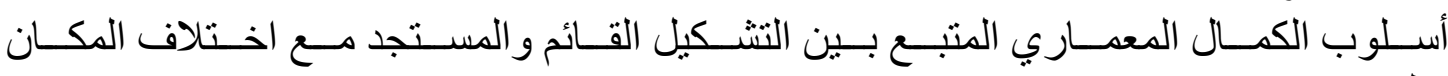

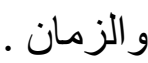

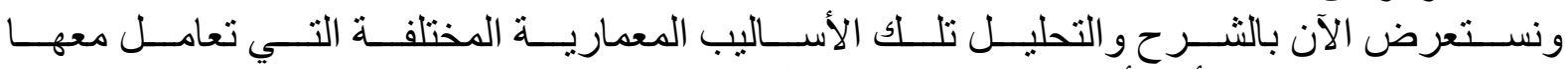

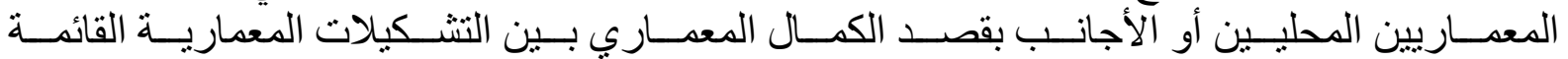

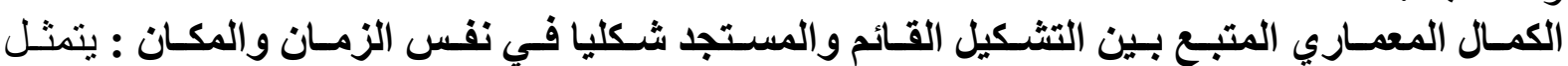

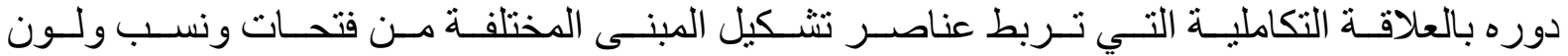

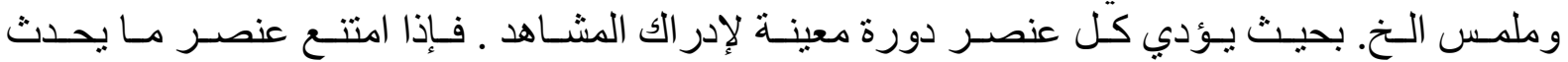

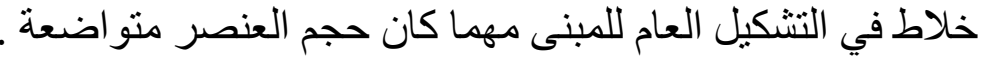

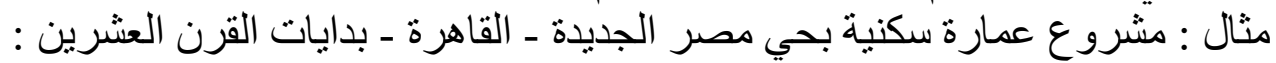

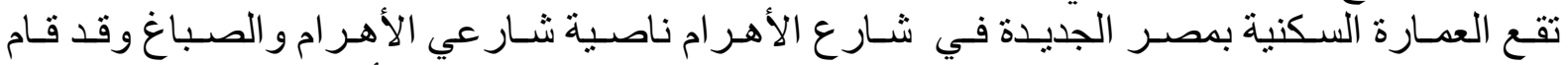

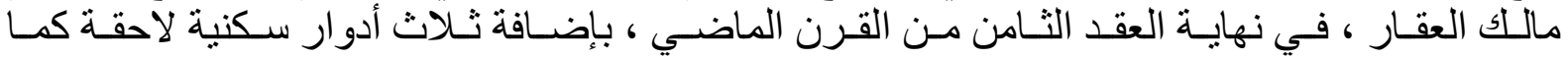

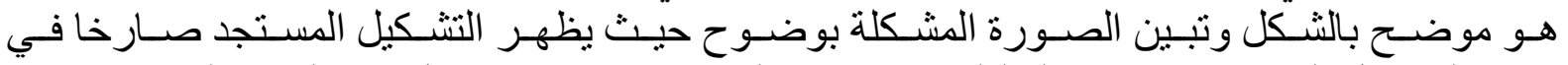

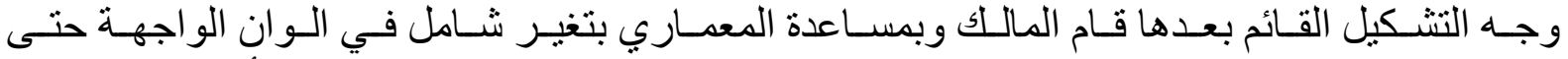

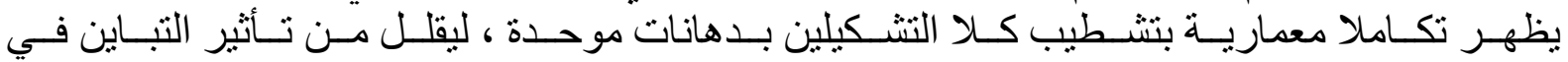

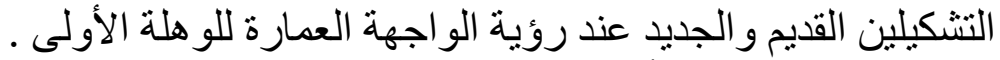

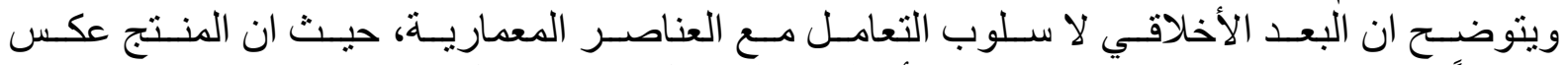

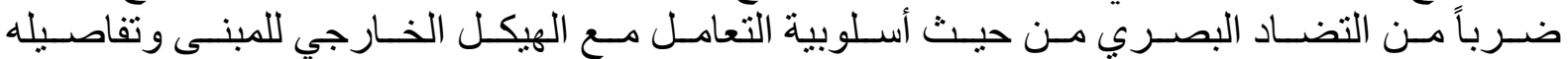

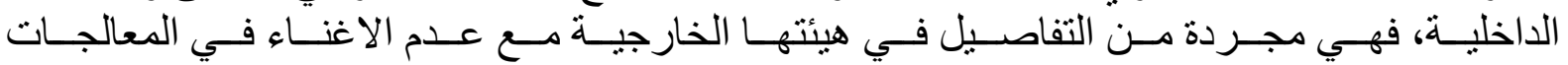

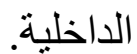
بعـد ذلـك عـولج هـذا التضــاد الأخلاقـي للمبنـى فأعيـد اســتخدام الـوان متناسـقة لتعطـي هيئـة المبنـى المتكامل

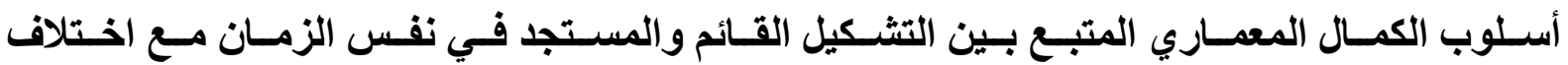

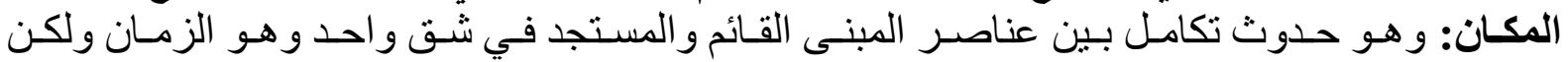

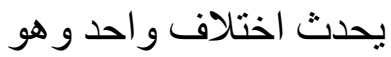

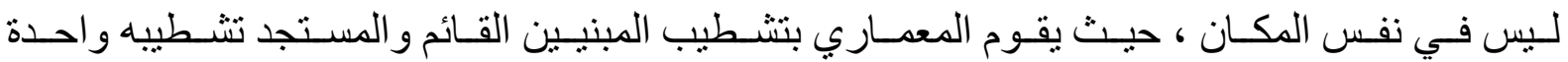

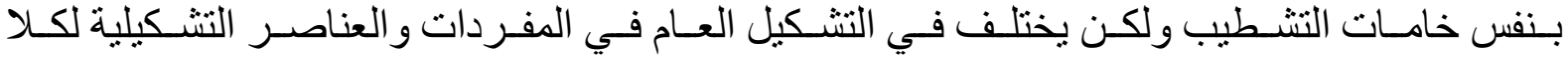

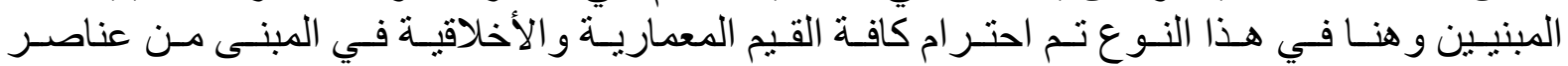
ومو اد انهاء ووظيفة أخلاقية هنية

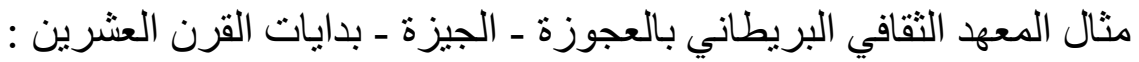

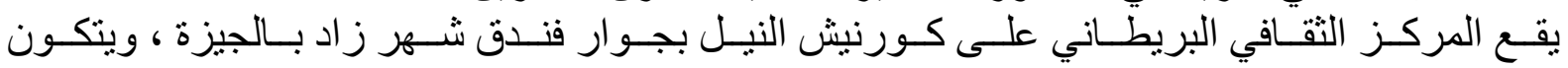

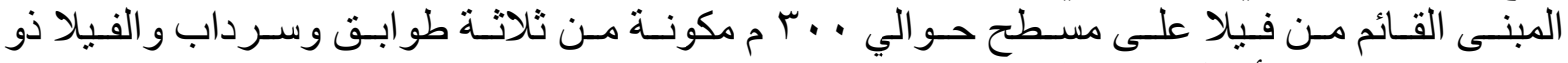

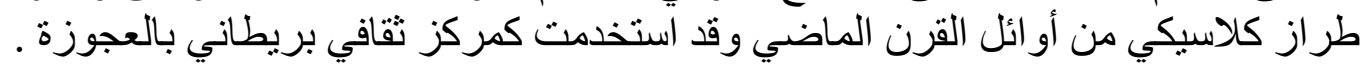




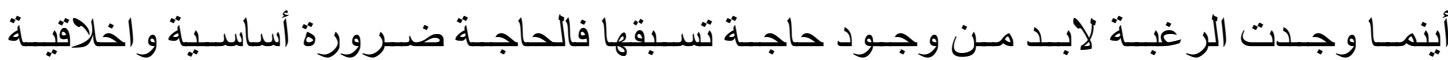

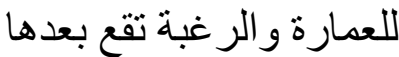

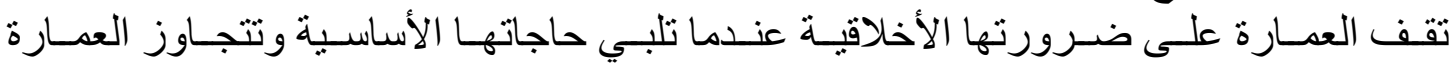

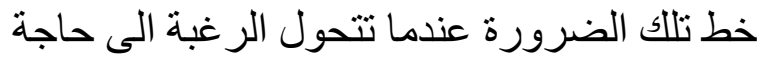

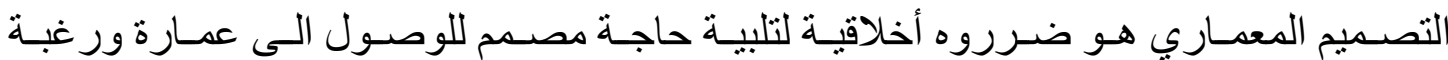
مستخدم للوصول الى الكمال

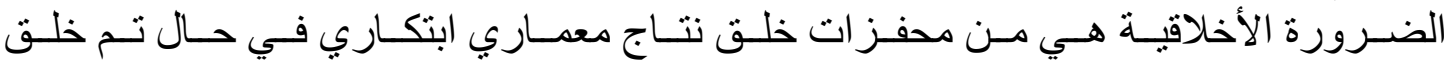

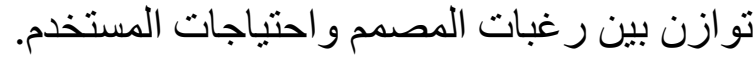

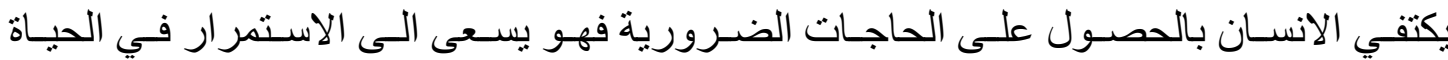

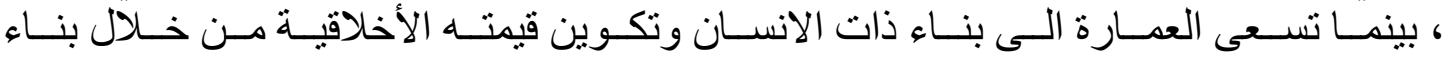

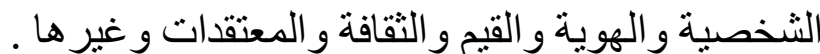

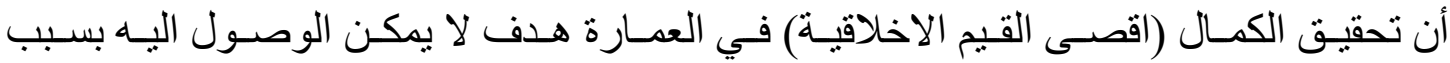

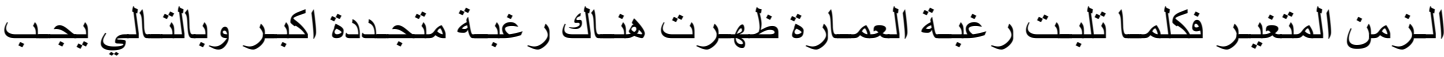

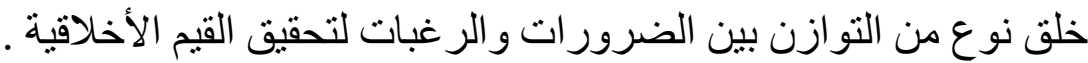

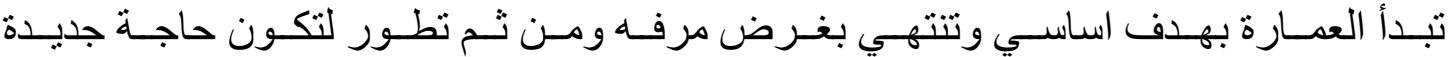

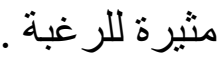

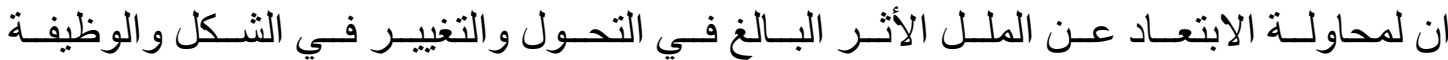
للوصول لأعظم هدف هي عمارة الكمال (اقصى الافداف الفاف العمارة الأخلاقية ).

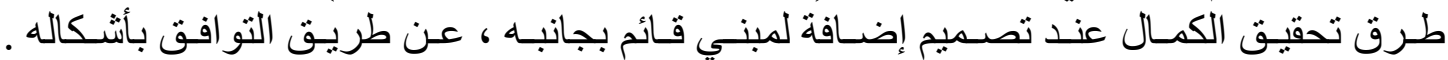

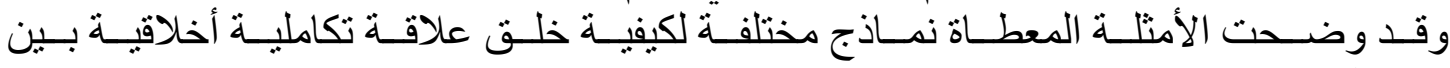

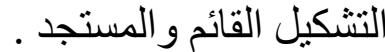

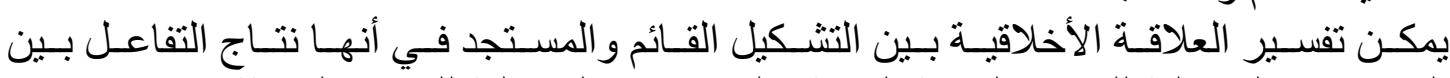
الخصائص التشكيلية للعمارة القديمة القائمة و الخصائص التشكيلية للعمارة الحديثة . لإنية

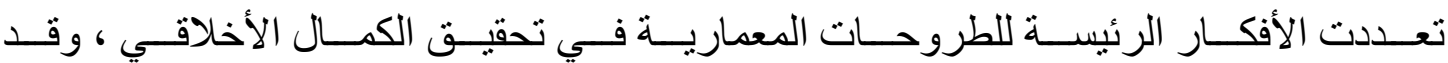

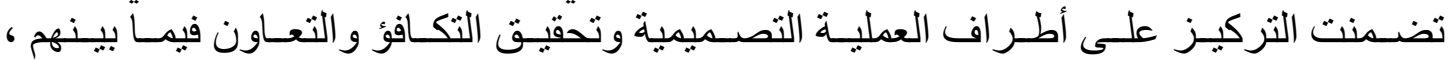

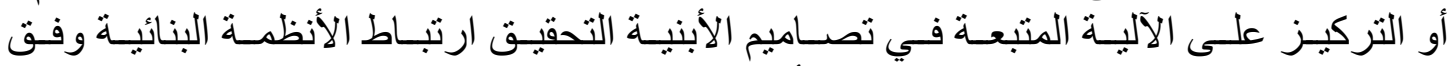

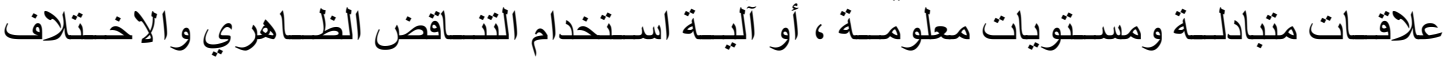

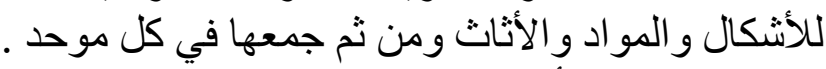

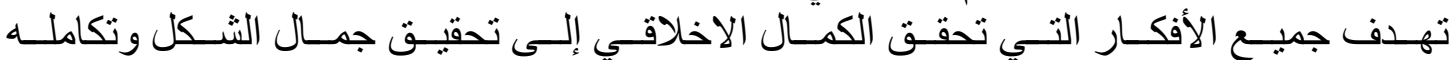

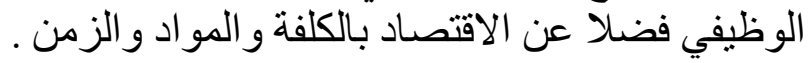

1. I. J. Kadhim, “التكاملية في نتاج وحركة العمارة," Iraqi J. Archit. Plan., vol. 16, no. 2, pp. 2023, 2017.

2. I. J. Kadhim and A. A. Jalowb, “الرغبة والحاجة في العمارة," Iraqi J. Archit. Plan., vol. 17, no. 2, 2018.

3. M. Agassi, Hands Are Not for Hitting/Las manos no son para pegar. Free Spirit Publishing, 2009.

4. S. L. Farhan, V. S. Akef, and Z. Nasar, "Revitalizing the historical center of Al-Najaf city in Iraq: learning from the British conservation experiences," J. Cult. Herit. Manag. Sustain. Dev., vol. ahead-of-p, no. ahead-of-print, Jan. 2021.

5. H. S. O. Adelphi, S. L. Farhan, and H. A. H. Alshamari, "The Threshold of Urban Sustainability within the Traditional Cities: Traditional Alnajaf city as a case study," IOP Conf. Ser. Mater. Sci. Eng., vol. 1058, no. 1, p. 12055, Feb. 2021. 
6. A. N. Sabeeh Lafta Farhan, Ihsan Abbass Jasim, "Urban sustainability in Old City Centres, a Comparison Between the City of Najaf in Iraq and Italian Cities Experiences," no. 12, 2016.

7. S. Farhan and M. G. Abdelmonem, "Navigating the socio-spatial and planning conditions of traditional public spaces in Iraq's holy cities," in Traditional Dwellings and Settlements Review, 2018, vol. 30, no. 1, p. 81.

8. S. L. Farhan, H. H. Samir, and H. S. Adelphi, "Urban changes and its impact on the tangible and intangible heritage of City's Centre: Najaf City as a Case Study," IOP Conf. Ser. Mater. Sci. Eng., vol. 1058, no. 1, p. 12070, 2021.

9. S. L. Farhan, "Effect of New Urban Transformations at Townscape of Historical Cities Urban Study of Alnajaf Hist," J. Eng., vol. 23, no. December, pp. 1-20, 2018.

10. S. L. Farhan, H. I. Alyasari, H. H. Samir, S. L. Zubaidi, and K. S. Hashim, "Conservation Approach as an Architectural Instrument to reviving Historical Cities; technical analysis for multi international cases," IOP Conf. Ser. Mater. Sci. Eng., vol. 1058, no. 1, p. 12071, 2021.

11. Z. A.; Farhan, Sabeeh Lafta 1; Nasar, "Urban identity in the holy cities of Iraq: Analysis trends of architectural designers in the city of Karbala," J. Urban Regen. Renew., vol. 14 Number, no. 2020, pp. 210-222(13), 2020.

12. I. A. Jasim, S. L. Farhan, and H. M. Hasan, "The Impact of Transit on Sustainable Urban Form," IOP Conf. Ser. Mater. Sci. Eng., vol. 1058, no. 1, p. 12049, 2021.

13. S. L. Farhan, H. I. Alyasari, V. S. Akef, S. L. Zubaidi, and K. S. Hashim, "Analysing the Transformed Urban Patterns of Al-Najaf Historical Center: Urgent Issues and Possible Solutions," IOP Conf. Ser. Mater. Sci. Eng., vol. 1058, no. 1, p. 12052, 2021.

14. J. Dancy, Ethics without principles. Oxford University Press on Demand, 2004.

15. B. Hooker, "Moral particularism: wrong and bad," 2000.

16. S. McKeever and M. Ridge, Principled ethics: Generalism as a regulative ideal. Oxford University Press, 2006.

17. S. Scheffler, Human morality. Oxford University Press on Demand, 1992.

18. D. Bakhurst, "Pragmatism and Ethical Particularism," New Pragmatists, pp. 122-141, 2007.

19. H. A. et al. S. Farhan, T.Mutas, "Digital Era Influence on Neighbourhood Planning," I O P Conf. Sci. Mater., 2021.

20. M. Lewicka, "Place attachment, place identity, and place memory: Restoring the forgotten city past," J. Environ. Psychol., vol. 28, no. 3, pp. 209-231, 2008.

21. S. S. A. Aly, "Modernization and regionalism: Approaches for sustainable revival of local urban identity," Procedia Eng., vol. 21, pp. 503-512, 2011.

22. S. Coleman, "Normalizing sustainability in a regenerative building: The social practice of being at CIRS," University of British Columbia, 2016.

23. I. Abbass Jasim, S. Lafta Farhan, and S. AL-MAMOORI, "Smart Government: Analysis of Shift Methods in Municipal Services Delivery: The Study Area: Al-Kut Iraq," J. Univ. Kerbala, vol. 15, no. 3, p. 2017, 2017.

24. I. A. Jasim, S. L. Farhan, and H. M. Hasan, "Ways to Activate Urban Transport to Achieve Urban Sustainability," IOP Conf. Ser. Mater. Sci. Eng., vol. 1090, no. 1, p. 012034, 2021.

25. C. Baumberger, "The Ethical Criticism of Architecture: In Defense of Moderate Moralism," Archit. Philos., vol. 1, no. 2, 2015.

26. Sabih 1. Farhan, "Visual pollution in the commercial urban scene Analysis of the optical axes elected in the Kut city.," Wasit J. Eng. Sci., no. 4, pp. 178-208, 2016.

27. O. Neurath, "Sociology in the Framework of Physicalism," in Philosophical Papers 1913-1946, Springer, 1983, pp. 58-90.

28. S. M. Falah, R. Williamson, P. Snadon, C. Kickert, and R. Haug, "The Shrine that Consumed Its Town: The Role of Religion and Politics in Reshaping the Iraqi City of 
Najaf," pp. 75-77, 2018.

29. T. Journal, "Restoring the Local Heritage and its Role in Sustainable Spatial Development the Great Market in Al-Najaf - a Case Study," vol. 37, no. 1, pp. 24-28, 2019. 